Aus der Poliklinik für Zahnärztliche Prothetik

(Prof. Dr. med. dent. R. Bürgers)

im Zentrum Zahn-, Mund- und Kieferheilkunde

der Medizinischen Fakultät der Universität Göttingen

\title{
Wirkung physiko-chemischer Oberflächencharakteristika auf Zytotoxizität verschiedener dentaler Komposite
}

\author{
INAUGURAL-DISSERTATION \\ zur Erlangung des Doktorgrades \\ für Zahnheilkunde \\ der Medizinischen Fakultät der \\ Georg-August-Universität zu Göttingen
}

vorgelegt von

Oliver Kurbad (geb. Hartmann)

aus

Leinefelde

Göttingen 2018 
Dekan:

\section{Betreuungsausschuss}

Betreuer/in:

Ko-Betreuer/in:

\section{Prüfungskommission}

Referent/in:

Ko-Referent/in:
Prof. Dr. rer. nat. H. K. Kroemer

Prof. Dr. med. dent. R. Bürgers

Prof. Dr. med. Dr. med. dent. H. Schliephake

Prof. Dr. med. dent. R. Bürgers

Prof. Dr. med. dent. Philipp Franz Meyer-Marcotty

Datum der mündlichen Prüfung: 16.05.2019 
Hiermit erkläre ich, die Dissertation mit dem Titel "Wirkung physiko-chemischer Oberflächencharakteristika auf Zytotoxizität verschiedener dentaler Komposite" eigenständig angefertigt und keine anderen als die von mir angegebenen Quellen und Hilfsmittel verwendet zu haben.

Göttingen, den

(Unterschrift) 


\section{INHALTSVERZEICHNIS}

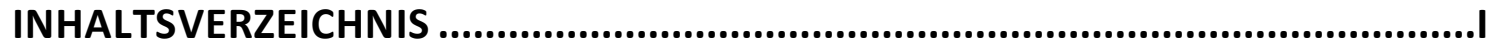

ABBILDUNGSVERZEICHNIS.................................................................... IV

TABELLENVERZEICHNIS.......................................................................... VII

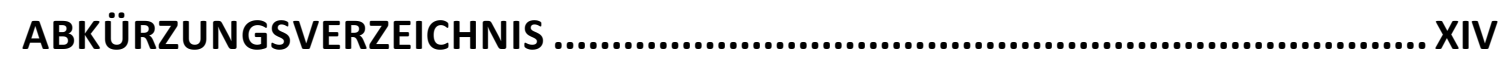

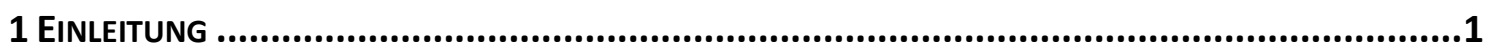

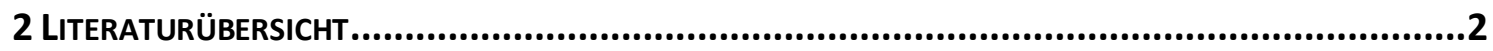

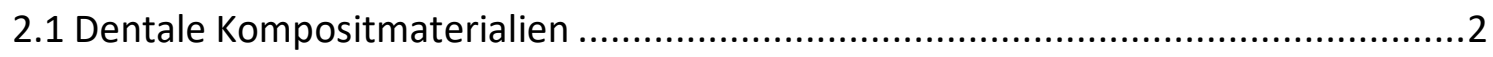

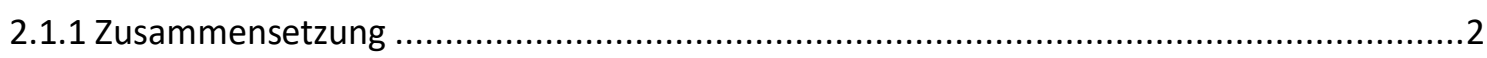

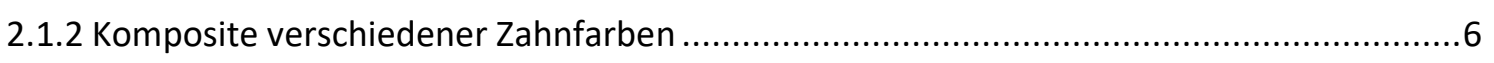

2.2. Untersuchung der Zytotoxizität dentaler Komposite........................................8

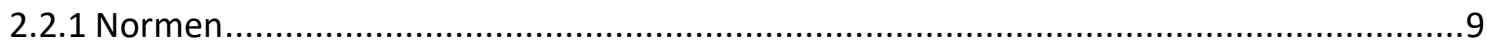

2.2.2 In-vitro-Methoden zur Untersuchung der Zellviabilität und Zytotoxizität........................10

2.3 Physiko-chemische Oberflächencharakteristika ..............................................11

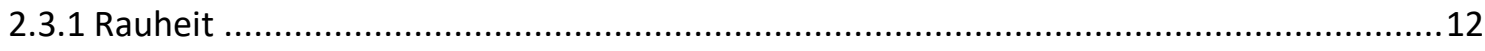

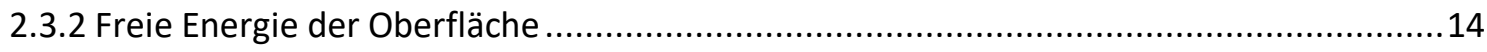

2.3.3 Andere physiko-chemische Oberflächeneigenschaften ..............................................15

2.3.4 Oberflächeneigenschaften und Zytotoxizität ............................................................. 17

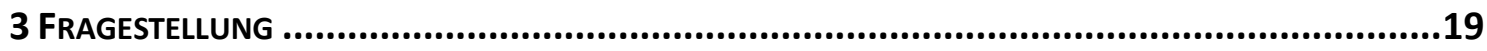

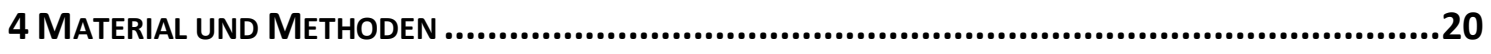

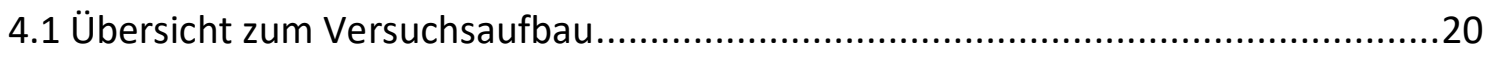

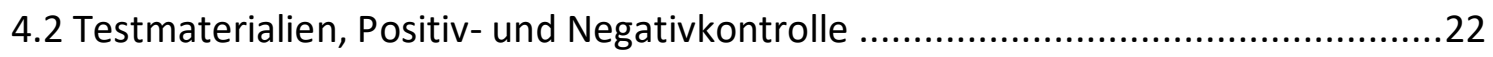




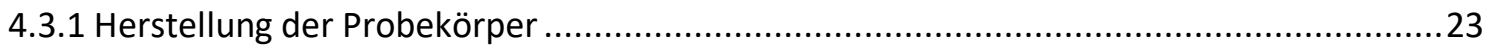

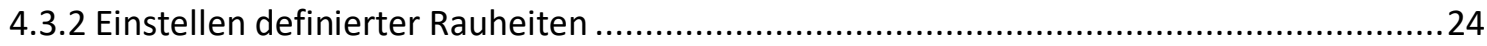

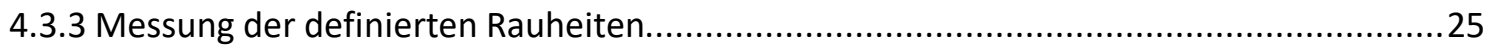

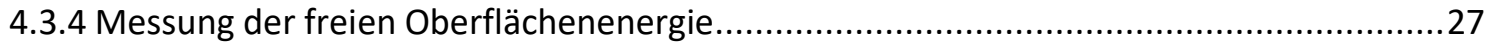

4.4 Zellkulturen und Versuchsvorbereitung ................................................28

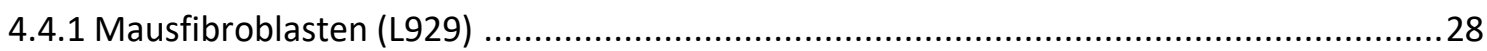

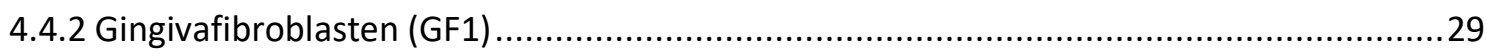

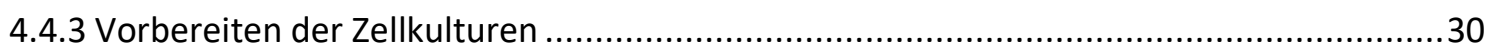

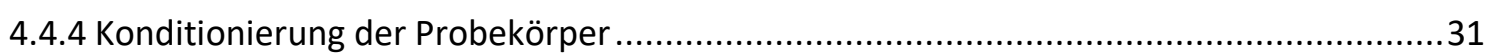

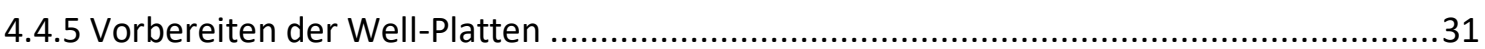

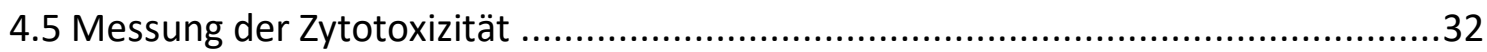

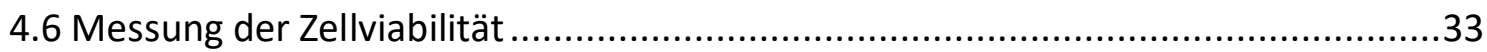

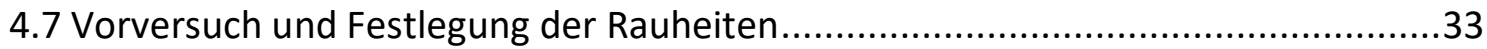

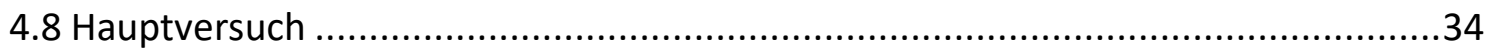

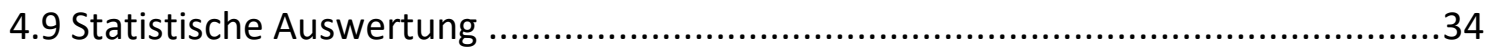

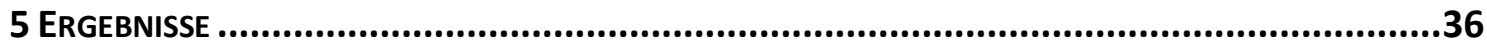

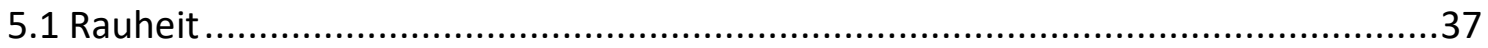

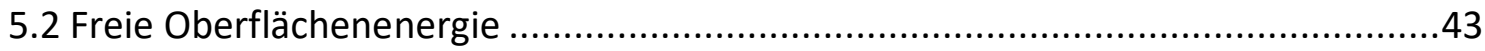

5.3 Korrelation von Rauheit und freier Oberflächenenergie .................................56

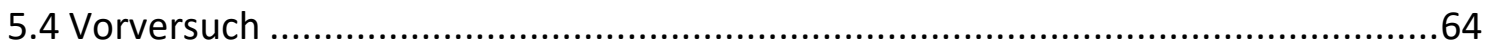

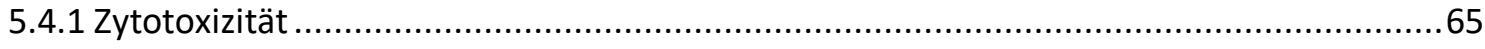

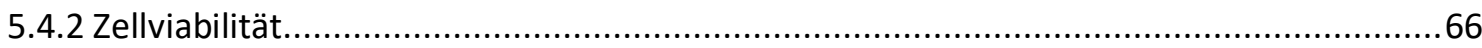

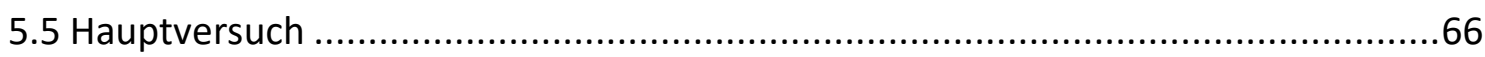

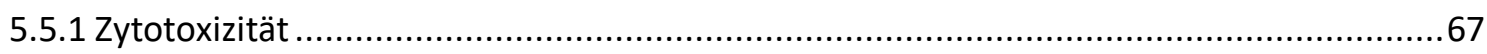

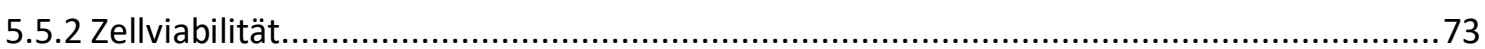




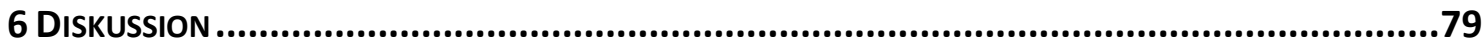

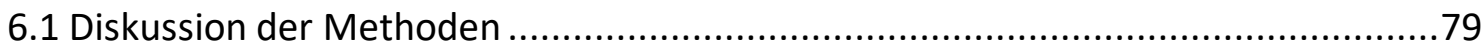

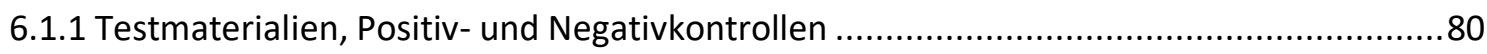

6.1.2 Herstellung und Konditionierung der Probekörper .................................................. 82

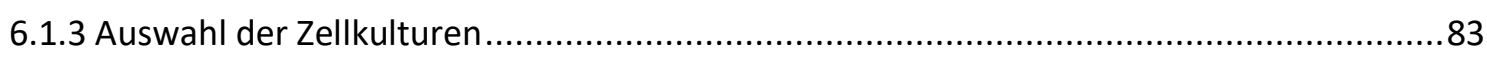

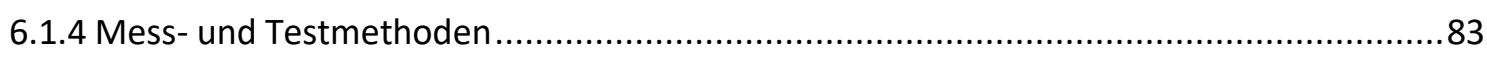

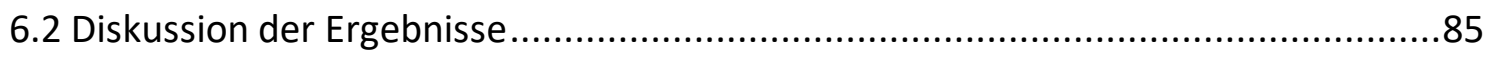

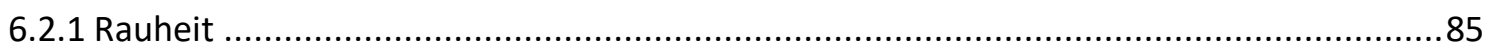

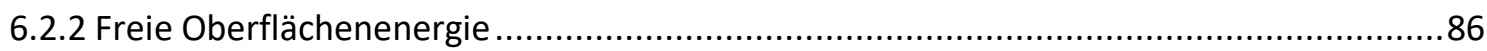

6.2.3 Korrelation von Rauheit und freier Oberflächenenergie.............................................87

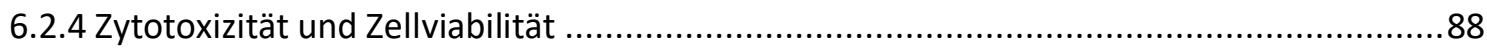

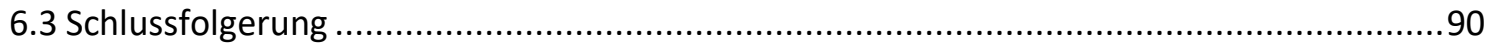

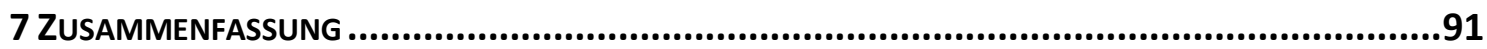

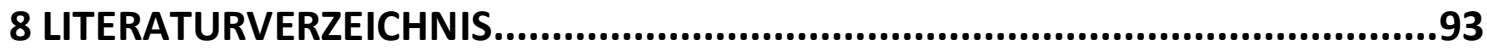

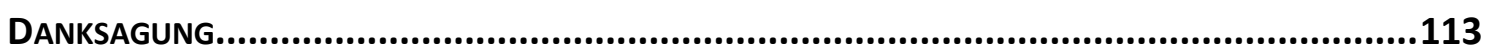

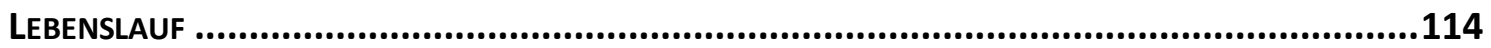




\section{ABBILDUNGSVERZEICHNIS}

Abbildung 1: Zusammensetzung Komposite (nach Janda 2008a-c)

Abbildung 2: Vita-Classical-Farbskala

Abbildung 3: Arithmetisches Mittel der Rauheit, grafische Darstellung

Abbildung 4: Young'sche Gleichung

Abbildung 5: Polymerisation der Komposit-Probekörper und Herstellung AmalgamProbekörper.

Abbildung 6: Probekörper auf Probekörperhalter

Abbildung 7: Rauheiten der Probekörper

Abbildung 8: Lichtmikroskopisches Bild von Mausfibroblasten (L929) auf Glasprobekörper 28

Abbildung 9: Lichtmikroskopisches Bild von Gingivafibroblasten (GF1) auf Glasprobekörper

Abbildung 10: Schematische Darstellung der Probekörperanordnung in den 48-Well-

Platten

Abbildung 11: Probekörper in 48-Well-Platte mit Silikon Z-Dupe fixiert

Abbildung 12: Beispielkastendiagramm

Abbildung 13: Boxplot der $\mathrm{R}_{\mathrm{a}}$-Messungen gruppiert nach Polierstufe und Farbe bzw.

Material 
Abbildung 14: Oberflächenmorphologie Grandio Voco A3 in 3D und 2D.

Abbildung 15: Boxplot der freien Oberflächenenergie- (FOE), Polar- und Dispersivmessungen gruppiert nach Polierstufe und Farbe bzw. Material 44

Abbildung 16: Korrelation (nach Pearson) von Rauheit $\left(R_{a}\right)$ und der freien Oberflächenenergie (FOE, Dispersiv, Polar) für alle Materialien 58

Abbildung 17: Korrelation (nach Pearson) von Rauheit $\left(R_{a}\right)$ und der freien Oberflächenenergie (FOE, Dispersiv, Polar) für Grandio Voco A1 59

Abbildung 18: Korrelation (nach Pearson) von Rauheit $\left(R_{a}\right)$ und der freien Oberflächenenergie (FOE, Dispersiv, Polar) für Grandio Voco A2 60

Abbildung 19: Korrelation (nach Pearson) von Rauheit $\left(R_{a}\right)$ und der freien Oberflächenenergie (FOE, Dispersiv, Polar) für Grandio Voco A3 61

Abbildung 20: Korrelation (nach Pearson) von Rauheit $\left(R_{a}\right)$ und der freien Oberflächenenergie (FOE, Dispersiv, Polar) für Grandio Voco A4

Abbildung 21: Korrelation (nach Pearson) von Rauheit $\left(R_{a}\right)$ und der freien Oberflächenenergie (FOE, Dispersiv, Polar) für Amalgam 63

Abbildung 22: $\mathrm{R}_{\mathrm{a}}$-Werte von Grandio Voco BL im Vorversuch 64

Abbildung 23: Kontaktwinkelmessungen Grandio Voco BL im Vorversuch .64

Abbildung 24: Zytotoxizitätsmesswerte von Grandio Voco BL im Vorversuch .65

Abbildung 25: Zellviabilität von Vovo Grandio BL im Vorversuch 66

Abbildung 26: Boxplot der Zytotoxizitäts-Messungen gruppiert nach Zelllinie, Polierstufe und Farbe bzw. Material 67 
Abbildung 27: An die Glas-Werte adjustierte Zytotoxizitätsmessungen gruppiert nach Polierstufe und Zelllinie... .68

Abbildung 28: Boxplot der Viabilitätsmessungen gruppiert nach Zelllinie, Polierstufe und Farbe bzw. Material 73

Abbildung 29: An die Glas-Werte adjustierte Viabilitätsmessungen gruppiert nach Polierstufe und Zelllinie..... 


\section{TABELLENVERZEICHNIS}

Tabelle 1: Gestaltabweichung nach DIN 4760:1982

Tabelle 2: Kontaktwinkel und Bezeichnung bei Benetzung mit Wasser (Jung und Bhushan 2006)

Tabelle 3: Referenz- und Lotnummern der Grandio-Komposite (Voco GmbH, Cuxhaven, Deutschland)

Tabelle 4: Versuchsablauf

Tabelle 5: Technische Daten Grandio laut Hersteller (Voco 2010)....

Tabelle 6: Inhaltsstoffe Amalgam Vivacap Größe 3 (Ivoclar Vivadent, Liechtenstein) ...22

Tabelle 7: Median und Interquartilsabstand (IQR) der Rauheitsmessungen ( $\left.R_{a}\right)$ unterteilt nach Polierstufe und Farbe bzw. Material

Tabelle 8: Differenzen (diff) und $p$-Werte (adjustiert) von $R_{a}$ zwischen den einzelnen Polierstufen bei Grandio Voco A1

Tabelle 9: Differenzen (diff) und p-Werte (adjustiert) von $R_{a}$ zwischen den einzelnen Polierstufen bei Grandio Voco A2

Tabelle 10: Differenzen (diff) und $p$-Werte (adjustiert) von $R_{a} z$ wischen den einzelnen Polierstufen bei Grandio Voco A3

Tabelle 11: Differenzen (diff) und $p$-Werte (adjustiert) von $R_{a}$ zwischen den einzelnen Polierstufen bei Grandio Voco A4

Tabelle 12: Differenzen (diff) und $p$-Werte (adjustiert) von $R_{a}$ zwischen den einzelnen Polierstufen bei Amalgam 
Tabelle 13: Differenzen (diff) und $p$-Werte (adjustiert) von $R_{a}$ zwischen den einzelnen Farben / Materialien bei Polierstufe 110

Tabelle 14: Differenzen (diff) und $p$-Werte (adjustiert) von $R_{a}$ zwischen den einzelnen Farben / Materialien bei Polierstufe 400 .40

Tabelle 15: Differenzen (diff) und $p$-Werte (adjustiert) von $R_{a} z$ wischen den einzelnen Farben / Materialien bei Polierstufe 1200

Tabelle 16: Differenzen (diff) und $p$-Werte (adjustiert) von $R_{a}$ zwischen den einzelnen Farben / Materialien bei Polierstufe HG

Tabelle 17: Median und Interquartilsabstand (IQR) der freien Oberflächenenergie (SFE) unterteilt nach Polierstufe und Farbe bzw. Material

Tabelle 18: Differenzen (diff) und p-Werte (adjustiert) von SFE zwischen den einzelnen Polierstufen bei Grandio Voco A1

Tabelle 19: Differenzen (diff) und p-Werte (adjustiert) von SFE zwischen den einzelnen Polierstufen bei Grandio Voco A2 45

Tabelle 20: : Differenzen (diff) und p-Werte (adjustiert) von SFE zwischen den einzelnen Polierstufen bei Grandio Voco A3.

Tabelle 21: : Differenzen (diff) und p-Werte (adjustiert) von SFE zwischen den einzelnen Polierstufen bei Grandio Voco A4

Tabelle 22: : Differenzen (diff) und p-Werte (adjustiert) von SFE zwischen den einzelnen Polierstufen bei Amalgam .46

Tabelle 23: Differenzen (diff) und p-Werte (adjustiert) von SFE zwischen den einzelnen Farben / Materialien bei Polierstufe 110 .46 
Tabelle 24: Differenzen (diff) und p-Werte (adjustiert) von SFE zwischen den einzelnen Farben / Materialien bei Polierstufe 400

Tabelle 25: Differenzen (diff) und p-Werte (adjustiert) von SFE zwischen den einzelnen Farben / Materialien bei Polierstufe 1200

Tabelle 26: Differenzen (diff) und p-Werte (adjustiert) von SFE zwischen den einzelnen Farben / Materialien bei Polierstufe HG

Tabelle 27: Median und Interquartilsabstand (IQR) der disperseren Komponente unterteilt nach Polierstufe und Farbe bzw. Material

Tabelle 28: Differenzen (diff) und p-Werte (adjustiert) der disperseren Komponente zwischen den einzelnen Polierstufen bei Grandio Voco A1

Tabelle 29: Differenzen (diff) und p-Werte (adjustiert) der disperseren Komponente zwischen den einzelnen Polierstufen bei Grandio Voco A2

Tabelle 30: Differenzen (diff) und p-Werte (adjustiert) der disperseren Komponente zwischen den einzelnen Polierstufen bei Grandio Voco A3

Tabelle 31: Differenzen (diff) und p-Werte (adjustiert) der disperseren Komponente zwischen den einzelnen Polierstufen bei Grandio Voco A4

Tabelle 32: Differenzen (diff) und p-Werte (adjustiert) der disperseren Komponente zwischen den einzelnen Polierstufen bei Amalgam

Tabelle 33:Differenzen (diff) und p-Werte (adjustiert) der disperseren Komponente zwischen den einzelnen Farben / Materialien bei Polierstufe 110

Tabelle 34: Differenzen (diff) und p-Werte (adjustiert) der disperseren Komponente zwischen den einzelnen Farben / Materialien bei Polierstufe 400 
Tabelle 35: Differenzen (diff) und p-Werte (adjustiert) der disperseren Komponente zwischen den einzelnen Farben / Materialien bei Polierstufe 1200

Tabelle 36: Differenzen (diff) und p-Werte (adjustiert) der disperseren Komponente zwischen den einzelnen Farben / Materialien bei Polierstufe HG

Tabelle 37: Median und Interquartilsabstand (IQR) der polaren Komponente unterteilt nach Polierstufe und Farbe bzw. Material

Tabelle 38: Differenzen (diff) und p-Werte (adjustiert) der polaren Komponente zwischen den einzelnen Polierstufen bei Grandio Voco A1.

Tabelle 39: Differenzen (diff) und p-Werte (adjustiert) der polaren Komponente zwischen den einzelnen Polierstufen bei Grandio Voco A2.

Tabelle 40: Differenzen (diff) und p-Werte (adjustiert) der polaren Komponente zwischen den einzelnen Polierstufen bei Grandio Voco A3

Tabelle 41: Differenzen (diff) und p-Werte (adjustiert) der polaren Komponente zwischen den einzelnen Polierstufen bei Grandio Voco A4

Tabelle 42: Differenzen (diff) und p-Werte (adjustiert) der polaren Komponente zwischen den einzelnen Polierstufen bei Amalgam

Tabelle 43: Differenzen (diff) und p-Werte (adjustiert) der polaren Komponente zwischen den einzelnen Farben / Materialien bei Polierstufe 110 54

Tabelle 44: Differenzen (diff) und p-Werte (adjustiert) der polaren Komponente zwischen den einzelnen Farben / Materialien bei Polierstufe 400 .55

Tabelle 45: Differenzen (diff) und p-Werte (adjustiert) der polaren Komponente zwischen den einzelnen Farben / Materialien bei Polierstufe 1200 
Tabelle 46: Differenzen (diff) und p-Werte (adjustiert) der polaren Komponente zwischen den einzelnen Farben / Materialien bei Polierstufe HG

Tabelle 47: Interpretation der Korrelationswerte nach Pearson.

Tabelle 48: Korrelation $r$ (nach Pearson) von Rauheit, der freien Oberflächenenergie (FOE), Dispersiv, Polar für alle Materialen

Tabelle 49: Two-Way-ANOVA für die Zytotoxizität der Zellline GF1 mit den Faktoren Polierstufen und Farbe/Material..... 69

Tabelle 50: Two-Way-ANOVA für Grandio Voco A1 - A4 für die Zytotoxizität des Keimes GF1 mit den Faktoren Polierstufen und Farbe 69

Tabelle 51: Paarvergleiche zwischen allen Polierstufen der Zytotoxizität der Zelllinie GF1 auf Grandio Voco ( $p$-Werte)

Tabelle 52: Paarvergleiche zwischen allen Polierstufen der Zytotoxizität der Zellline GF1 auf Grandio Voco A1 - A4 ( $p$-Werte)

Tabelle 53: One-Way-ANOVA für die Viabilität der Zelllinie GF1 mit dem Faktor Polierstufen auf AG

Tabelle 54: Paarvergleiche zwischen allen Polierstufen der Viabilität der Zelllinie GF1 auf Amalgam.

Tabelle 55: Two-Way-ANOVA für die Viabilität der Zelllinie L929 mit den Faktoren Polierstufen und Farbe/Material.

Tabelle 56: One-Way-ANOVA für die Zytotoxizität der Zelllinie L929 mit dem Faktor Polierstufen auf Farben A1-A4

Tabelle 57: Paarvergleiche zwischen allen Polierstufen der Zytotoxizität der Zelllinie L929 auf Grandio Voco A1 - A4 
Tabelle 58: Paarvergleiche zwischen allen Polierstufen der Zytotoxizität des Zellline L929 auf Grandio Voco A1 - A4 (p-Werte)

Tabelle 59: One-Way-ANOVA für die Zytotoxizität der Zelllinie L929 mit dem Faktor Polierstufen auf AG

Tabelle 60: Paarvergleiche zwischen allen Polierstufen der Zytotoxizität der Zelllinie L929 auf Grandio Voco ( $p$-Werte)

Tabelle 61: Two-Way-ANOVA für die Viabilität der Zelllinie GF1 mit den Faktoren Polierstufen und Farbe/Material. 75

Tabelle 62: One-Way-ANOVA für die Viabilität des Keimes GF1 mit dem Faktor Polierstufen gemittelt über die Level A1 - A4 ..... .75

Tabelle 63: Paarvergleiche zwischen allen Polierstufen der Viabilität der Zelllinie GF1 auf Grandio Voco

Tabelle 64: Paarvergleiche der Viabilität zwischen den Farben von Grandio Voco des Zelllinie GF1 aufgetrennt nach Polierstufen

Tabelle 65: One-Way-ANOVA für die Viabilität der Zelllinie GF1 mit dem Faktor Polierstufen Amalgam

Tabelle 66: Paarvergleiche zwischen allen Polierstufen der Viabilität der Zelllinie GF1 auf Amalgam ( $p$-Werte)

Tabelle 67: Two-Way-ANOVA für die Viabilität der Zelllinie L929 mit den Faktoren Polierstufen und Farbe/Material.....

Tabelle 68: One-Way-ANOVA für die Viabilität der Zelllinie L929 mit dem Faktor Polierstufen auf Grandio Voco 
Tabelle 69: Paarvergleiche zwischen allen Polierstufen der Viabilität der Zell linie L929

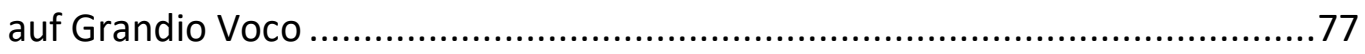

Tabelle 70: One-Way-ANOVA für die Viabilität der Zelllinie L929 mit dem Faktor Polierstufen auf AG .77

Tabelle 71: Paarvergleiche zwischen allen Polierstufen der Viabilität der Zelllinie L929

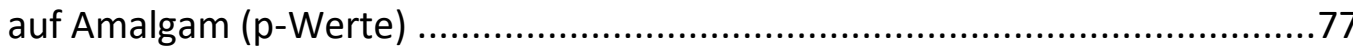




\section{ABKÜRZUNGSVERZEICHNIS}

AAS

ANOVA

ATP

C

CCK8

$\mathrm{CO}_{2}$

DIN

DMEM

FCS

G

Gew. \%

GF1

$\mathrm{L}$

L929

$\mathrm{LDH}$

Methoxy-PMS

MMA

MPG

MTT

PBS

PMMA

PMS

$\mathrm{R}_{\mathrm{a}}$

rpm

Vol. \%

WST-8

XTT
Atomabsorptionsspektrometrie

analysis of variance (Varianzanalyse)

Adenosintriphosphat

Kontrolle

Cell Counting Kit-8®

Kohlenstoffdioxid

Deutsches Institut für Normung e.V.

Dulbecco's Modified Eagle's Medium

fetales Kälberserum

Glas

Gewichtsprozent

humane Gingivafibroblasten, Zellinie GF1

Latex

Mausfibroblasten, Zelllinie L929

Laktat-Dehydrogenase

1-Methoxy-5-Methylphenaziniummethylsulfat

Methylmethacrylat/Methacrylsäuremethylester

Medizinproduktegesetz

3-(4,5-Dimethylthiazol-2-yl)-2,5-diphenyltetrazoliumbromid

phosphatgepufferte Salzlösung

Polymethylmethacrylat

phenazinium methyl sulfate

Mittenrauwert

revolutions per minute (Umdrehungen pro Minute)

Volumenprozent

2-(2-methoxy-4-nitrophenyl)-3-(4-nitrophenyl)-5-(2,4disulfophenyl)-

2H-tetrazolium

2,3-Bis-(2-Methoxy-4-Nitro-5-Sulfophenyl)-2H-Tetrazolium5-Carboxanilid 


\section{EINLEITUNG}

Als Kunststoffe werden synthetische Werkstoffe bezeichnet, die hauptsächlich aus Makromolekülen bestehen. Die meisten industriellen Produkte oder Halbfabrikate werden heute aus Kunststoffen hergestellt, so z. B. in der Halbleiterindustrie, der Textilindustrie oder dem Fahrzeugbau. Durch die ständige Weiterentwicklung haben Kunststoffe auch im medizinischen Bereich weite Einsatzgebiete und werden dort vorübergehend (z. B. als Kontaktlinse) oder permanent (z. B. als Implantatkomponente) in den Körper eingebracht. In der Zahnmedizin werden Kunststoffe standardmäßig in allen Bereichen, z. B. als Prothesenbasis, direktes Füllungsmaterial, Membranen, Verblendungen und Provisorien, eingesetzt.

Im Dentalbereich werden vorwiegend Kunststoffe bzw. Komposite eingesetzt, deren organische Matrix aus Methacrylaten besteht. Diesen Monomeren werden viele unterschiedliche Additive zugesetzt, um gezielt Werkstoffeigenschaften indikationsspezifisch zu modifizieren. Um die ästhetischen Parameter von Kompositen, d. h. Farbgebung, Transluzenz, Opazität etc., den natürlichen Zähnen anzupassen, werden vor allem unterschiedliche Metalloxide beigemischt, die aber - zumindest in höheren Konzentrationen - auch zytotoxische Effekte erzielen könnten. Direkte Kompositfüllungen haben als zahnfarbene Alternative in der restaurativen Zahnheilkunde die Amalgamfüllungen verdrängt, weil diese aufgrund ihres Quecksilbergehaltes sehr kritisch betrachtet werden. Moderne Komposite haben aber ein hohes Potenzial für Allergien und wirken im nicht abgebundenen Zustand toxisch auf menschliche Gewebe. Minimale Unterschiede in der Zusammensetzung dieser Kompositbzw. Kunststoffmaterialien könnten die Zytotoxizität beeinflussen. Es ist daher wenig nachvollziehbar, dass kaum aussagekräftige Studien zu den Auswirkungen von Mischungsänderungen und Variationen der physiko-chemischen Eigenschaften auf die Zytotoxizität dentaler Komposite existieren.

In der vorliegenden Studie sollen deshalb dentale Kompositwerkstoffe unterschiedlicher Zahnfarben, d. h. mit minimalen Unterschieden in der Zusammensetzung, und Amalgam in Bezug auf Zellviabilität und Zellzytotoxizität untersucht werden. Des Weiteren wurden Modifikationen in Oberflächenrauheit und -energie untersucht, um auch hier eventuelle Einflüsse auf Zellviabilität und Zellzytotoxizität zu evaluieren. 


\section{LITERATURÜBERSICHT}

\subsection{Dentale Kompositmaterialien}

Der Begriff Komposit (lat. compositus = zusammengesetzt) beschreibt ein Material, welches aus unterschiedlichen Stoffgruppen mit unterschiedlichen physikochemischen Eigenschaften zusammengesetzt ist. Die Entwicklung der Komposite war bereits in den 1960er Jahren so weit vorangeschritten, dass Zahnhartsubstanzdefekte mit ihnen suffizient therapiert werden konnten (Bowen 1963; Owen et al. 2017; Palotie et al. 2017). Durch stetige Weiterentwicklung und Verbesserungen der Eigenschaften ersetzten Kompositfüllungen zunehmend das bis dato weit verbreitete metallisch-silberne Amalgam, welches seinerseits bereits im 7. Jahrhundert als Füllungsmaterial in China Verwendung fand (Burke 2004; Forss und Widström 2009; Riethe 1980). Gestiegene ästhetische Ansprüche von Patienten spielen für die - trotz höherer Kosten - zunehmende Verbreitung von zahnfarbenen Kompositmaterialien ebenfalls eine entscheidende Rolle (Krastl und Weiger 2010; Bandel 2015). Eine auch in den Breitenmedien öffentlich geführte Diskussion um eine wissenschaftlich nicht belegte Toxizität von Amalgam bzw. dem darin enthaltenen Quecksilber trug zusätzlich zur Weiterentwicklung zahnfarbener Füllungsmaterialien bei (Rathore et al. 2012; Wu et al. 2015; Ferracane 2011). Unter anderem als Resultat dieser „Amalgamdiskussion“ wurden die Indikationen für Amalgamfüllungen eingeschränkt, sodass z. B. bei Kindern, Schwangeren, stillenden Müttern und Patienten mit einer nachgewiesenen Allergie gegen die Bestandteile von Amalgam keine Amalgamfüllungen inseriert werden sollen (Harhammer 2001; Bundesinstitut für Arzneimittel (BfArM) 2005; Takahashi et al. 2003; Baek et al. 2016; Bedir Findik et al. 2016).

\subsubsection{Zusammensetzung}

Die Stoffgruppen, aus denen sich dentale Komposite zusammensetzen, sind hauptsächlich organische Bestandteile, welche zusammengefasst auch als organische Matrix bezeichnet werden, sowie zum anderen zugefügte anorganische oder organischen Stoffe, wie z. B. Quarz, welche insgesamt als Füllstoffe bezeichnet werden (siehe Abbildung 1). Um diese verschiedenen Komponenten zu verbinden, werden Silane verwendet. Durch deren Einsatz kommt es zu einer stabilen chemischen Bindung von anorganischen und organischen Bestandteilen der Komposite. 


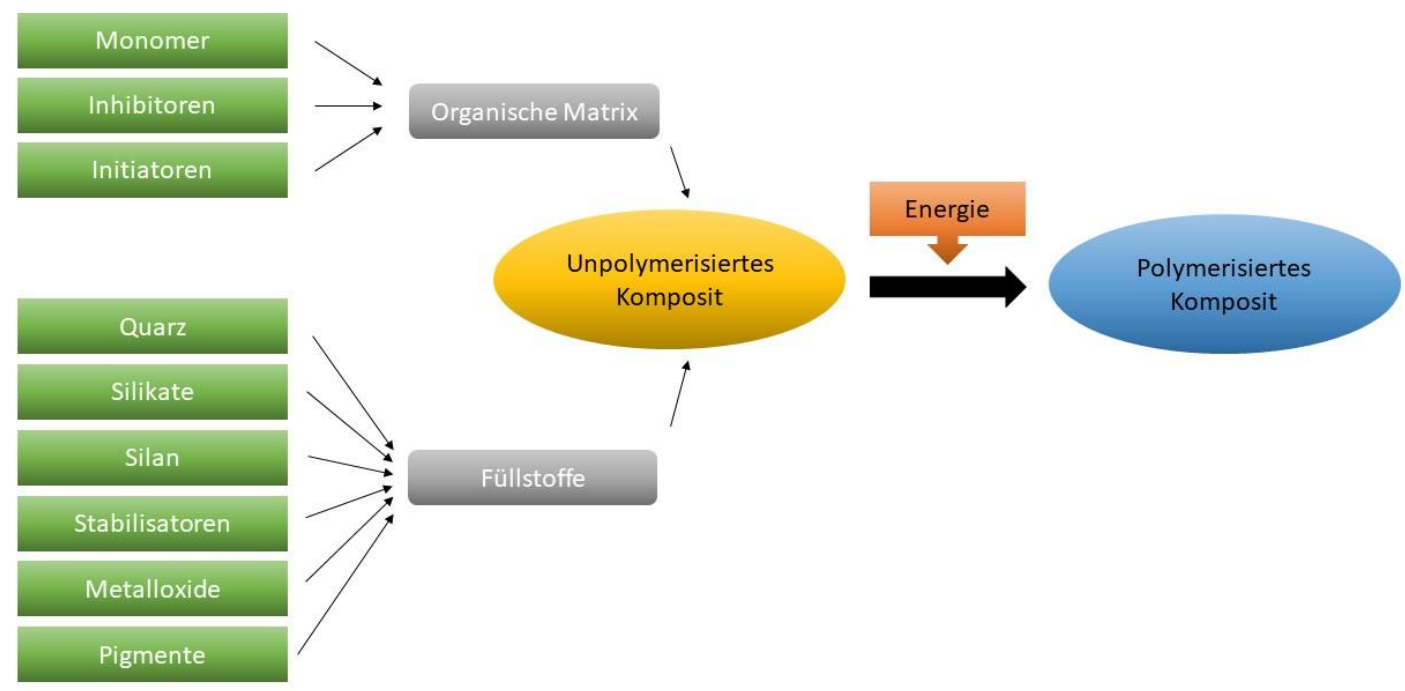

Abbildung 1: Zusammensetzung Komposite (nach Janda 2008a-c)

Die organische Matrix dentaler Komposite besteht aus Methacrylat-Estern mit ein- oder mehrwertigen Alkoholen (Peutzfeldt 1997; Rüttermann et al. 2010). Am häufigsten wird in der Zahnmedizin Bisphenolglycidylmethacrylat (BisGMA) verwendet (Sandner et al. 1997; Ilie und Hickel 2011). Entwickelt wurde dieser Kunststoff durch den amerikanischen Zahnarzt Dr. Rafael Bowen, welcher ihn 1962 als Bowen-Monomer vorstellte (Bowen 1959; Ilie et al. 2007). Er verknüpfte hierzu ein Epoxidharz mit einem Methacrylat; das so erzeugte Molekül war verhältnismäßig starr und besaß im Verbund als Polymer ein höheres Elastizitätsmodul (Pfeifer et al. 2009).

Nach der kommerziellen Einführung dentaler Komposite kamen diese hauptsächlich bei Frontzahndefekten zum Einsatz, da die Restauration von Seitenzähnen durch deren erhöhte Kaubelastung noch starken Verlusten unterlag (Frankenberger 2009; Demarco et al. 2017). Das Hinzufügen von Füllstoffen zur organischen Matrix und das damit einhergehende verbesserte Abrasionsverhalten führte zu einer Vergrößerung des Indikationsspektrums bis zu ausgedehnten Substanzdefekten im Seitenzahnbereich (Manhart et al. 2000; Rasines Alcaraz et al. 2014). Diese der organischen Matrix zugefügten Füllstoffe können sowohl anorganischer als auch organischer Natur sein (Sabbagh et al. 2004; Salazar et al. 2013). Als ein anorganischer Füllstoff kommt beispielsweise Siliziumdioxid zum Einsatz (Hosseinalipour et al. 2010). Durch die im weiteren Verlauf noch genauer beschriebene Silanschicht wird eine dauerhafte Verbindung zwischen BisGMA und dem anorganischen Füllstoff hergestellt (Bowen 1963; Karabela und Sideridou 2011). Moderne Komposite haben durch Modifikation mit 
verschiedenen anorganischen Stoffen, wie Gläsern, Silikaten oder auch Zirkoniumdioxid, anorganische Füllstoffanteile von 50-80 Volumenprozent (Han et al. 2012; Guo et al. 2012). Durch diese Füllstoffe erhalten Komposite ihre hervorragenden ästhetischen und mechanischen Eigenschaften (Bowen 1979; Lim et al. 2008; Wang et al. 2017). Je höher die Füllkörpergröße ist, desto mehr nehmen die Festigkeit und das Elastizitätsmodul der Kunststoffe zu, gleichzeitig jedoch nehmen Polierbarkeit und Ästhetik ab (Ilie und Hickel 2009; Ilie et al. 2016). Dementsprechend bewirkt eine mittlere Korngröße von zirka $1 \mu \mathrm{m}$ eine bessere Polierbarkeit, Abrasions- und Farbbeständigkeit bei einer gleichzeitig verringerten Plaqueanlagerung (Albert et al. 2000; Oliveira et al. 2012; Polydorou 2014). Damit die für den klinischen Einsatz relevante Röntgenopazität erzielt wird, werden schließlich schwermetalldotierte Barium- oder Strontiumsilikatgläser oder Yttrium- oder Ytterbiumtrifluorid als Füllstoffe hinzugefügt (Ruyter 1988; van Dijken et al. 1989; Janda 2008b).

Durch die Beschichtung der anorganischen Füllstoffe mit Silanen wird deren chemische Verbindung mit der organischen Phase ermöglicht (Cucuruz et al. 2017). Erreicht wird dieses durch die chimäre Eigenschaft der Silanmoleküle, sowohl einen organischen als auch einen anorganischen Anteil zu besitzen. Bei Kompositmaterialien wird für die Silanisierung der Füllstoffe in der Regel 3-Methacryloyloxypropyltrimethoxysilan in einer Schichtdicke von 5$20 \mathrm{~nm}$ verwendet (Karabela und Sideridou 2008). Durch die Methacrylgruppe des Silans erfolgt die Bindung zwischen dem Silan und den Monomeren der organischen Matrix, wohingegen der anorganische Teil über Sauerstoffbrücken an die Füllstoffoberfläche bindet (Söderholm und Shang 1993; Zhu und Zhang 2015). Dies ermöglicht eine gute Benetzung der anorganischen Füllstoffe mit der organischen Matrix (Sideridou and Karabela 2009). Durch saure Hydrolyse kann eine solche Bindung wieder gelöst werden, was einen Füllkörperverlust zur Folge hat und schließlich zu einer schnelleren Abnutzung des Komposits führt. Eine Verbesserung der Bindungshydrolysestabilität ist daher u. a. Gegenstand aktueller Materialentwicklungen (Lung und Matinlinna 2012). Neben der chemischen Bindung über Silane findet auch eine mechanische Bindung zwischen Füllstoffen und organischer Matrix statt. Diese ist stark abhängig von der Oberflächenbeschaffenheit der Füllkörper, wobei die Bindung zwischen Matrix und gleichförmigen Füllstoffen deutlich geringer ist als z. B. bei porösen Füllstoffen (Atai et al. 2012; Tamura et al. 2013; Lim et al. 2002).

Als plastisches direktes Füllungsmaterial muss dentales Komposit nach dem Einbringen in eine Kavität aus seiner viskösen Form in seine ausgehärtete beständige Form überführt werden. Die Verkettung von Monomeren zu Polymeren, die sognannte Polymerisation, muss erfolgen. Diese Polymerisation wird durch Initiatoren gestartet, welche bei der folgenden Reaktion vollständig verbraucht werden (Ferracane 2016; Ilie 2016). Die chemische Härtung, 
die Lichthärtung und die duale Härtung sind hierbei die drei hauptsächlichen Polymerisationsmechanismen. Die Initiatoren sind bei chemischer Härtung meist Benzoylperoxid, bei Lichthärtung meist Kampferchinon (mit einem Absorptionsmaximum des Lichtes von $468 \mathrm{~nm}$ Wellenlänge) und bei der dualen Härtung ein kombiniertes System aus chemischer und Lichthärtung (Ely et al. 2012; Santini et al. 2013; Meereis et al. 2016). Zeitgleich beeinflussen die eingesetzten Initiatoren die physikalischen und chemischen Eigenschaften der Komposite sowie deren Polymerisationsgrad (Albuquerque et al. 2013; Randolph et al. 2016). Um eine ausreichende Lagerfähigkeit und praktikable Vorbereitungszeit zu gewährleisten, erhalten dentale Komposite als weitere Zusatzstoffe Inhibitoren oder auch Stabilisatoren. Diese stabilisieren das Komposit chemisch und verhindern eine vorzeitige Polymerisation. Beispiele für zur Anwendung kommende Inhibitoren bzw. Stabilisatoren sind Hydrochinonmonomethylether und sterisch gehinderte Phenole (Hellwig et al. 2013; Janda 2008a). Einen weiteren wichtigen Bestandteil von Kompositen stellen UV-Stabilisatoren dar. Diese absorbieren einwirkendes UV-Licht. Ohne diese Absorption würde es zu Alterungsprozessen des Komposits kommen, welche sich beispielsweise als gelbliche Verfärbung darstellen und damit zu einer unerwünschten Änderung der Ästhetik führen (Ferracane et al. 1985; Uchida et al. 1998). Somit sind UV-Stabilisatoren eine wichtige ästhetische Komponente, obwohl sie selbst farblos sind. Wichtige Vertreter aus der Gruppe der UV-Stabilisatoren sind 2-Hydroxybenzophenone und 2-Hydroxyphenylbenzotriazole.

Die Imitation der natürlichen Zahnfarbgebung durch Komposite wird durch Zusatz von Pigmenten erreicht. Diese im Durchmesser 0,01 bis $1 \mu \mathrm{m}$ messenden Pigmente können anorganischer oder organischer Natur sein. Als wichtige Eigenschaften müssen diese unlöslich, farbstabil und unempfindlich gegenüber Licht bzw. Wärme sowie toxikologisch unbedenklich sein. Die hauptsächlich zum Einsatz kommenden Pigmente sind anorganisch. Zu diesen zählen Titandioxid, Zirkoniumdioxid, Aluminiumoxid sowie Eisenoxid (Janda 2008c).

Im Gegensatz zum Amalgam wird Komposit nicht (nur) durch Makroretentionen mit der Zahnhartsubstanz verbunden, sondern durch die Säure-Ätz-Technik (SÄT) zusätzlich mikroretentiv verankert (Gandhi et al. 2018; Watari 2005). Die zugrundeliegende Technik zur Schmelzätzung wurde bereits 1955 etabliert und führt im Ergebnis zu einer sehr hohen Randdichtigkeit im Schmelzbereich (Buonocore 1955; Buonocore et al. 1968; Gupta et al. 2017; Rosa et al. 2015). Durch die hydrophilen Eigenschaften des Dentins bei gleichzeitig hydrophoben Eigenschaften des Komposits wird der Verbund zwischen diesen beiden erschwert. Um eine spaltfreie Verbindung zwischen Dentin und Komposit herstellen zu kön- 
nen, wird daher auch das Dentin mit Säure vorbehandelt und schließlich mit einer Monomerlösung benetzt, die in das nun freiliegende Geflecht aus Dentintubuli und Kollagenfasern eindringt (Ferreira et al. 2017; Torii et al. 2002).

\subsubsection{Komposite verschiedener Zahnfarben}

Durch Wechselwirkungen der Zahnhartsubstanzen mit Licht, wie Reflexion, Brechung, Streuung und Absorption, wird die Zahnfarbe beeinflusst bzw. in der Folge unterschiedlich vom Betrachter wahrgenommen (Joiner 2004). Dabei spielt die Stärke der Lichteinwirkung und die der individuellen Erfassbarkeit eine große Rolle (Faber 2006; Milagres et al. 2012). Die verschiedenen Zahnhartsubstanzen verhalten sich hierbei unterschiedlich. Der Schmelz, welcher zum Zahnhals dünn ausläuft, verändert die Farbwirkung des Dentins durch seine Opaleszenz und Transluzenz an verschiedenen Stellen des Zahnes heterogen (Oguro et al. 2016). Als Zahnhartsubstanz mit der größten Masse ist das Dentin hauptverantwortlich für die Zahnfarbe (Battersby und Battersby 2015). Weitere Einflussfaktoren sind pigmentreiche Nahrungsmittel, hierzu zählen z. B. Kaffee, Tabak und Rotwein, welche durch verschiedene Wechselwirkungen ebenfalls einen Einfluss auf die Farbgebung und -stabilität von Komposit-restaurationen haben können (Topcu et al. 2009; Nasim et al. 2010; Catelan et al. 2011). Zur Bestimmung der Zahnfarben kann auf unterschiedliche Weise vorgegangen werden. Es kommen klassische Farbringe, aber auch Kolorimeter, Spektrophotometer (z B. VITA Easyshade ${ }^{\circledR}$, VITA Zahnfabrik, Bad Säckingen, Deutschland) bzw. Digitalkameras zur elektronischen Farbbestimmung zum Einsatz (Hammad 2003; Igiel et al. 2017). Im Laufe der Zeit haben verschiedene Hersteller eigene Farbskalen entwickelt und vertrieben, wobei die Farbskala „VITA-Classical“ (VITA Zahnfabrik, Bad Säckingen, Deutschland, Abbildung 2) die größte Verbreitung und Anwendung findet (Chu et al. 2010).

Der Einsatz von Kompositen als Biomaterial im menschlichen Körper erfordert Biokompatibilität. Neben den anderen Bestandteilen müssen daher die farbgebenden Zusätze in Kompositen beständig gegenüber chemischen und physikalischen Einflüssen sein, was die Auswahl der Materialien einschränkt (Kappert und Eichner 2005). Die farbgebenden Zusätze selbst können in Farbpigmente, welche in einem Bindemittel (hier das Komposit) fein verteilt werden müssen, und Farbstoffe, welche sich in der organischen Phase (hier der Matrix) lösen lassen, unterschieden werden (Herbst und Hunger 2009; Bertau et al. 2013). Es ist daher möglich, dass sich die im Komposit gelösten Farbstoffe mit zunehmendem Alter des Komposits an dessen Oberfläche ablagern und auch an die Umgebung abgegeben werden; sie sind also nicht migrationsecht (Müller 2002). Am häufigsten werden anorganische Pigmente zur 
Farbgebung eingesetzt, da sie die verschiedenen Materialanforderungen (Lichtbeständigkeit, chemische Beständigkeit etc.) am besten erfüllen. Durch Mischung von Pigmenten unterschiedlicher Art und Menge werden schließlich die unterschiedlichen Zahnfarben realisiert (Kappert und Eichner 2005; Ghinea et al. 2015). Die in Kompositen zum Einsatz kommenden Pigmente sind hauptsächlich Metalloxide wie z. B. Titandioxidpigmente (Schmidseder 2008; Thorat et al. 2012; Sun et al. 2011). Im Gegensatz zu Sulfiden oder Chromaten, die unbeständig auf wechselnde pH-Werte reagieren, zeigen Titanoxide die beste Beständigkeit gegen Änderungen des pH-Wertes (Elsner et al. 2012). Bei der Herstellung von Medizinprodukten wird auf bestimmte farbgebende Schwermetallverbindungen, wie z. B. aus Cadmiumoder Bleipigmenten, verzichtet (Kappert und Eichner 2005). Durch die Verwendung organischer Leuchtpigmente wird ferner die natürliche Fluoreszenz des Zahnes nachgeahmt (Janda 2008c).

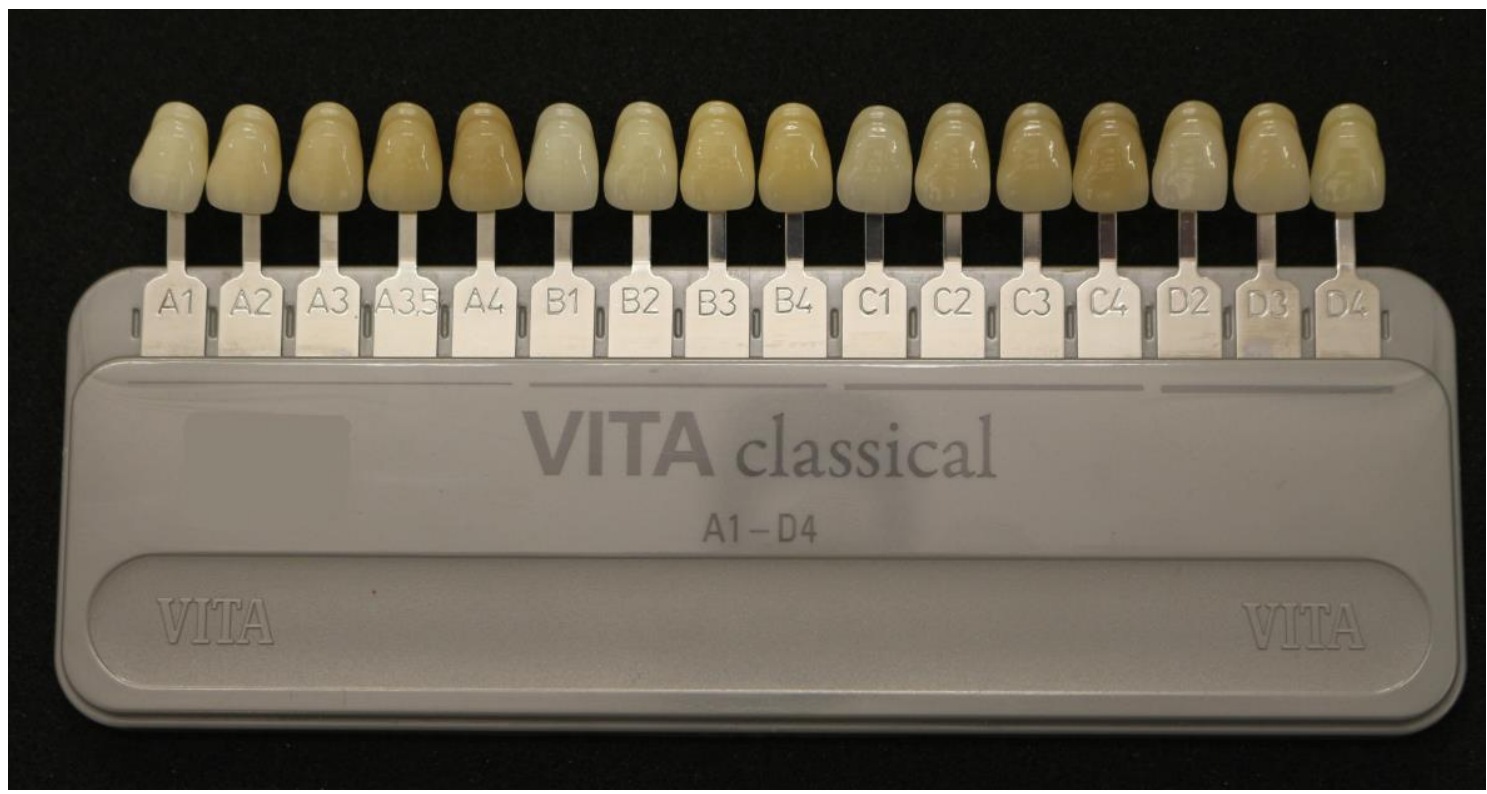

Abbildung 2: Vita-Classical-Farbskala 


\subsection{Untersuchung der Zytotoxizität dentaler Komposite}

Die Verknüpfung der Monomere zu Polymeren benötigt Energie, welche in Form von Licht, Wärme oder auch Redoxreaktionen zugeführt wird. Es wird nach der Energiezufuhr zwischen Photo-, Heiß- und Autopolymerisation unterschieden (Janda 2008a). Da die Polymerisation von Kunststoffen nicht zu 100\% (also ideal) erfolgt, verbleibt auch im polymerisierten Zustand immer ein gewisser Anteil von Restmonomeren erhalten. Reaktionsfähige Monomere, welche in die umliegenden Gewebe diffundieren, können sich zytotoxisch auf die ortsständigen Wirtszellen auswirken (Pradeep und Sreekumar 2012; Goiato et al. 2015; Salehi et al. 2015). Hierbei gilt, dass je lipophiler ein Acrylat bzw. Methacrylat und je kürzer die Kette von Dimethacrylaten ist, desto besser können diese die Doppellipidmembran von Zellen durchdringen und somit stärkeren Einfluss auf die Zellen haben (Yoshii 1997). Die Menge an Restmonomer von Heiß- und Autopolymerisaten, gemessen als Eluat im Speichel, wurde Zellkulturen humaner Gingivafibroblasten zugeführt; so konnte ein Zusammenhang zwischen der Menge des freigesetzten Monomers und der Zytotoxizität auf Fibroblasten gezeigt werden (Kedjarune et al. 1999a). Um diese monomer-induzierte Zytotoxizität zu verringern, wurden und werden Versuche unternommen, den Gehalt an Restmonomeren zu reduzieren, so z. B. mit N-Acetylcystein (NAC). Es zeigte sich beispielsweise, dass die Zugabe von 0,15 Gew. \% NAC die Biokompatibilität von Polymethmethylacrylat (PMMA) signifikant verbessern konnte, ohne einen signifikant negativen Einfluss auf die mechanischen und physikalischen Eigenschaften von PMMA zu bewirken (Jiao et al. 2015). Autopolymersiate zeigen im Vergleich zu anderen Polymerisationsformen aufgrund der höheren Anteile an Restpolymeren auch ein erhöhtes zytotoxisches Potenzial (Brackett et al. 2007). Hingegen ist die Photopolymerisation die Polymerisationsform mit dem geringsten Anteil an Restmonomeren, womit auch ihre auf Monomere zurückgeführte Zytotoxizität am geringsten ist (Buyukerkmen und Ozturk 2013). Die im heißen Wasserbad polymerisierenden Heißpolymerisate wiederum enthalten auspolymerisiert weniger Restmonomer als Autopolymerisate, jedoch mehr Restmonomer als Photopolymerisate (Melilli et al. 2009; Ata and Yavuzyilmaz 2009). Im Zuge der Verwendung und Bearbeitung von Polymethylmethacrylat existieren zudem kritische Überlegungen in Bezug auf die Arbeitsplatzbelastung mit Methylmethacrylat (MMA). Es zeigte sich in diesem Kontext, dass Zahnärzte bzw. zahnmedizinisches Fachpersonal Überempfindlichkeitsreaktionen, asthmatische Reaktionen, lokale neurologische Symptome, Reizungen und lokale dermatologische Reaktionen entwickelten (Kanerva et al. 1993; Piirilä et al. 1998; Aalto-Korte et al. 2007). Klinisch relevant ist zudem, dass die Intakt- 
heit und somit die Schutzfunktion von Latex-Handschuhen nach Kontakt mit MMA beeinträchtigt sein kann. Zahnärztliches Personal sollte daher den direkten Kontakt mit MMA vermeiden und die Raumventilation sollte ausreichend sein (Leggat und Kedjarune 2003).

Als weitere potentiell zytotoxisch wirkende und von dentalen Kompositen freigesetzte Substanz konnte im Speichel Formaldehyd nachgewiesen werden (Tsuchiya et al. 1994). Formaldehyd wird durch die Oxidation von Restmonomeren gebildet oder auch durch die Entstehung eines Peroxid-Co-Oligomers. Dieses Oligomer ist instabil und zerfällt zu Formaldehyd und Methylpyruvat (Ruyter 2009). Zu beachten ist, dass Formaldehyd in niedrigen Konzentrationen toxischer wirkt als MMA (Tsuchiya et al. 1994).

Der Hauptbestandteil des Basismonomers BisGMA, Bisphenol A, ist durch die Eigenschaft, an zelluläre Östrogenrezeptoren binden zu können, Gegenstand aktueller Untersuchungen. Die durch Bisphenol A ausgelösten endokrinen Effekte sind sowohl in vivo als auch in vitro nachweisbar; eine östrogene Wirkung muss daher angenommen werden (Steinmetz et al. 1997). Die relativen Mengen dieser vermutlich nur schwach östrogen-wirkenden Verbindungen sind jedoch als gering einzuschätzen und führen wahrscheinlich zu einem geringen Risko unerwünschter Wirkungen (Schuurs und Moorer 2000).

\subsubsection{Normen}

Da Komposite als Medizinprodukte unter das Medizinproduktegesetz (MPG) fallen, müssen sie auf ihre Biokompatibilität gegenüber lebenden Geweben getestet werden (Janda 2007; Knebel 2010). Hierbei durchlaufen sie mehrere Standardtests (Renisch und Lauer 2014). Bei erfolgreichem Testverlauf erhalten Medizinprodukte eine Zulassung und werden damit für kurz- oder langfristigen Körperkontakt zugelassen (Polzin und Seitz 2012). Eines der Prüfverfahren schreibt vor, die In-vitro-Zytotoxizität des Produktes mit Zellkulturen zu testen, um Tierversuche zu vermeiden. Als Zellkultur werden meist Fibroblasten der Maus (Ziellinie L929) verwendet. Das Prüfungsschema ist dabei festgelegt in der DIN EN ISO 109935:2009-10. 


\subsubsection{In-vitro-Methoden zur Untersuchung der Zellviabilität und Zytotoxizität}

Als etablierte Methoden zur Zellviabilitätsmessung kommen auf wasserlöslichem Tetrazoliumsalzen (engl.: water-soluble tetrazolium salt, WST) basierende Testmethoden zum Einsatz, wie z. B. WST-8 (Lutter et al. 2017). Aufgrund ihrer Ladung können WST-Derivate nicht in Zellen eindringen (Gstraunthaler und Lindl 2013). In Verbindung mit einem Elektronenakzeptor, wie beispielsweise 1-Methoxy-5-Methylphenaziniummethylsulfat (1-Methoxy PMS) gelangen sie ins Zellinnere. 1-Methoxy PMS wird intra-mitochondrial zu PMS (engl.: phenazinium methyl sulfate) reduziert, welches ein wichtiger Katalysator für den Farbumschlag ist. Es wird damit hellgelbes WST-8 in wasserlösliches, orange gefärbtes WST-8-Formazan umgewandelt (Ishiyama et al. 1997; Riss et al. 2016). Die Konzentration des Formazans kann aufgrund des Farbumschlages im Spektralphotometer bei 450-570 nm photometrisch bestimmt werden (Ishiyama et al. 1997). Durch die einfache Durchführbarkeit der Tests und die schnell verfügbaren Ergebnisse, u. a. weil komplexe Vorbereitungen der Zellen entfallen, ist ein hoher Probendurchsatz in kurzer Zeit möglich (Tominaga et al. 1999; Gstraunthaler und Lindl 2013).

Zytotoxizitätmessungen mittels LDH-basierten (Laktat-Dehydrogenase) Testmethoden werden z. B. mit Resazurin durchgeführt (Rodríguez-Corrales and Josan 2017). Resazurin ist ein Redoxindikator, der in die Zelle eindringt und dort zu Resorufin reduziert wird (Präbst et al. 2017). Resazurin wird zu einer tiefblauen Lösung, wenn es in physiologischen Puffern gelöst wird. Es wird direkt zu Zellkulturen hinzugegeben; lebensfähige Zellen mit aktivem Metabolismus können das blaue Resazurin zu rosa fluoreszierenden Resorufin reduzieren (Riss et al. 2016). Auch hier erfolgt die Quantifizierung der Zellviabilität bzw. der zytotoxischen Effekte über den entsprechenden Farbumschlag im Photometer.

Mit Hilfe sogenannter ATP-Assays können lebende Zellen indirekt nachwiesen werden. Dies geschieht, indem man den intrazellulären Energieträger Adenosintriphosphat (ATP) mit Enzymen reagieren lässt, die dann aufgrund ihrer biolumineszenten Eigenschaften nachgewiesen werden können (Lomakina et al. 2015). Diese Enzyme, auch Luciferasen genannt, setzen bei der Reaktion vorhandenes ATP unter Ausstrahlung sichtbaren Lichtes zu Adenosindiphosphat (ADP) um (Riss et al. 2011). Diese ATP-Assays sind schnelle Quantifizierungsverfahren und dabei weniger anfällig für Artefakte als andere Viabilitäts-Assays (Riss et al. 2011). Ursprünglich als Chemosensitivitätsassay für Tumoren entwickelt, hat sich der Test als In-vitro-Assay mit breitem Einsatzspektrum für zelluläre Testungen erwiesen (Cree und Andreotti 1997). Das ATP-Assay ist darüber hinaus auch für die Messung der Viabilität bzw. Zytotoxizität bei geringer Zellanzahl geeignet (Petty et al. 1995). 
Auch durch Fluoreszenzfarbstoffe kann das zytotoxische Potenzial von Stoffen in Zellkulturen sichtbar gemacht werden (Chiaraviglio and Kirby 2014; Grootjans et al. 2016). Dabei bindet der zugeführte Farbstoff an die freigesetzte DNS abgestorbener Zellen (Thakur et al. 2015). Da diese Farbstoffe nicht membrangängig sind, werden die lebenden Zellen mit intakter Doppellipidmembran nicht angefärbt, und damit steht eine stärkere Fluoreszenz direkt mit einer höheren Zytotoxizität der Zellen in Verbindung (Valdés et al. 2013).

Experimentelle Studien finden hauptsächlich in der Grundlagenforschung Anwendung. Dabei wird zwischen In-vivo-Studien (Tierexperimente) und In-vitro-Studien (Zellkulturen) unterschieden (Teaford and Oyen 1989). Es werden Fragestellungen, welche sich aus klinischen Beobachtungen ergeben haben, in einer kontrollierten Umgebung untersucht. Der Vorteil an In-vitro-Studien ist die hohe Standardisierung durch die Ausschaltung von störenden Variablen, wodurch geringere Fallzahlen für ein zeitnahes aussagekräftiges Ergebnis benötigt werden (Krukemeyer und Alldinger 2005). Der größte Nachteil ist, dass die Ergebnisse sich nur bedingt auf die Klinik übertragen lassen, da das System Mensch komplexer ist als das Studiendesign (Goldberg 2008). In-vivo-Studien haben meist eine höhere Aussagekraft, da sie im komplexen System eines Lebewesens durchgeführt werden, was ethisch betrachtet aber auch den größten Nachteil darstellt, da sich der Mensch anderer Lebewesen bedient, um anthropozentrische Interessen zu verfolgen (Leyh et al. 2002).

\subsection{Physiko-chemische Oberflächencharakteristika}

Einen entscheidenden Einfluss auf die Integration von Biomaterialien in den menschlichen Körper hat die Oberfläche des zugeführten Materials (Romanò et al. 2015; Jäger 2018). Dabei spielen unter anderem die Rauheit, die freie Energie der Oberfläche, die Topografie und mögliche Oberflächenbeschichtung eine große Rolle (Bacchelli et al. 2009; Coelho et al. 2011; Mai et al. 2012). Das Ziel aktueller Forschung ist es daher, über die Modifikation von spezifischen Oberflächenparametern eine bessere Biokompatibilität und intensivere Integration in die umgebenden menschlichen Gewebe zu erreichen (Nyberg et al. 2013; Shah et al. 2016). 


\subsubsection{Rauheit}

Die Oberflächenrauheit und Substratmorphologie von dentalen Biomaterialien ist von essentieller Bedeutung, da sie die Akkumulation von Mikroorganismen maßgeblich beeinflusst und zusätzlich spezifische Wirkungen auf umgebende humane Zellen hat (Hahnel et al. 2010a; Cazzaniga et al. 2015). Die betreffende aktuelle Literatur beschreibt eindeutig, dass auf glatten Oberflächen die mikrobielle Adhäsion geringer ausfällt als auf rauen Oberflächen (Aykent et al. 2010; Mei et al. 2011; Tsarev et al. 2014). Als Rauheiten werden Unebenheiten in der Oberfläche von Werkstoffen bezeichnet (Trautwein et al. 2014). In der DIN 4760:1982 (Deutsches Institut für Normung e.V.) werden Oberflächen, deren Gestalt von der idealen Oberflächenbeschaffenheit abweicht, in sechs verschiedene Ordnungen unterteilt (siehe Tabelle 1).

Tabelle 1: Gestaltabweichung nach DIN 4760:1982

\begin{tabular}{|l|l|} 
Gestaltab- & Bezeichnung \\
weichung & \\
\hline 1. Ordnung & Formabweichungen (Geradheits-, Ebenheits-, Rundheitsabweichungen) \\
\hline 2. Ordnung & Welligkeit (Wellen) \\
\hline 3. Ordnung & Rauheit (Rillen) \\
\hline 4. Ordnung & Rauheit (Riefen, Schuppen, Kuppen) \\
\hline 5. Ordnung & Rauheit der Gefügestruktur \\
\hline 6. Ordnung & Gitteraufbau des Werkstoffs \\
\hline
\end{tabular}

Um die Rauheit einer Oberfläche zu messen, kommen unterschiedliche Methoden zur Anwendung. In der Literatur wird die 2D-Profilometrie durchgehend als adäquate Methode beschrieben (Kocher et al. 2002). Dabei erfolgt die Rauheitsmessung durch mechanisches Abtasten der Oberfläche mit einer Diamantspitze. Die mechanischen Signale werden in elektrische umgewandelt und digital ausgewertet (Rai and Gupta 2013). Die neuesten Systeme zur Bestimmung der Oberflächenrauheit und Darstellung sind die Laser-Scanning-Mikroskopie und die Konfokalmikroskopie (Paddock und Eliceiri 2014; Bayguinov et al. 2018). Bei der Laser-Scanning-Mikroskopie wird die Oberfläche der Probe mit einem fokussierten Laserstrahl abgerastert (Reddy 2007). Wenn das Abrastern nur durch einen Punkt erfolgt, ist die Erstellung einer Aufnahme zeitintensiv. Werden Bilder in unterschiedlichen Fokusebenen erstellt, ist es möglich, ein dreidimensionales Bild zu erzeugen (Göbel 2008). Konfokalmikroskope sind Lichtmikroskope, welche nur einen geringen Anteil der Probe belichten; sie 
erzeugen damit viele Einzelbilder, welche nach dem Abrastern der Probe zu einem Gesamtbild zusammengesetzt werden. Durch die Einzelaufnahmen haben sie einen hohen Kontrast, da nur das Licht aus der scharf abgebildeten Ebene aufgenommen wird (Xiao et al. 1988). Die beiden Arten von Lichtmikroskopen wurden in den letzten 30 Jahren miteinander kombiniert und mithilfe der konfokalen Laser-Scanning-Mikroskope werden kontrastreiche dreidimensionale Aufnahmen mit sehr hoher Auflösung erzeugt (Engelhardt und Knebel 1993; Netuschil et al. 1998; Bitter et al. 2004; Heurich et al. 2010; Pilownic et al. 2017).

Die Rauheit zahnmedizinischer Werkstoffe wird meistens durch den Rauheitswert $\mathrm{R}_{\mathrm{a}}$ angegeben (Ishikiriama et al. 2015; Leal et al. 2015). $\mathrm{R}_{a}$ stellt nach DIN EN ISO 4287:2010 das arithmetische Mittel der Abweichung einer konstruierten Mittellinie mit nach beiden Seiten gleicher Verteilung des Materials durch die Werkstoffoberfläche dar (siehe Abbildung 3). Die Rauheit $\mathrm{R}_{a}$ wird in der Einheit $\mu \mathrm{m}$ angegeben (Kappert und Eichner 2005). Dabei zeigte sich, dass die Grenzflächenrauheit für die bakterielle Adhäsion (auf Titan) bei einem arithmetischen Mittel der Rauheit $\left(\mathrm{R}_{\mathrm{a}}\right)$ 0,2 $\mu \mathrm{m}$ liegt. Das heißt, dass auch aus einer weiteren Verringerung des $R_{a}$-Wertes unter 0,2 $\mu \mathrm{m}$ keine weitere Reduktion der Bakterienakkumulation resultiert (Bollen et al. 1997). Darüber hinaus hat auch der verwendete Werkstoff einen Einfluss auf die Bakterienanhaftung (Hahnel et al. 2015). Für die Osseointegration dentaler Implantate wurde gezeigt, dass sich die Oberflächenrauheit eines Implantatkörpers direkt auf die Anhaftung von Zellen auswirkt (Sammons et al. 2005; Jayaraman et al. 2004; Feller et al. 2014). Es hat sich gezeigt, dass die 3D-Oberflächenrauheit (Abstands-, Höhen-, und Hybridparameter (Kombination von Abstands- und Höheninformationen)) eine bessere Quantifizierung der Oberfläche ermöglicht, z. B. bei oberflächenbehandelten dentalen Implantaten. Dabei wird die Oberfläche mit einem Stereo-Rasterelektronenmikroskop aus verschiedenen Winkeln aufgenommen und daraus ein dreidimensionales Bild erstellt (Rothe et al. 2015). 


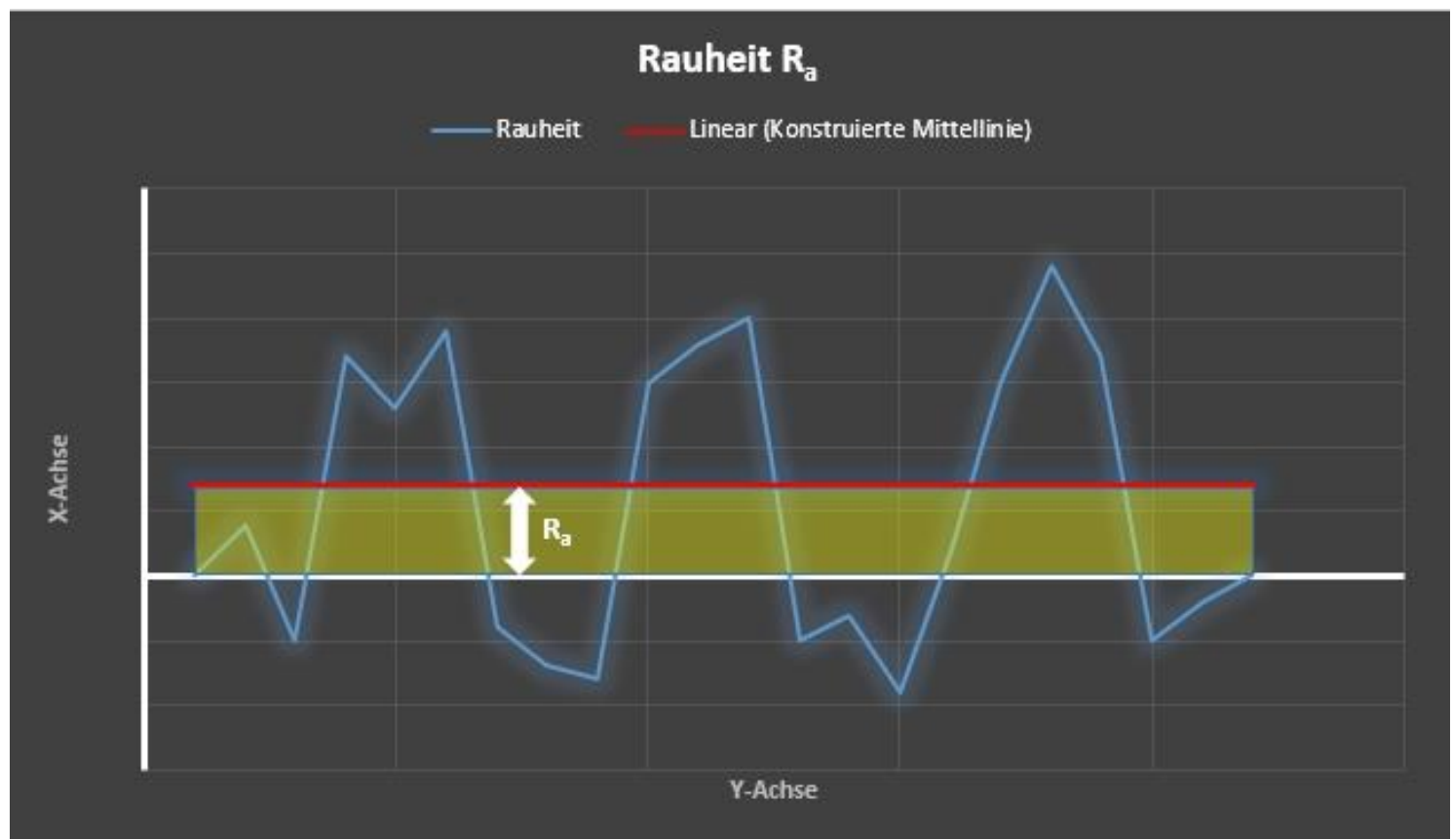

Abbildung 3: Arithmetisches Mittel der Rauheit, grafische Darstellung

\subsubsection{Freie Energie der Oberfläche}

Die freie Energie der Oberfläche ist die Arbeit, welche pro Fläche aufgewendet werden muss, um die Oberfläche eines Stoffes zu vergrößern. Ein Verfahren zum Messen der Oberflächenenergie von Festkörpern ist die Messung des Kontaktwinkels zwischen einem Festkörper und einem Tropfen einer Flüssigkeit mit bekannten Eigenschaften. Häufig werden aufgrund ihrer komplementären Eigenschaften hierfür Wasser (polare Eigenschaften) und Methyleniodid (unpolare Eigenschaften) eingesetzt (Attal et al. 1994; Rüttermann et al. 2014). Durch die Größe des Kontaktwinkels kann man Rückschlüsse auf die Wechselwirkung zwischen der Flüssigkeit und dem Festkörper ziehen, d. h. je größer die Wechselwirkung, desto geringer der Kontaktwinkel. Im Fall von Wasser als benetzende Flüssigkeit bezeichnet man die Oberfläche wie in Tabelle 2 dargestellt.

Tabelle 2: Kontaktwinkel und Bezeichnung bei Benetzung mit Wasser (Jung und Bhushan 2006)

\begin{tabular}{|l|l|}
\hline Kontaktwinkel & Bezeichnung \\
\hline $\mathbf{U m} \mathbf{0}^{\circ}$ & hydrophil (wasserliebend) \\
\hline $\mathbf{5 9 0 ^ { \circ }}$ & hydrophob (wasserabweisend) \\
\hline $\mathbf{9} \mathbf{9 0}^{\circ}$ & superhydrophob \\
\hline
\end{tabular}


Aus dem Kontaktwinkel, d. h. dem Winkel zwischen Tropfen und Festkörperoberfläche, kann mit Hilfe der Young'schen Gleichung (Abbildung 4) die freie Oberflächenenergie des Festkörpers errechnet werden. Die Young'sche Gleichung beschreibt den Zusammenhang zwischen Festkörper und Flüssigkeit $(\theta)$, der freien Oberflächenenergie des Festkörpers ( $\left.\sigma_{S G}\right)$, der Oberflächenspannung der Flüssigkeit $\left(\sigma_{\mathrm{LG}}\right)$ und der Grenzflächenenergie zwischen Flüssigkeit und Festkörper ( $\left.\sigma_{\mathrm{LS}}\right)$ (Krüss 2010).

\section{$\cos \theta=\frac{\sigma_{S G}-\sigma_{L S}}{\sigma_{L G}}$ \\ $\sigma_{L G}$}

Abbildung 4: Young'sche Gleichung

Dabei wird durch die Young'sche Gleichung der Kontaktwinkel bei idealen Verhältnissen beschrieben, d. h. die Beziehung zwischen einer reinen Flüssigkeit und einem chemisch homogenen und topographisch einheitlichen Festkörper, welche von einer einheitlichen Gasphase umgeben sind. Da alle Probekörper jedoch reale Feststoffe darstellen, unterliegt der Kontaktwinkel in der Folge einer örtlichen und zeitlichen Veränderung (Starov et al. 2003; Farris et al. 2011).

Das Verfahren der Kontaktwinkelmessung eignet sich besonders für die Oberflächencharakterisierung von Polymeren und hat in der zahnmedizinischen Biomaterialforschung besondere Bedeutung im Kontext der Wechselwirkungen von Biomaterialien und Biofilmen (Owens und Wendt 1969; Quirynen 1994; da Silva et al. 2015).

\subsubsection{Andere physiko-chemische Oberflächeneigenschaften}

Die physiko-chemischen Oberflächeneigenschaften von Biomaterialien spielen eine wichtige Rolle bei der Reaktion des menschlichen Körpers auf die Implantation eines Fremdkörpers, insbesondere in den ersten zwei bis vier Wochen nach der Insertion (Anderson et al. 2008). Durch die Verletzung des Gewebes werden verschiedene Prozesse des Wirtes initiiert, beginnend mit dem extrinsischen und intrinsischen Gerinnungssystem, des Komplementsystems und des fibrinolytischen Systems. Weiterhin erfolgt eine Entzündungsreaktion und die Aktivierung von Magrophagen. Durch Botenstoffe des Immunsystems erweitern sich die Blutgefäße, was eine stärkere Durchblutung des umliegenden Gewebes zur Folge hat. Die Blutgefäße werden durchlässiger für Immun- und Plasmazellen, welche in das Gewebe im- 
migrieren (Anderson 2001). Die spezifische Fremdkörperreaktion an der Grenzfläche zwischen Gewebe und Material ist für den Langzeiterfolg der Implantation eines Medizinprodukts ausschlaggebend. Modifikationen enossaler Titanimplantate, die auf eine bessere Biointegration abzielen, zeigten in verschiedenen Studien gewünschte Zell- und Gewebeantworten (Mendonça et al. 2008). Schlegel et al. (2013) untersuchte konventionelle SLA (Sandblasting with Large grit followed by Acid etching)-Implantate und SLActive ${ }^{\circledR}$-Implantate der Firma Straumann (Straumann Holding AG, Basel, Schweiz) an gesunden und diabetischen Hausschweinen. Jeweils sechs Implantate wurden in die Kalotte von 11 diabetischen und 4 gesunden Hausschweinen gelegt. 30 und 90 Tage nach der Implantatinsertion wurden der Knochen-Implantat-Kontakt und die Knochendichte beurteilt. Als Ergebnis nach 90 Tagen zeigten die SLActive ${ }^{\circledR}$-Implantate signifikant höhere Knochen-Implantat-Kontakte im Vergleich zu den konventionellen SLA-Implantaten bei den diabetischen Tieren. Die Knochendichte war in der SLActive ${ }^{\circledR}$-Gruppe nach 30 und 90 Tagen bei gesunden und diabetischen Tieren höher. Es hat sich gezeigt, dass Diabetes einen Einfluss auf die Implantatinsertation hat, wiederum die modifizierte SLA Oberfläche eine beschleunigte Osseointegration von Zahnimplantaten auslöst. Das könnte bedeuten, dass bei der Verwendung von SLActive ${ }^{\mathbb{R}}$-Implantaten bei Diabetespatienten höhere Einheilraten erzielt werden könnten. Metzler et al. (2013) hat die Osseointegration von diamantbeschichteten Dentalimplantaten untersucht. Es wurden 24 diamantbeschichtete und 24 SLA-Implantate aus Titanlegierungen in die Schädel von acht erwachsenen Schweinen implantiert. Es erfolgte eine histologische Untersuchung nach zwei und fünf Monaten. Dabei konnte kein signifikanter Unterschied zwischen den unterschiedlichen Oberflächenmodifikationen festgestellt werden und es stellte sich heraus, dass ein vergleichbar hoher Grad an Osseointegration bestand. Dies wiederum bedeutet, dass beide Oberflächenmodifikationen zu einem guten klinischen Ergebnis führen könnten.

Insbesondere bei dentalen Implantaten wurden vielfältige und komplexe Oberflächenbehandlungen im Hinblick auf eine verbesserte Osseointegration bei gleichzeitig guter Gewebeverträglichkeit bzw. geringer zytotoxischer Wirkung entwickelt und getestet (Orsini et al. 2000; Conserva et al. 2013; Gardin et al. 2014; Alves et al. 2016; Möller et al. 2012; Malkoc et al. 2012). Gleichwohl kann es bei zahnärztlichen Biomaterialien durch Oberflächenmodifikationen wie Mikrostrukturierungen oder Hydrophilisierungen zu einer vermehrten Anlagerung von pathogenen Biofilmen oder zum Auftreten von Allergien kommen (Bollen et al. 1996; Schmalz 2002; Elter et al. 2008; Bürgers et al. 2010b; Al-Radha et al. 2012). Da eine möglichst geringe Biofilmbildung eine wichtige Voraussetzung für den langfristigen Erfolg von dentalen Implantaten darstellt, wurde beispielweise versucht, diese durch Beschichtung 
mit Silber, welches eine antimikrobielle Wirkung besitzt, zu minimieren (Cochis et al. 2015; Necula et al. 2012).

\subsubsection{Oberflächeneigenschaften und Zytotoxizität}

Der Zusammenhang zwischen verschiedenen Oberflächencharakteristika und der Adhäsion von Biofilmen wurde in multiplen Studien detailliert untersucht (zusammengefasst in Teughels et al. 2006; Hannig and Hannig 2009). Dagegen existiert erstaunlicherweise wenig Literatur zum Einfluss von Oberflächenveränderungen dentaler Materialien auf die Zytotoxizität von Zellen der Mundhöhle. So wurde beobachtet, dass bei dentalen Legierungen, welche einen hohen Anteil von unedleren Metallen enthalten, die unedleren Ionen eine Schicht auf der Oberfläche bilden und diese Schicht die Zytotoxizität der Legierung erhöht (Kato 1976; Wataha et al. 1999). Daher ist es von entscheidender Bedeutung, die Freisetzung von Ionen aus Legierungen in der Mundhöhle aufzuklären und die biologischen Wechselwirkungen freigesetzter Metallkomponenten mit oralen und systemischen Geweben zu bestimmen (Geurtsen 2002). Um die mechanischen Eigenschaften von dentalen Legierungen zu verbessern, werden dem Gefüge unedle Metalle hinzugefügt, was sich wiederum negativ auf die Biokompatibilität auswirkt (Bumgardner and Lucas 1994; Zhang et al. 2012; Ristic et al. 2014). Bei hochgoldhaltigen Legierungen haben unterschiedliche Rauheiten der Oberfläche keine toxische Wirkung (Altvater et al. 2000). Can et al. haben nichtedle Legierungen in Bezug auf Oberflächenrauheit und Zytotoxizität untersucht. Dazu wurden zwanzig Proben aus einer Nickel-Chrom-Legierung hergestellt. Zehn Proben wurden unter Verwendung einer herkömmlichen Technik getrennt poliert. Die verbleibenden zehn Proben wurden mit $50 \mu \mathrm{m}$ Aluminiumoxid $\left(\mathrm{Al}_{2} \mathrm{O}_{3}\right)$ sandgestrahlt. Zehn Proben (5 poliert, 5 sandgestrahlt) wurden in Wells mit Dulbecco's Modified Eagle's Medium gegeben. Die anderen zehn Proben wurden in Wells mit künstlichem Speichel platziert. Die Proben wurden 30 Tage lang in Kontakt mit diesen Medien gebracht. Diese Medien wurden alle 7 Tage gesammelt und am Ende der Expositionszeit wurde die Atomabsorptionsspektrometrie (AAS) verwendet, um die Freisetzung von Elementen aus den Legierungen in das gesamte gesammelte Medium zu bestimmen. Als Ergebnis stellte sich heraus, dass elementare Freisetzungen in allen Medien auftraten. Die elementaren Freisetzungen von Legierungsbestandteilen waren bei den sandgestrahlten Proben höher als bei polierten Proben. Weiterhin wurde festgestellt, dass künstli- 
cher Speichel mehr Freisetzung von Elementen aus den Proben verursacht. In beiden Medien war Nickel, das aus polierten und sandgestrahlten Legierungen freigesetzt wurde, höher nachweisbar als Chrom und Molybdän.

Mit Hilfe von Nano-Beschichtungen wird versucht, dentalen Legierungen einerseits eine antimikrobielle Wirkung zu verschaffen, anderseits eine gute Anlagerung für Fibroblasten zu gewährleisten (Shimojo et al. 2007; Lamolle et al. 2009; Brunetto et al. 2011; Walter et al. 2014). Dieser Ansatz wird verfolgt, um bei Titanimplantaten eine schnellere und bessere Integration in den Knochen zu gewährleisten (Monjo et al. 2012; Kirmanidou et al. 2016; Chiang et al. 2016; Henningsen et al. 2018).

Bei Kunststoffen spielt die Zytotoxizität vor allem bei der Polymerisation und in der primären Phase nach dem Einbringen - in Form von eluiertem Restmonomer - eine Rolle (Ausiello et al. 2013; Lee et al. 2017; Attik et al. 2017). Es hat sich gezeigt, dass sich bei Photopolymerisaten zur Oberflächenversiegelung das zytotoxische Potenzial nicht ändert, selbst wenn man die Lichthärtezeit verkürzt (Wegehaupt et al. 2014). Der Photoaktivierungsabstand spielt hingegen eine wichtige Rolle bei der zytotoxischen Wirkung; je größer der Abstand bei der Polymerisation ist, desto zytotoxischer ist das Komposit (Carvalho et al. 2013). Durch Veränderung der chemischen Zusammensetzung von dentalen Kunststoffen wird versucht, die physikalischen Eigenschaften zu verbessern, ohne negativen Einfluss auf die Biokompatibilität zu nehmen (Kamonwanon et al. 2015; Dafar et al. 2016; Chadda et al. 2016; Jin et al. 2017). Mit der Modifikation durch Nanopartikel ist es möglich, die Mikrofilmbildung auf Kompositen zu reduzieren (Yudovin-Farber et al. 2008).

Dentale Keramiken wirken sich unabhängig von ihrer Oberflächenmorphologie nicht negativ auf den menschlichen Körper aus (Griggs et al. 2003). Keramikimplantate mit modifizierter Oberfläche zeigen eine bessere Osseointegration als unbehandelte Implantate (KunertKeil et al. 2012; Caravaca et al. 2016). Veränderungen in der Zusammensetzung und der Vorbehandlung können die Zytotoxizität zahnmedizinischer Werkstoffe stark beeinflussen. Daher ist es wichtig, die Anweisungen des Herstellers beim Umgang mit Dentalmaterialien sorgfältig zu befolgen (Sjogren et al. 2000; Cairovic et al. 2016). 


\section{FragestelLung}

Auf Basis der vorgestellten Literatur sollten folgende Fragen in der vorliegenden Arbeit geklärt werden. Wirken bzw. wie wirken sich minimale Änderungen in der Zusammensetzung von Kompositen auf die physiko-chemischen Oberflächencharakteristika und die Zellviabilität anhaftender humaner Gingiva- und Mausfibroblasten aus?

Um klinisch relevante Unterschiede bei verschiedenen Kompositen zu untersuchen, wurden hierfür verschiedene Farbmischungen eines bestimmten Komposits (Grandio der Firma Voco) als Testmaterialien und Amalgam bzw. Glas als Vergleichsmaterialien verwendet. Jedes der Füllungsmaterialien wurde mit vier unterschiedliche Rauheiten versehen. Die Oberflächeneigenschaften der Testmaterialien wurden mittels Weitfeld-Konfokal-Mikroskopie und digitaler Goniometrie bestimmt und verglichen. Anschließend erfolgte eine Inkubation der entsprechenden Probekörper mit humanen Gingiva- und Mausfibroblasten; nach 48 Stunden wurden Zellviabilitätstests durchgeführt. 


\section{Material und Methoden}

\section{1 Übersicht zum Versuchsaufbau}

Als Testmaterialien dienten vier verschiedenfarbige lichthärtende Nano-Hybrid-Komposite (Grandio, Voco GmbH, Cuxhaven) und Amalgam (Vivacap, Ivoclar Vivadent, Schaan, Liechtenstein). Im Hauptversuch kamen Grandio-Kompositmaterialien in den Farben A1, A2, A3 und A4 (siehe Tabelle 3) und das Amalgam Vivacap zum Einsatz, im Vorversuch Grandio in der Farbe BL (Bleach-Light, siehe Tabelle 3). Im Vorversuch wurden 35 Probekörper (Durchmesser 10,0 mm) und im Hauptversuch 212 Probekörper (192 mit einem Durchmesser von 6,0 mm und 20 Probekörper mit einem Durchmesser von 10,0 mm) je Testmaterial untersucht. Insgesamt erfolgte die Herstellung von 1095 Probekörpern. Zusätzlich wurden für Zellviabilität- und Zytotoxizitätskontrollen genormte Glasprobekörper sowohl mit 6,0 mm Durchmesser (Menzelgläser, Thermo Fisher Scientific Gruppe, Braunschweig, Deutschland) als auch mit 10,0 mm Durchmesser (Deckgläser, Paul Marienfeld GmbH \& Co. KG, Lauda-Königshofen, Deutschland) eingesetzt.

Tabelle 3: Referenz- und Lotnummern der Grandio-Komposite (Voco GmbH, Cuxhaven, Deutschland)

\begin{tabular}{|l|l|l|}
\hline Farbe & REF - Nummer & LOT - Nummer \\
\hline A1 & 1810 & 1746620 \\
\hline A2 & 1811 & 1802670 \\
\hline A3 & 1812 & 1804414 \\
\hline A4 & 1814 & 1804650 \\
\hline BL & 1853 & 1701254 \\
\hline
\end{tabular}

Die Probekörper wurden durch standardisierte Politur mit verschiedenen definierten Rauheiten ( $n=5$ im Vorversuch; $n=4$ im Hauptversuch) versehen. Mit Hilfe der Weitfeld-Konfokalmikroskopie wurde der Mittenrauheitswert $\left(\mathrm{R}_{\mathrm{a}}\right)$ ermittelt. Zusätzlich wurden die freien Oberflächenenergien mittels Kontaktwinkelmessungen bestimmt. Die humanen Gingivaund Mausfibroblasten wurden auf den Probekörpern inkubiert, und nach 48 Stunden erfolgte die Messung der Zellviabilitäten. Des Weiteren wurden Positiv- und Negativkontrollen, in Form von Glasprobekörpern und Latex, untersucht. In Untersuchungen hat sich gezeigt, dass Latex hochgradig zytotoxisch auf die Zelllinien wirkt (Stellet Lourenço et al. 2014). Der Versuchsablauf ist in Tabelle 4 im Überblick dargestellt. 
Tabelle 4: Versuchsablauf

\section{Versuchsablauf}

1. Herstellung der Probekörper für 5 Testmaterialien

2. Einstellen von 4 unterschiedlichen Rauheiten

3. Messung des Mittenrauheitswertes $\left(\mathrm{R}_{\mathrm{a}}\right)$ und Darstellung der Oberflächenmorphologie mit Hilfe der Weitfeld-Konfokalmikroskopie

4. Messung der freien Oberflächenenergie (SFE) mittels Goniometrie

5. Inkubation der Zelllinie L929 (Mausfibroblasten) auf den Probekörpern für $48 \mathrm{~h}$

6. Messung der zytotoxischen Effekte auf die Zelllinie L929 mittels Pierce ${ }^{\text {TM }}$ LDH Cytotoxicity Assay Kit (Thermo Fisher Scientific Inc., Waltham, Massachusetts, USA)

7. Messung der Zellviabilität der Zelllinie L929 mittels WST8 des Cell Counting Kit-8 (CCK8, Dojindo EU GmbH, München, Deutschland)

8. Inkubation der Zelllinie GF1 (Gingivafibroblasten) auf den Probekörpern für $48 \mathrm{~h}$

9. Messung der zytotoxischen Effekte auf die Zelllinie GF1 mit Pierce ${ }^{\mathrm{TM}}$ LDH Cytotoxicity Assay Kit (Thermo Fisher Scientific Inc., Waltham, Massachusetts, USA)

10 Messung der Zellviabilität der Zelllinie GF1 mit WST8 des Cell Counting Kit-8 (CCK8, Dojindo EU GmbH, München, Deutschland)

11. Statistische Auswertung der Messergebnisse 


\subsection{Testmaterialien, Positiv- und Negativkontrolle}

Grandio (Voco GmbH, Cuxhaven, Deutschland) ist ein lichthärtendes Nano-Hybrid-Komposit für direkte Füllungen im Front- und Seitenzahnbereich. Aus dem hohen Füllstoffanteil von 87 Gew. \% resultiert eine geringe Schrumpfung bei der Polymerisation von 1,57 Vol.\% (Voco 2010). Alle technischen Daten werden in Tabelle 5 aufgeführt.

Tabelle 5: Technische Daten Grandio laut Hersteller (Voco 2010)

\begin{tabular}{|l|l|}
\hline Technische Daten & Wert \\
\hline Füllstoffgehalt Gew. \% (Vol. \%) & $87,0 \%(71,4 \%)$ \\
\hline Polymerisationsschrumpfung & $1,57 \mathrm{Vol} . \%$ \\
\hline Biegemodul & $17100 \mathrm{MPa}$ \\
\hline Biegefestigkeit & $161 \mathrm{MPa}$ \\
\hline Oberflächenhärte (Vickers) & $84 \mathrm{HV}$ \\
\hline Abrasion & $18 \mu \mathrm{m}$ \\
\hline Wasserlöslichkeit & $<0,3 \mu \mathrm{g} / \mathrm{mm}^{3}$ \\
\hline Wasseraufnahme (7 Tage) & $10 \mu \mathrm{g} / \mathrm{mm}^{3}$ \\
\hline Durchhärttiefe & $3 \mathrm{~mm} / 20 \mathrm{sec}$ \\
\hline Farbbeständigkeit (24h) & $\mathrm{Keine} \mathrm{Entfärbung}$ \\
\hline Tageslichtbeständigkeit & Entspricht ISO 4049 \\
\hline Röntgenopazität & $250 \% \mathrm{Al}$ \\
\hline Dentinhaftung mit Solobond M & $29,8 \mathrm{MPa}$ \\
\hline
\end{tabular}

Das Amalgam Vivacap Größe 3 (Ivoclar Vivadent, Schaan, Liechtenstein) in selbstaktivierenden Kapseln dient zur Versorgung von großen Seitenzahnkavitäten. Es besteht aus sphärischen unregelmäßigen Partikeln und gehört der Gruppe Gamma-2-freier Silberamalgame an. In den Kapseln sind die pulverförmigen Bestandteile und die flüssigen Bestandteile durch eine Membran während der Lagerung getrennt und werden durch Trituieren kurz vor der Verarbeitung zusammengeführt. Die Inhaltsstoffe nach Herstellerangabe sind in Tabelle 6 aufgeführt.

Tabelle 6: Inhaltsstoffe Amalgam Vivacap Größe 3 (Ivoclar Vivadent, Liechtenstein)

\begin{tabular}{|l|l|l|}
\hline Aggregatzustand & Inhaltsstoff & Menge \\
\hline Pulver & Silber & $394 \mathrm{mg}$ \\
\hline Pulver & Zinn & $256 \mathrm{mg}$ \\
\hline Pulver & Kupfer & $197 \mathrm{mg}$ \\
\hline Flüssigkeit & Quecksilber & $800 \mathrm{mg}$ \\
\hline
\end{tabular}


Die Glasprobekörper mit 6,0 mm Durchmesser (Menzelgläser) wurden über die Thermo Fisher Scientific Gruppe (Braunschweig, Deutschland) und die Glasprobekörper mit dem Durchmesser von 10,0 mm (Deckgläser) über die Firma Paul Marienfeld GmbH \& Co. KG (Lauda-Königshofen, Deutschland) bezogen. Diese Probekörper fanden zur Negativkontrolle („,minimale zytotoxische Wirkung“) Verwendung. Als Positivkontrolle („,maximale zytotoxische Wirkung $\left.{ }^{6}\right)$ wurde nach 24 Stunden ein Stück steriles Latex $(5 \times 5 \mathrm{~mm})$ in ein Well mit inkubierten Zellen gegeben (Stellet Lourenço et al. 2014).

\subsection{Probekörper}

\subsubsection{Herstellung der Probekörper}

Die Komposit-Probekörper wurden in einer Negativform aus Silikon (Z-Dupe, Shore Härte 20, Henry Schein Dental GmbH, Langen, Deutschland) hergestellt. Dazu wurde das Komposit unter Zuhilfenahme eines Zementspatels (1058, Carl Martin GmbH, Solingen Deutschland) in die Negativform eingebracht und für genau 60 Sekunden mit einer Polymerisationslampe (Bluephase Style, Ivoclar Vivadent, Schaan, Liechtenstein) ausgehärtet (Abbildung 5). Der Abstand der Polymerisationslampe zum Komposit betrug fünf Millimeter und sämtliche Herstellerangaben wurden strikt eingehalten. Die fertig polymerisierten Probekörper wurden, sortiert nach Zahnfarben, trocken in Zentrifugenröhrchen (Sarstedt AG, Nümbrecht, Deutschland) aufbewahrt.

Die Anfertigung der Amalgam-Probekörper (Vivacap Größe 3, Ivoclar Vivadent, Schaan, Liechtenstein) erfolgte in entsprechenden Silikonnegativformen (Abbildung 5). Dazu wurden die Kapseln mit Hilfe des CapMix ${ }^{\text {TM }}$ Universalmischgeräts (3M Deutschland GmbH, Neuss, Deutschland) zehn Sekunden trituriert. Die Amalgameinbringung und -kompression in die Silikonform geschah ebenfalls mit Hilfe eines Zementspatels und nach vollständigem Aushärten erfolgte die Lagerung in Zentrifugenröhrchen.
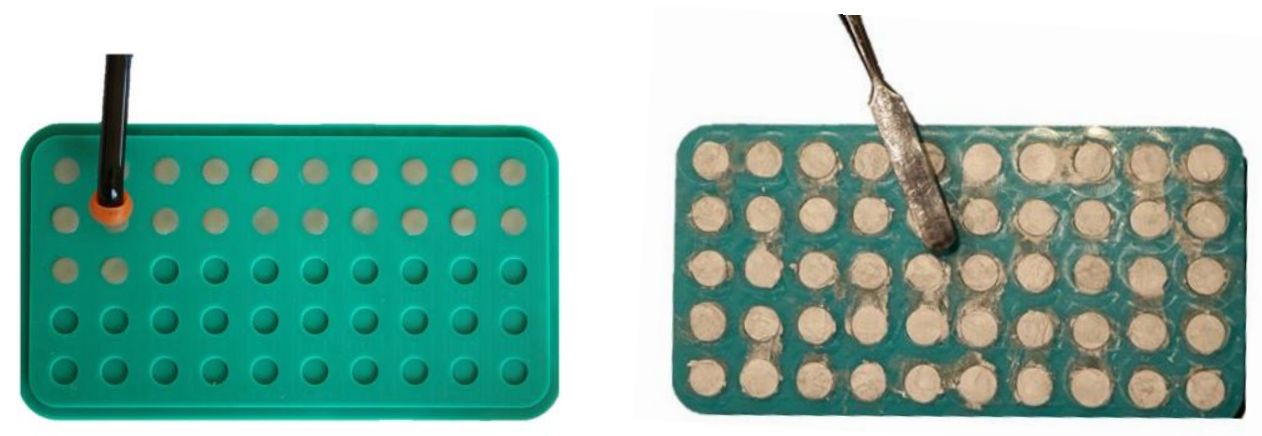


\subsubsection{Einstellen definierter Rauheiten}

Die Rauheiten der Probekörperoberfläche wurden mit Hilfe einer Schleif- und Poliermaschine (Digprep 251, Metkon Instruments Inc., Bursa, Türkei) und anhand eines standardisierten Polierprotokolls eingestellt. Hierfür erfolgte die Fixierung der Probekörper auf speziellen Probekörperhaltern aus Polymethylmethacrylat (PMMA) mit doppelseitigem Klebeband (Powerbond, tesa SE, Norderstedt, Deutschland) (Abbildung 6).

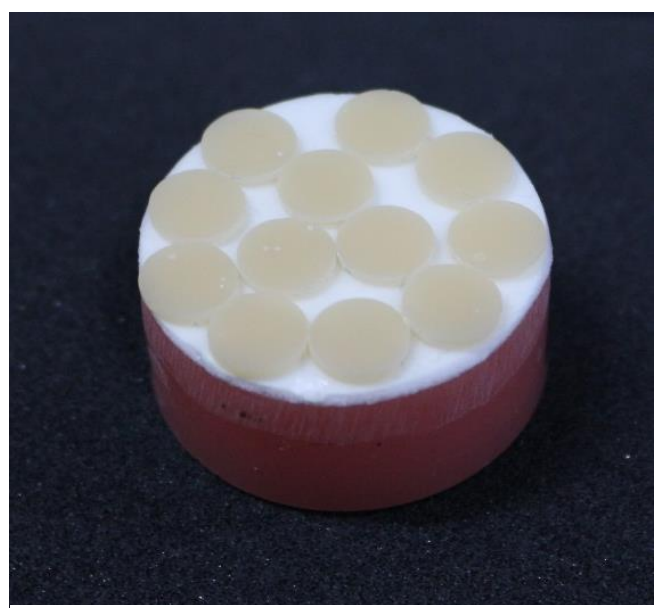

Abbildung 6: Probekörper auf Probekörperhalter

Zuerst wurden alle Probekörper in vier Schleifstufen geglättet und in einem zweistufigen Prozess poliert. Bei den wassergekühlten Schleifprozessen wurde die Drehzahl des Schleifkopfes auf 100 Umdrehungen pro Minute und die der Schleifscheibe gegenläufig auf 150 Umdrehungen pro Minute eingestellt. Alle Schleifvorgänge erfolgten mit einem Anpressdruck von $15 \mathrm{~N} / \mathrm{cm}^{2}$ und genau 180 Sekunden pro Schleifvorgang. Der erste Schleifprozess wurde mit einer Diamantscheibe mit $50 \mu \mathrm{m}$ Körnung vorgenommen (Metkon, Bursa, Türkei). Darauf folgten drei weitere Schleifprozesse mit Schleifpapier der Körnung 400, 1200 und 4000 (Hermes Schleifmittel GmbH, Hamburg, Deutschland). Die Polierstufen wurden mit zwei Poliertüchern und Diamatsuspension der Körnung $3 \mu \mathrm{m}$ und $1 \mu \mathrm{m}$ absolviert (Metkon, Bursa, Türkei). Dabei wurden die Drehzahl des Schleifkopfes und die der Schleifscheibe gegenläufig, sowie Schleifdruck und -dauer beibehalten.

Jeweils eine Gruppe von Testmaterialien, d. h. 48 Probekörper mit 6,0-mm-Probekörpern und 5 mit 10,0-mm-Probekörpern je Farbe bzw. Material im Hauptversuch und 7 Probekörper mit 10,0 mm im Vorversuch, wurde mit einem Sandstrahlgerät (2-Kammer-Sandstrahler Typ PG 360, Harnisch \& Rieth GmbH \&Co.KG, Winterbach, Deutschland) bei 2 bar Druck mit $110 \mu \mathrm{m}$ Aluminiumoxid (Alublast 110 Micron, Henry Schein Inc, Langen, Deutschland) mit einem Düsenabstand von $10 \mathrm{~cm}$ für 30 Sekunden in horizontaler und vertikaler Richtung 
abgestrahlt. Die anderen finalen Oberflächenrauheiten wurden mit der Schleif- und Poliermaschine (Digprep 301, Metkon Instruments Inc., Bursa, Türkei) eingestellt. Hierzu erfolgte die Drehzahleinstellung des Schleifkopfes auf 100 Umdrehungen pro Minute, die der Schleifscheibe gegenläufig auf 150 Umdrehungen pro Minute und der Anpressdruck lag bei $10 \mathrm{~N} / \mathrm{cm}^{2}$. Die Bearbeitungszeit betrug dabei exakt 300 Sekunden.

\subsubsection{Messung der definierten Rauheiten}

Für die Messung der Oberflächenrauheiten wurden von jeder Probekörpergruppe $(n=20)$ jeweils fünf Probekörper mit größerem Durchmesser $(10,0 \mathrm{~mm})$ hergestellt. Diese wurden nach den entsprechenden Schleif- und Polierprotokollen bearbeitet (siehe Kapitel 4.3.2 und Abbildung 7). Die Analyse der Probekörperoberflächen erfolgte mit einem Weitfeld-Konfokalmikroskop (Smartproof 5, Carl Zeiss AG, Oberkochen, Deutschland). Für die Steuerung des Weitfeld-Konfokalmikroskops wurde die Software Zeiss Efficient Navigation (ZEN) (Carl Zeiss AG, Oberkochen, Deutschland) eingesetzt. Die so aufgenommenen Bilder wurden mit der Software ConfoMap (Carl Zeiss AG, Oberkochen, Deutschland) verarbeitet und ausgewertet. Von jedem Probekörper $(n=100=5$ Materialen $\times 4$ Rauheitsgrade $\times 5$ Probekörper) wurden an drei Stellen Analysen der Oberfläche vorgenommen. Die Probekörper wurden zuerst bei 2,5-facher Vergrößerung fokussiert. Dann folgten weitere Einstellungen der Schärfe mit Objektiven der Vergrößerung 5-fach, 10-fach und 20-fach. Um die Oberfläche dreidimensional aufzunehmen, wurde dann ein Z-Stapel festgelegt. Hierfür wurde das Weitfeld-Konfokalmikroskop in der Horizontalen sowohl oberhalb als auch unterhalb aus dem Focus geführt. Diese zwei Punkte stellten den Anfang und das Ende des Z-Stapels dar. Dann wurden Bilder der Oberfläche im festgelegten Bereich automatisch in verschiedener Fokussierung aufgenommen und anschließend digital durch die Software ZEN zusammengeführt. Dadurch entstanden Oberflächenaufnahmen mit hoher Tiefenschärfe, die zusätzlich für dreidimensionale Darstellungen genutzt werden konnten. Die Errechnung der verschiedenen Oberflächenparameter erfolgte vollautomatisch über die Software ConfoMap.

Durch die Auswertung der Aufnahmen mittels ConfoMap wurden die erforderlichen Oberflächenparameter dargestellt und analysiert. Für die drei Messpunkte pro Probekörper wurde primär jeweils ein Mittelwert errechnet, um so eventuelle Abweichungen durch herstellungsbedingte Oberflächendefekte innerhalb einer Messserie auszugleichen. Des Weiteren wurden dreidimensionale Bilder der Oberfläche zur Visualisierung der Oberflächenmorphologien erstellt. 


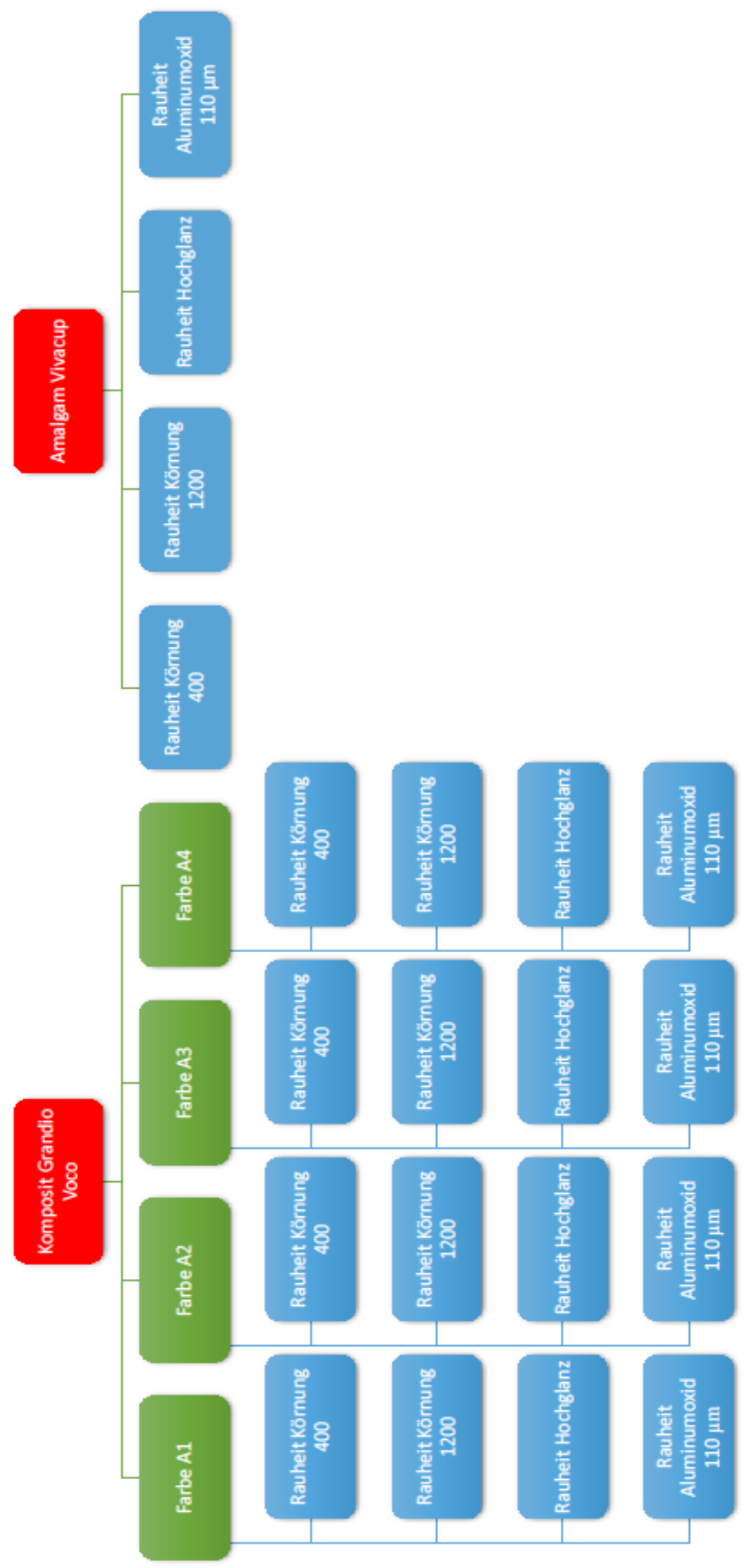

Abbildung 7: Rauheiten der Probekörper 


\subsubsection{Messung der freien Oberflächenenergie}

Die freie Oberflächenenergie (SFE) wurde mit Hilfe des Drop Shape Analyzer-DSA25 (Krüss GmbH, Hamburg, Deutschland) ermittelt. Hierbei handelt es sich um ein Kontaktwinkelmessgerät zur Bestimmung des Kontaktwinkels zwischen Flüssigkeiten und Festkörpern. Hierfür wurden die zu messenden Probekörper mit Isopropylalkohol gereinigt. Danach wurden sie durch die Automatik des Drop Shape Analyzer-DSA25 mit Deionat und Methyleniodid benetzt und der Kontaktwinkel digital gemessen. Da die Probekörper reale Feststoffe darstellen, unterliegt der Kontaktwinkel einer örtlichen und zeitlichen Veränderung. Dies berücksichtigend wurde über Software ADVANCE (Krüss GmbH, Hamburg, Deutschland) für den Drop Shape Analyzer-DSA25 ein Messprotokoll vorgegeben. Dabei wird zwei Sekunden nach Auftropfen der Flüssigkeiten im Abstand von einer Sekunde zehnmal der Kontaktwinkel gemessen und aus dem Mittelwert die freie Oberflächenenergie des Probekörpers durch das System berechnet. 


\subsection{Zellkulturen und Versuchsvorbereitung}

\subsubsection{Mausfibroblasten (L929)}

Für die Studie wurde die Zellline L929 (Mausfibroblasten) vom Leibniz-Institut DSMZ (Deutsche Sammlung von Mikroorganismen und Zellkulturen GmbH, Braunschweig, Deutschland) der Passagen 5, 7, 9, 22, 24, 26 verwendet (Abbildung 8).

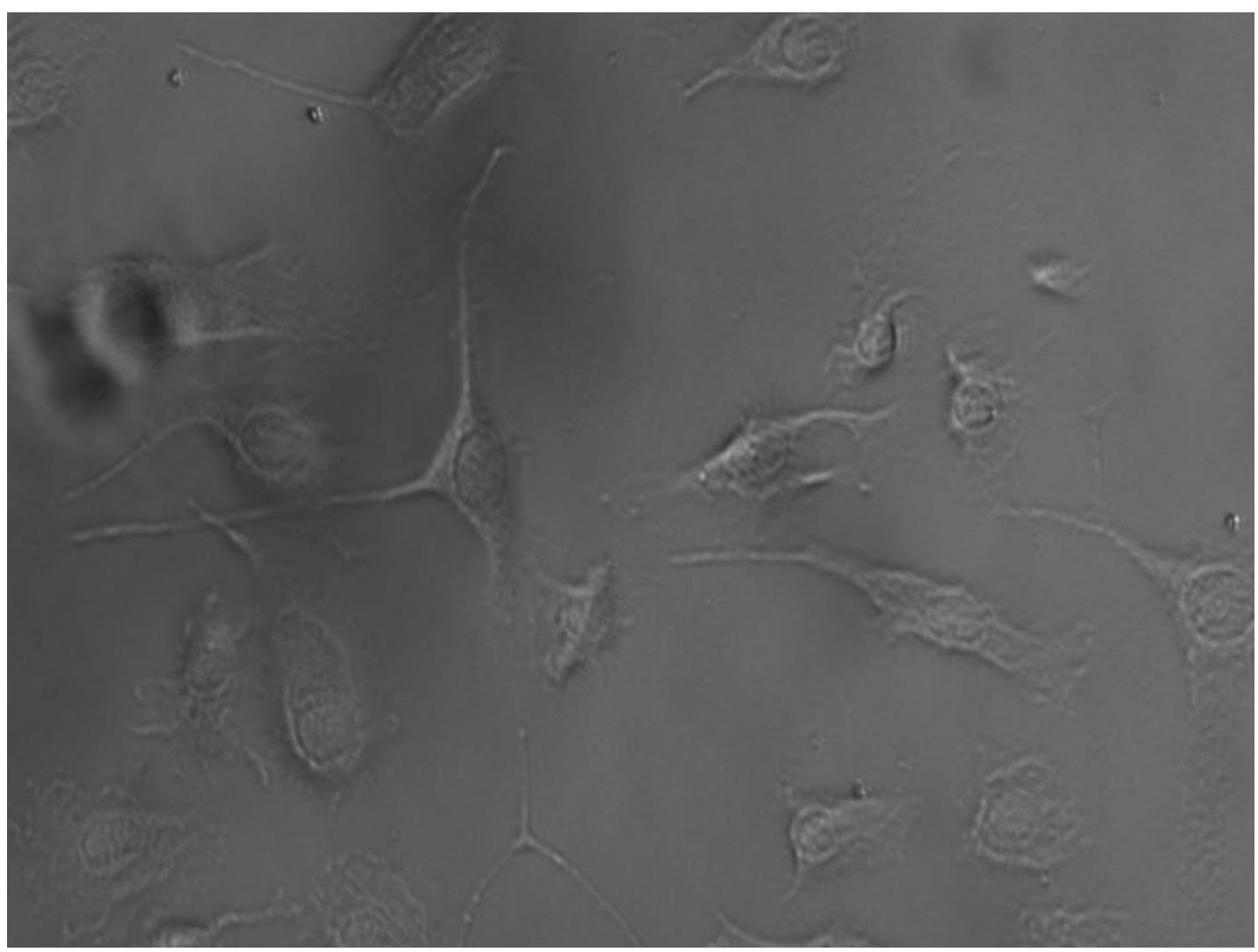

Abbildung 8: Lichtmikroskopisches Bild von Mausfibroblasten (L929) auf Glasprobekörper (40fache Vergrößerung) 


\subsubsection{Gingivafibroblasten (GF1)}

Durch die AG Orale Biologie und Geweberegeneration der Abteilung für Zahnärztliche Prothetik der Universitätsmedizin Göttingen wurde die Zelllinie GF1 für die Studie zur Verfügung gestellt (Abbildung 9). Dabei fanden Zellen der Passagen 13, 15, 23, 25, 27,28 Verwendung. Die Zellen wurden aus gesundem Gewebe gewonnen, welches an der Universitätsmedizin Göttingen (UMG) entnommen wurde. Ein durch die Ethikkommission der UMG genehmigter Ethikantrag liegt vor (Antragsnummer 16/6/09).

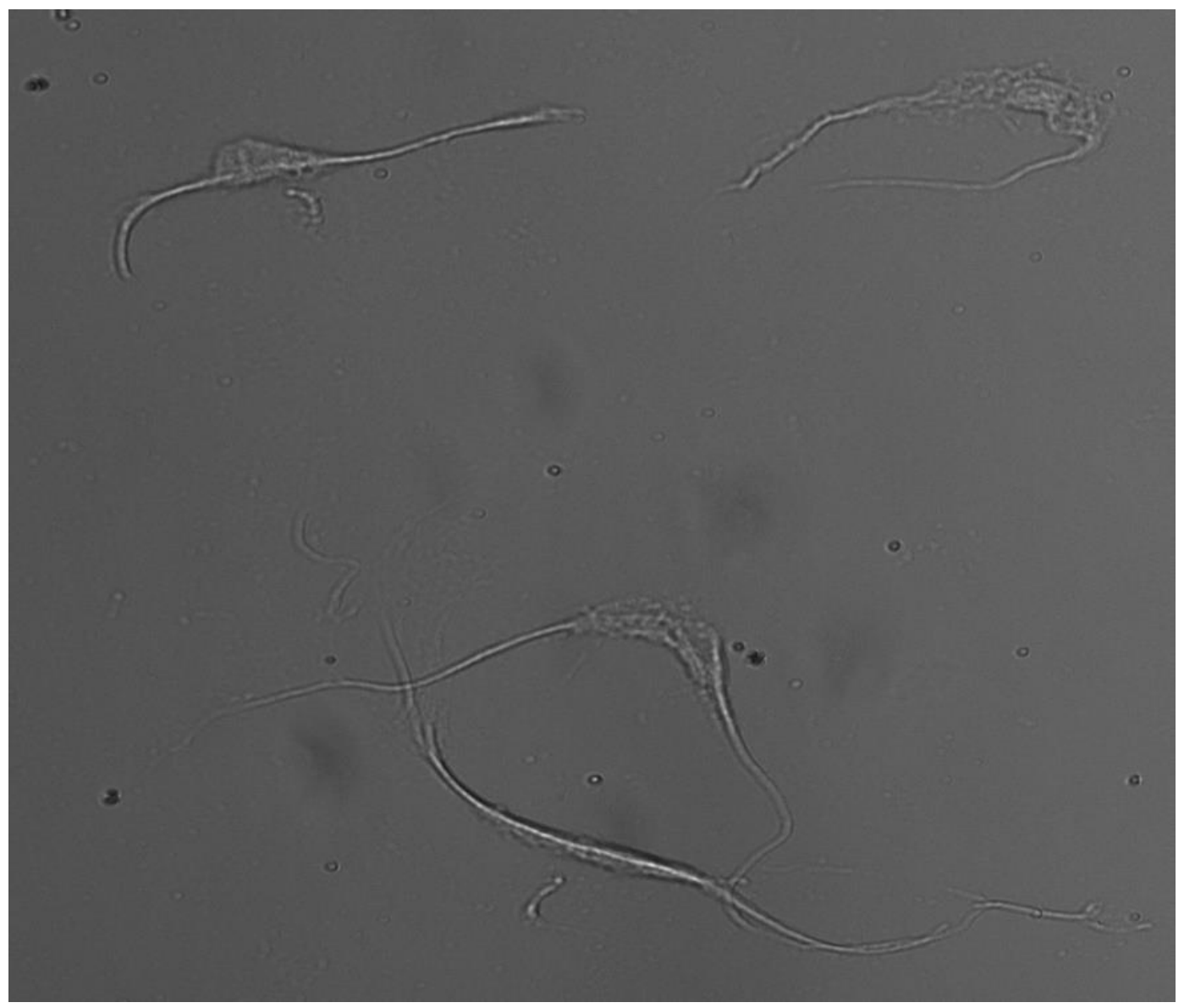

Abbildung 9: Lichtmikroskopisches Bild von Gingivafibroblasten (GF1) auf Glasprobekörper (40fache Vergrößerung) 


\subsubsection{Vorbereiten der Zellkulturen}

Beide Zellreihen waren bei $-192{ }^{\circ} \mathrm{C}$ tiefgekühlt gelagert. Um ein schonendes Auftauen zu gewährleisten, wurden die Kryoröhrchen in ein $37^{\circ} \mathrm{C}$ warmes Wasserbad gegeben. Nach abgeschlossenem Auftauen wurden die Zellkulturen in je eine $250-\mathrm{ml}\left(75 \mathrm{~cm}^{2}\right)$-Kulturflasche (Sarstedt AG \& Co, Nümbrecht, Deutschland) mit $10 \mathrm{ml}$ vorgewärmtem Medium (Dulbecco's Modified Eagle’s Medium + 4,5 g/l D-Glucose + L-Glutamin) mit 20 \% fetalem Kälberserum (FCS, Life Technologies GmbH / Thermo Fisher Scientific, Darmstadt, Deutschland) und mit $1 \%$ Penicillin / Streptomycin (PAN-Biotech GmbH, Aidenbach, Deutschland) inkubiert. Die Inkubation erfolgte bei $37^{\circ} \mathrm{C}, 95 \%$ Luftfeuchtigkeit und $5 \%$ Kohlenstoffdioxid $\left(\mathrm{CO}_{2}\right)$ im Inkubationsschrank Heracell Vios 160i (Thermo Fisher Scientific Inc., Waltham, Massachusetts, Vereinigte Staaten von Amerika). Nach 24 Stunden wurde das Nährmedium durch $10 \mathrm{ml} 10 \%$ fetales Kälberserum (FCS, Life Technologies GmbH / Thermo Fisher Scientific, Darmstadt, Deutschland) ersetzt, um Zelltrümmer sowie tote Zellen zu entfernen und danach wurde die Inkubation fortgesetzt. Es folgten regelmäßige Kontrollen der Zellen unter dem Lichtmikroskop (Labovert FS, Leitz, Wetzlar, Deutschland). Das Nährmedium wurde nach 72 Stunden durch 5 \%iges fetales Kälberserum (FCS, Life Technologies GmbH / Thermo Fisher Scientific, Darmstadt, Deutschland) ersetzt. Die weitere Inkubation erfolgte, bis die Zellen am Kulturflaschenboden eine Konfluenz von ca. $80 \%$ erreicht hatten. Dann wurde mit dem Subkultivieren der Zellen begonnen. Zuerst wurde das Nährmedium verworfen und die Zellen gewaschen. Dies geschah zweimal mit $5 \mathrm{ml}$ phospatgepufferter Salzlösung (PBS, Life Technologies GmbH / Thermo Fisher Scientific, Darmstadt, Deutschland). Mit 2 ml Trypsin (PAN Biotech, Aidenbach, Deutschland) wurden die Zellen vom Boden und voneinander getrennt. Es folgte eine Kontrolle mit dem Lichtmikroskop (Labovert FS, Leitz, Wetzlar, Deutschland), ob sich die adhärenten Zellen gelöst hatten. Durch frisches Nährmedium wurde das Trypsin neutralisiert, die Zellsuspension anschließend in ein Zentrifugenröhrchen gefüllt und dieses für 8 Minuten bei $950 \mathrm{rpm}$ (Megafuge 8R, Thermo Fisher Scientific Inc., Waltham, Massachusetts, Vereinigte Staaten von Amerika) zentrifugiert (siehe Abb. 13). Nach Verwerfen des Überstandes und Resuspendieren mit frischem Nährmedium wurden die Zellen in der Zählkammer Neubauer improved (Brand GmbH, Wertheim, Deutschland) gezählt. Um die Anzahl der Zellen in einem $\mathrm{ml}$ Suspension zu bestimmen, werden $20 \mu \mathrm{l}$ in die Zählkammer gegeben und unter dem Lichtmikroskop ausgezählt. 50.000 Zellen wurden in eine neue Kulturflasche mit frischem, $5 \%$ igem fetalem Kälberserum (FCS) gegeben und weiter inkubiert. 


\subsubsection{Konditionierung der Probekörper}

Es wurden 48 Probekörper (6,0 mm Durchmesser) in jeder der vier untersuchten Farben des Komposits und 48 (6,0 mm Durchmesser) Probekörper des Amalgams mit der gleichen Rauheit versehen. Jeweils 24 Probekörper jeder Prüfgruppe wurden mit einer Zelllinie untersucht, nach 48 Stunden erfolgten die Messungen.

\subsubsection{Vorbereiten der Well-Platten}

Die konditionierten Probekörper wurden mit 70 \%-igem Ethanol gereinigt und dann fünfmal mit destilliertem Wasser gespült. Zur Trocknung wurden die Probekörper auf sterilem Papier ausgebreitet und unter der Sterilbank (HERAsafe Ks12, Thermo Fisher Scientific, Waltham, Vereinigte Staaten von Amerika) luftgetrocknet. Um die Probekörper in den 48Well-Platten (Sarstedt AG \& Co, Nümbrecht, Deutschland) zu fixieren, wurde das Silikon Z-Dupe (Shore Härte 20, Henry Schein Dental GmbH, Langen, Deutschland) in einer sterilen Petrischale angemischt und mit Hilfe von sterilen Impfösen (Sarstedt AG, Nümbrecht, Deutschland) in die Well-Platten eingebracht. Mit Hilfe einer sterilen Pinzette (Aesculap AG, Tuttlingen, Deutschland) wurden die Probekörper mit der unbehandelten Seite in den Wellplatten fixiert.

Die Anordnung der Proben in den 48-Well-Platten ist in den Abbildungen 10 und Abbildung 11 dargestellt.

\begin{tabular}{|c|c|c|c|c|c|c|c|c|}
\hline & 1 & 2 & 3 & 4 & 5 & 6 & 7 & 8 \\
\hline A & C & $\mathrm{L}$ & G & G & G & G & G & G \\
\hline B & PK A1 & PK A1 & PK A1 & PK A1 & PK A1 & PK A1 & PK A1 & PK A1 \\
\hline C & PK A2 & PK A2 & PK A2 & PK A2 & PK A2 & PK A2 & PK A2 & PK A2 \\
\hline D & PK A3 & PK A3 & PK A3 & PK A3 & PK A3 & PK A3 & PK A3 & PK A3 \\
\hline $\mathbf{E}$ & PK A4 & PK A4 & PK A4 & PK A4 & PK A4 & PK A4 & PK A4 & PK A4 \\
\hline$F$ & PK AG & PK AG & PK AG & PK AG & PK AG & PK AG & PK AG & PK AG \\
\hline
\end{tabular}

Abbildung 10: Schematische Darstellung der Probekörperanordnung in den 48-Well-Platten, PK = Probekörper; A1, A2, A3, A4 Farben von Grandio Voco; L = Latex; G = Glas; C = Kontrolle 


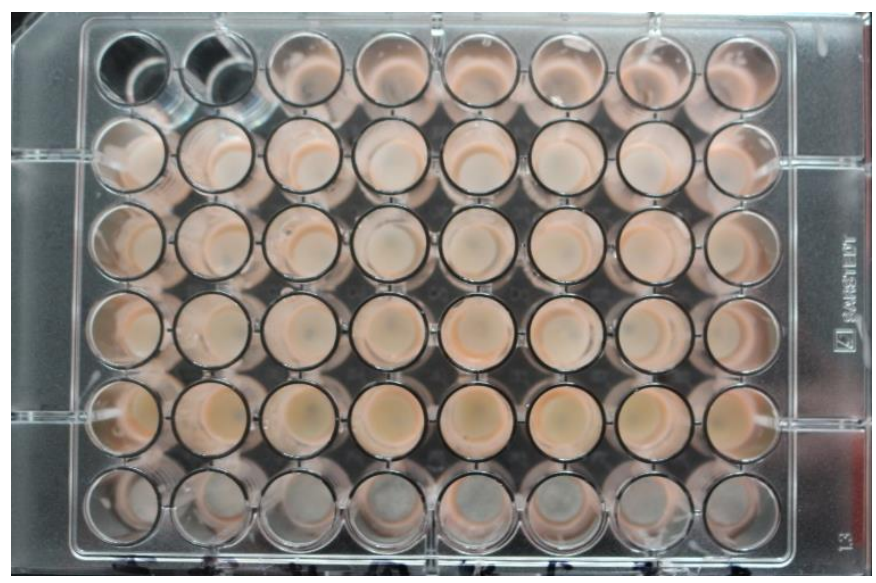

Abbildung 11: Probekörper in 48-Well-Platte mit Silikon Z-Dupe fixiert

\subsection{Messung der Zytotoxizität}

Die Messung der Zytotoxizität erfolgte mit dem Pierce ${ }^{\mathrm{TM}}$ LDH Cytotoxicity Assay Kit (Thermo Fisher Scientific Inc., Waltham, Massachusetts, Vereinigte Staaten von Amerika). Die Zellen wurden für 48 Stunden in 48 Well-Platten (Sarstedt AG \& Co, Nümbrecht, Deutschland) im Inkubator Heracell Vios 160i (Thermo Fisher Scientific Inc., Waltham, Massachusetts, Vereinigte Staaten von Amerika) unter Standardbedingungen inkubiert. Nach 48 Stunden wurden $50 \mu \mathrm{l}$ des Überstandes pro Well in eine 96 Well-Platte (Sarstedt AG \& Co, Nümbrecht, Deutschland) überführt und je $50 \mu$ Reaction Mixture (Pierce ${ }^{\mathrm{TM}}$ LDH Cytotoxicity Assay Kit, Thermo Fisher Scientific Inc., Waltham, Massachusetts, Vereinigte Staaten von Amerika) hinzugegeben. Nach 30 Minuten Inkubation im Dunkeln bei Raumtemperatur wurden noch $50 \mu$ l Stopplösung (Pierce ${ }^{\mathrm{TM}}$ LDH Cytotoxicity Assay Kit, Thermo Fisher Scientific Inc., Waltham, Massachusetts, Vereinigte Staaten von Amerika) hinzugegeben und es erfolgte eine Spektralphotomessung mit der Wellenlänge $490 \mathrm{~nm}$ und einer Referenzwellenlänge von $680 \mathrm{~nm}$ mit dem FluoStar Omega (BMG LABTECH, Ortenberg, Deutschland). Die Probekörper in Reihe acht der Wellplatten wurden als Nullprobe (blank) gesetzt. Von dem gemessenen Wert der LDH Cytotoxicity Assay wurde der gemessene Wert des blanks vom entsprechenden Material subtrahiert. Dadurch wurde der Wert auf die rein mikrobiell bedingte Lumineszenz reduziert. 


\subsection{Messung der Zellviabilität}

Die Zellviabilität wurde mittels WST-8-Test gemessen. Die Zellen wurden analog zur Subkultivierung vorbereitet. Nachdem sie gewaschen und trypsiniert worden waren, wurden sie zentrifugiert und in der Zählkammer Neubauer Improved (Brand GmbH, Wertheim, Deutschland) gezählt. Anhand dieser Zählung und der Bodenfläche des Wells $(1 \mathrm{~cm} 2)$ konnte die benötigte Menge Zellsuspension festgelegt werden. Durch das Festlegen von $1 \mathrm{ml}$ Suspension pro Well wurde die Aussaat mit 20.000 Zellen vorgenommen und diese dann 48 Stunden unter Standardbedingungen im Inkubator Heracell Vios 160i inkubiert. Nach 48 Stunden wurde das Medium abgesaugt und durch 0,3 $\mathrm{ml}$ der Messlösung aus WST8 des Cell Counting Kit-8 (CCK8, Dojindo EU GmbH, München, Deutschland) und Nährmedium im Verhältnis 1:10 ersetzt. Anschließend wurden die Well-Platten für weitere zwei Stunden bei $37^{\circ} \mathrm{C}, 5 \% \mathrm{CO}^{2}$ und $95 \%$ Luftfeuchtigkeit in den Inkubator eingebracht. Danach erfolgte die Übertragung der Messlösung in eine neue 48 Well-Platte.

Die Wells mit der Messlösung wurden auf Luftblasen untersucht und diese gegebenenfalls mit einer sterilen Sonde (Henry Schein Dental Deutschland GmbH, Langen, Deutschland) entfernt, da Luftblasen das Ergebnis der Messung im Spektralphotometer verfälscht hätten. Die Spektalphotomessung wurde mit dem FluoStar Omega bei der Wellenlänge $450 \mathrm{~nm}$ und einer Referenzwellenlänge von $650 \mathrm{~nm}$ durchgeführt. Durch das Subtrahieren der Referenzwellenlänge von den Messwellenlängen wurde die Extinktion des WST-8 gemessen. Die Probekörper in Reihe acht der Wellplatten wurden als Nullprobe (blank) gesetzt. Von dem gemessenen Wert der WST-8 wurde der gemessene Wert des blank vom entsprechenden Material subtrahiert. Dadurch wurde der Wert auf die rein mikrobiell bedingte Lumineszenz reduziert.

\subsection{Vorversuch und Festlegung der Rauheiten}

Im Vorversuch wurden jeweils sieben 10,0-mm-Probekörper des Nano-Hybrid-Komposits Grandio (Voco GmbH, Cuxhaven) in der Farbe BL in fünf unterschiedlichen Rauheiten untersucht. Die Rauheiten wurden eingestellt mit Schleifpapier der Körnung 400, 1200, 4000, Hochglanzpolitur und durch Sandstrahlen mit $110 \mu \mathrm{m}$ Aluminiumoxid (Alublast 110 Micron, Henry Schein Inc, Langen, Deutschland) wie oben beschrieben. Nach dem Messen der freien Energie der Oberfläche und der Analyse der Oberfläche mit dem Weitfeld-Konfokalmikroskop (Smartproof 5, Carl Zeiss AG, Oberkochen, Deutschland) wurden die vier 
Rauheiten mit den größten Abweichungen voneinander ausgewählt, um die Menge und Kosten der Versuchsreihen einzudämmen. Der Vorversuch wurde mit der Zelllinie L929 durchgeführt.

\subsection{Hauptversuch}

Der Hauptversuch wurde mit dem Nano-Hybrid-Komposit Grandio (Voco GmbH, Cuxhaven) in der Farben A1, A2, A3, A4 und Amalgam (Vivacap Größe 3, Ivoclar Vivadent, Schaan, Liechtenstein) in den Rauheiten der Körnung 400, 1200, 4000, Hochglanzpolitur und durch Sandstrahlen mit $110 \mu \mathrm{m}$ Aluminiumoxid durchgeführt. Als Negativkontrolle wurden Glasprobekörper einsetzt und als Positivkontrolle Latex (5x5 mm). Je Zelllinie und Rauheit wurden 8 Probekörper untersucht, es erfolgten drei Messwiederholungen.

\subsection{Statistische Auswertung}

Die Untersuchungsergebnisse wurden mit der Statistik-Software R, Version 3.4.0 (The R Foundation for Statistical Computing (www.r-projekt.org), Wien, Österreich) ausgewertet. Das Signifikanzniveau für die durchgeführten statistischen Untersuchungen wurde auf $\alpha=5 \%$ festgelegt.

Aufgrund der ermittelten Daten ist die Analyse in zwei Teile gegliedert. Der erste Teil umfasst die Messungen der Rauheiten $\left(\mathrm{R}_{\mathrm{a}}\right)$ und der freien Oberflächenenergien (FOE, Dispersiv, Polar) und die Überprüfung möglicher Korrelationen (nach Pearson) zwischen beiden Parametern. Im folgenden Teil wurde überprüft, inwieweit die Polierstufen die Viabilität bzw. Toxizität der Zelllinien beeinflussen. Die Viabilität und Zytotoxizität der Zelllinien wurde mit einer Varianzanalyse (ANOVA, analysis of variance) ausgewertet. Die abschließenden Paarvergleiche wurden mit einem t-Test durchgeführt. Durch den t-Test wurde anhand der Mittelwerte einer Probe überprüft, ob sich der Mittelwert der Gesamtheit von einem vorgegebenen Sollwert unterscheidet. Die durchgeführten Analysen wurden alle mit der Bonferoni-Holm-Methode angepasst, sodass die family-wise error rate von alpha $=5 \%$ eingehalten wurde.

Die Kontrollmessungen auf den Glasprobekörpern unterschieden sich stark bei den unterschiedlichen Durchgängen und wurden deshalb an die jeweilige Zellpassage adjustiert. Dafür wurden alle Zytotoxizitäts- bzw. Viabilitätsmessungen durch die mittlere Zytotoxizität bzw. Viabilität von jeder Passage auf Glas geteilt. Die Analyse wurde schrittweise durchgeführt. 
Erst wurde das globale Modell untersucht mit allen Materialien und Polierstufen sowie deren Interaktionen (Material - Polierstufe). Wenn das Zusammenspiel von Material - Polierstufe eine Signifikanz ergab, wurde der Datensatz aufgeteilt in die vier Stufen Grandio Voco A1 - A4 und Amalgam. Die Stufen Grandio Voco A1 - A4 wurden mit einer Two-WayANOVA und Amalgam mit einer One-Way- ANOVA untersucht. Ist bei der Two-WayANOVA die Interaktion Material - Polierstufe im Ergebnis nicht signifikant, verhalten sich die Materialien A1-A4 statistisch nicht unterschiedlich über die Polierstufen. Die Paarvergleiche wurden dann für die gepoolte Gruppe A1-A4 durchgeführt. Anhand der Paarvergleiche lässt sich erkennen, bei welchem Material Unterschiede zwischen verschiedenen Polierstufen bestanden. 


\section{ERGEBNISSE}

Die Auswertung der Ergebnisse wurde teilweise in Kastengrafiken (engl.: whisker-box-plots) dargestellt (Abbildung 12). Der Kasten (engl.: box) beinhaltet dabei die mittleren $50 \%$ der Werte. Die Begrenzung der box wird durch das obere Quartil und das untere Quartil gebildet. Damit entspricht die Länge des Kastens dem Interquartilsabstand (IQR, interquartile range). Werte, welche ober- und unterhalb des Kastens liegen, werden durch Antennen (whisker) an dem Kasten dargestellt. Die Antennen sind auf das Anderthalbfache der IQR begrenzt (nach John W. Tukey). Wenn es Werte außerhalb dieser Bereiche gibt, werden sie als Punkt dargestellt und stellen Ausreißer dar. Gibt es keine Ausreißer, zeigen die Enden der Antennen die Maximal- bzw. Minimalwerte an, was zur Folge haben kann, dass die whisker unterschiedlich lang ausfallen. Ein Strich innerhalb der box stellt den Medianwert dar.

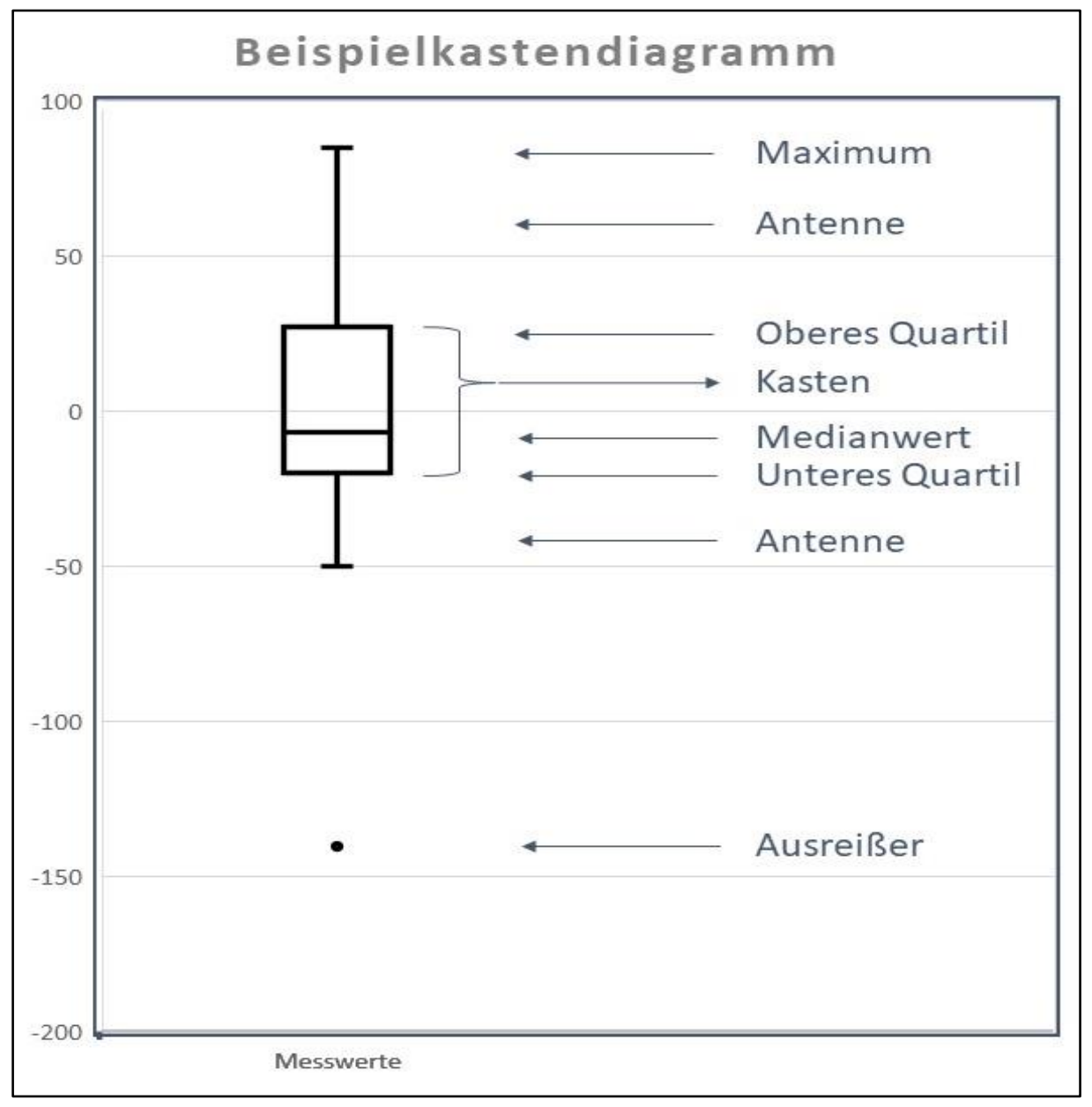

Abbildung 12: Beispielkastendiagramm 


\subsection{Rauheit}

In Tabelle 7 und Abbildung 13 sind die Rauheitswerte aller Testmaterialien nach den verschiedenen Polierstufen (Körnung 110, 400, 1200 und Hochglanz HG) dargestellt. Die sukzessiven Polierstufen hatten bei den unterschiedlichen Materialien verschieden stark ausgeprägte Wirkungen auf die Rauheitswerte.

So waren die Unterschiede in der Rauheit der Polierstufen 1200 (Körnung 1200) und HG (Hochglanz) für Grandio Voco der Farben A3, A4 und AG (Amalgam) gering. Bei den Farben A1 und A2 hingegen unterschieden sich diese Polierstufen stärker und folgten einem klaren Trend von 110 (mit $110 \mu \mathrm{m}$ Aluminumoxid sandgestrahlt) über 400 (Körnung 400) und 1200 bis zu HG. Dieser Trend ist bei dem Material A1 am deutlichsten zu erkennen.

Tabelle 7: Median und Interquartilsabstand (IQR) der Rauheitsmessungen $\left(\mathbf{R}_{a}\right)$ unterteilt nach Polierstufe und Farbe bzw. Material ( $\mathrm{n}=15$, jeweils)

\begin{tabular}{|c|c|c|c|c|c|}
\hline Farbe/Material & & 110 & 400 & 1200 & $\mathrm{HG}$ \\
\hline \multirow[t]{2}{*}{ A1 } & Median & 1.93 & 1.06 & 0.45 & 0.11 \\
\hline & IQR & 0.5 & 0.8 & 0.4 & 0.1 \\
\hline \multirow[t]{2}{*}{ A2 } & Median & 2.3 & 0.34 & 0.16 & 0.02 \\
\hline & IQR & 0.5 & 0.1 & 0.2 & 0 \\
\hline \multirow[t]{2}{*}{ A3 } & Median & 2.53) & 0.49 & 0.12 & 0.03 \\
\hline & IQR & 0.4 & 0.2 & 0 & 0 \\
\hline \multirow[t]{2}{*}{ A4 } & Median & 2.49 & 0.16 & 0.14 & 0.04 \\
\hline & IQR & 0.3 & 0 & 0 & 0.1 \\
\hline \multirow[t]{2}{*}{$A G$} & Median & 1.16 & 0.18 & 0.2 & 0.14 \\
\hline & IQR & 0.8 & 0.2 & 0 & 0 \\
\hline
\end{tabular}




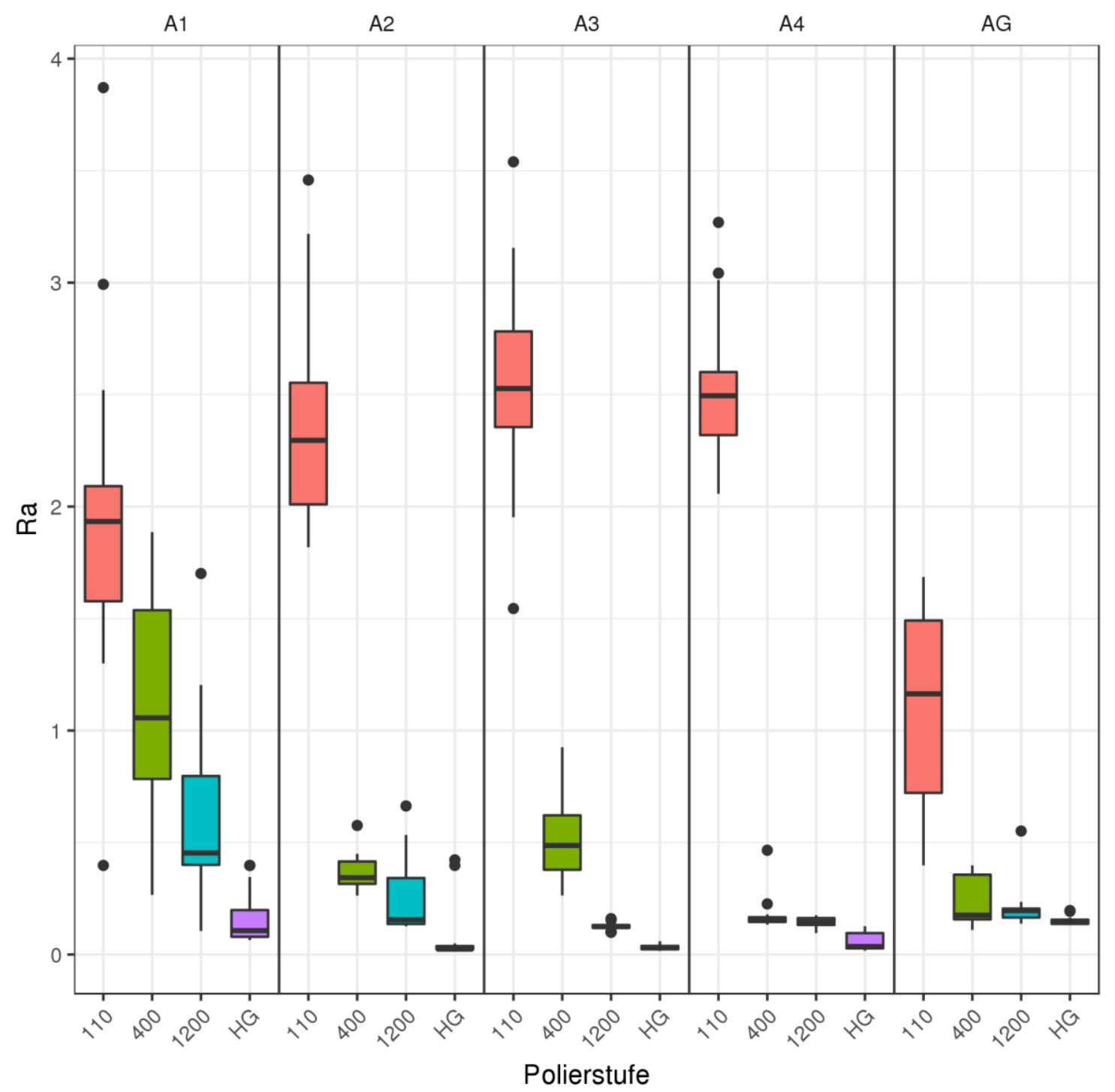

Abbildung 13: Boxplot der $\mathbf{R}_{\mathrm{a}}$-Messungen gruppiert nach Polierstufe und Farbe bzw. Material

Die Tabelle 8 bis Tabelle 12 zeigen die Unterschiede zwischen den einzelnen Polierstufen bei den einzelnen Farben bzw. Materialien für Ra und entsprechende p-Werte.

Tabelle 8: Differenzen (diff) und p-Werte (adjustiert) von $\mathbf{R}_{\mathrm{a}}$ zwischen den einzelnen Polierstufen bei Grandio Voco A1

\begin{tabular}{|l|l|l|l|l|}
\hline A1 & & 110 & 400 & 1200 \\
\hline 400 & diff & -0.61 & & \\
\hline & p adj & 0.24 & & \\
\hline 1200 & diff & -1.34 & -0.73 & \\
\hline & p adj & $<\mathbf{0 . 0 1}$ & 0.13 & -1.31 \\
\hline HG & diff & -2.65 & -2.04 & $<\mathbf{0 . 0 1}$ \\
\hline & p adj & $<\mathbf{0 . 0 1}$ & $<\mathbf{0 . 0 1}$ & \\
\hline
\end{tabular}


Tabelle 9: Differenzen (diff) und p-Werte (adjustiert) von $\mathbf{R}_{\mathrm{a}}$ zwischen den einzelnen Polierstufen bei Grandio Voco A2

\begin{tabular}{|l|l|l|l|l|}
\hline A2 & & 110 & 400 & \\
\hline $\mathbf{4 0 0}$ & diff & -1.91 & & \\
\hline & p adj & $\mathbf{< 0 . 0 1}$ & & \\
\hline 1200 & diff & -2.39 & -0.48 & \\
\hline & p adj & $<\mathbf{0 . 0 1}$ & 0.23 & -1.97 \\
\hline HG & diff & -4.36 & -2.46 & $<\mathbf{0 . 0 1}$ \\
\hline & p adj & $<\mathbf{0 . 0 1}$ & $<\mathbf{0 . 0 1}$ & \\
\hline
\end{tabular}

Tabelle 10: Differenzen (diff) und p-Werte (adjustiert) von $\mathbf{R}_{\mathrm{a}}$ zwischen den einzelnen Polierstufen bei Grandio Voco A3

\begin{tabular}{|l|l|l|l|l|}
\hline A3 & & 110 & 400 & 1200 \\
\hline 400 & diff & -1.6 & & \\
\hline & p adj & $\mathbf{< 0 . 0 1}$ & & \\
\hline 1200 & diff & -2.99 & -1.39 & \\
\hline & p adj & $<\mathbf{0 . 0 1}$ & $<\mathbf{0 . 0 1}$ & -1.5 \\
\hline HG & diff & -4.49 & -2.89 & $<\mathbf{0 . 0 1}$ \\
\hline & p adj & $<\mathbf{0 . 0 1}$ & $<\mathbf{0 . 0 1}$ & \\
\hline
\end{tabular}

Tabelle 11: Differenzen (diff) und p-Werte (adjustiert) von $\mathbf{R}_{\mathrm{a}}$ zwischen den einzelnen Polierstufen bei Grandio Voco A4

\begin{tabular}{|l|l|l|l|l|}
\hline A4 & & 110 & 400 & \\
\hline 400 & diff & -2.73 & & \\
\hline & p adj & $<\mathbf{0 . 0 1}$ & & \\
\hline 1200 & diff & -2.9 & -0.17 & \\
\hline & p adj & $<\mathbf{0 . 0 1}$ & 0.91 & -1.15 \\
\hline HG & diff & -4.06 & -1.32 & $<\mathbf{0 . 0 1}$ \\
\hline & p adj & $<\mathbf{0 . 0 1}$ & $<\mathbf{0 . 0 1}$ & \\
\hline
\end{tabular}


Tabelle 12: Differenzen (diff) und p-Werte (adjustiert) von $\mathbf{R}_{\mathrm{a}}$ zwischen den einzelnen Polierstufen bei Amalgam

\begin{tabular}{|l|l|l|l|l|}
\hline AG & & 110 & 400 & 1200 \\
\hline 400 & diff & -1.5 & & \\
\hline & p adj & $\mathbf{< 0 . 0 1}$ & & \\
\hline 1200 & diff & -1.73 & -0.23 & \\
\hline & p adj & $\mathbf{< 0 . 0 1}$ & 0.71 & -0.19 \\
\hline HG & diff & -1.92 & -0.42 & 0.83 \\
\hline & p adj & $<\mathbf{0 . 0 1}$ & 0.26 & \\
\hline
\end{tabular}

Die Tabelle 13 bis Tabelle 16 stellen die Signifikanzen der Mittenrauheitswerte zwischen den einzelnen Farben für die unterschiedlichen Polierstufen dar.

Tabelle 13: Differenzen (diff) und p-Werte (adjustiert) von $\mathbf{R}_{\mathrm{a}}$ zwischen den einzelnen Farben / Materialien bei Polierstufe 110

\begin{tabular}{|c|c|c|c|c|c|}
\hline \multicolumn{2}{|l|}{110} & $\mathrm{~A} 1$ & $\mathrm{~A} 2$ & A3 & $\mathrm{A} 4$ \\
\hline \multirow{2}{*}{ A2 } & diff & 0.18 & & & \\
\hline & $\mathrm{p}$ adj & 0.87 & & & \\
\hline \multirow[t]{2}{*}{ A3 } & diff & 0.24 & 0.07 & & \\
\hline & $\mathrm{p}$ adj & 0.68 & 1 & & \\
\hline \multirow[t]{2}{*}{ A4 } & diff & 0.27 & 0.1 & 0.03 & \\
\hline & p adj & 0.59 & 0.98 & 1 & \\
\hline \multirow[t]{2}{*}{$\mathrm{AG}$} & diff & -0.64 & -0.81 & -0.88 & -0.91 \\
\hline & p adj & 0.02 & $<0.01$ & $<0.01$ & $<0.01$ \\
\hline
\end{tabular}

Tabelle 14: Differenzen (diff) und p-Werte (adjustiert) von $\mathbf{R}_{\mathrm{a}}$ zwischen den einzelnen Farben / Materialien bei Polierstufe 400

\begin{tabular}{|c|c|c|c|c|c|}
\hline \multicolumn{2}{|l|}{400} & $\mathrm{~A} 1$ & \multicolumn{2}{|l|}{ A2 } & \multirow[t]{2}{*}{ A4 } \\
\hline A2 & diff & -1.12 & & & \\
\hline & $\mathrm{p}$ adj & $<0.01$ & & & \\
\hline A3 & diff & -0.74 & 0.38 & & \\
\hline & $\mathrm{p}$ adj & 0.01 & 0.36 & & \\
\hline A4 & diff & -1.85 & -0.73 & -1.11 & \\
\hline & p adj & $<0.01$ & 0.01 & $<0.01$ & \\
\hline $\mathrm{AG}$ & diff & -1.52 & -0.4 & -0.78 & 0.33 \\
\hline & p adj & $<0.01$ & 0.29 & $<0.01$ & 0.5 \\
\hline
\end{tabular}


Tabelle 15: Differenzen (diff) und p-Werte (adjustiert) von $\mathbf{R}_{\mathrm{a}}$ zwischen den einzelnen Farben / Materialien bei Polierstufe 1200

\begin{tabular}{|c|c|c|c|c|c|}
\hline \multicolumn{2}{|c|}{1200} & $\mathrm{~A} 1$ & $\mathrm{~A} 2$ & A3 & $\mathrm{A} 4$ \\
\hline \multirow[t]{2}{*}{ A2 } & diff & -0.87 & & & \\
\hline & p adj & 0.02 & & & \\
\hline \multirow[t]{2}{*}{ A3 } & diff & -1.4 & -0.53 & & \\
\hline & $\mathrm{p}$ adj & $<0.01$ & 0.26 & & \\
\hline \multirow[t]{2}{*}{ A4 } & diff & -1.29 & -0.42 & 0.11 & \\
\hline & $\mathrm{p}$ adj & $<0.01$ & 0.49 & 0.99 & \\
\hline \multirow[t]{2}{*}{$\mathrm{AG}$} & diff & -1.03 & -0.15 & 0.38 & 0.26 \\
\hline & $\mathrm{p}$ adj & $<0.01$ & 0.97 & 0.59 & 0.83 \\
\hline
\end{tabular}

Tabelle 16: Differenzen (diff) und p-Werte (adjustiert) von $\mathbf{R}_{\mathrm{a}}$ zwischen den einzelnen Farben / Materialien bei Polierstufe HG

\begin{tabular}{|c|c|c|c|c|c|}
\hline \multicolumn{2}{|c|}{$\mathrm{HG}$} & \multirow{2}{*}{$\begin{array}{l}\text { A1 } \\
-1.53\end{array}$} & \multirow[t]{2}{*}{$\mathrm{A} 2$} & \multirow[t]{2}{*}{ A3 } & \multirow[t]{2}{*}{ A4 } \\
\hline A2 & diff & & & & \\
\hline & p adj & $<0.01$ & & & \\
\hline \multirow[t]{2}{*}{ A3 } & diff & -1.59 & -0.06 & & \\
\hline & $\mathrm{p}$ adj & $<0.01$ & 1 & & \\
\hline \multirow[t]{2}{*}{ A4 } & diff & -1.13 & 0.4 & 0.46 & \\
\hline & $\mathrm{p}$ adj & 0.01 & 0.71 & 0.6 & \\
\hline \multirow[t]{2}{*}{ AG } & diff & 0.1 & 1.63 & 1.69 & 1.23 \\
\hline & $\mathrm{p}$ adj & 1 & $<0.01$ & $<0.01$ & $<0.01$ \\
\hline
\end{tabular}


Anhand des Testmaterials Grandio Voco A3 soll beispielhaft in Abbildung 14 gezeigt werden, wie die Oberflächenmorphologie bei den unterschiedlichen Polierstufen in 3D und 2D visualisiert wurde.

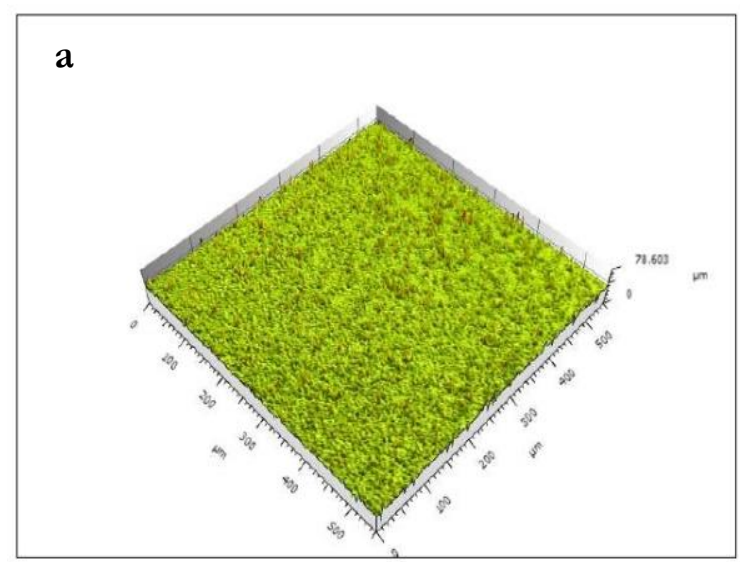

b
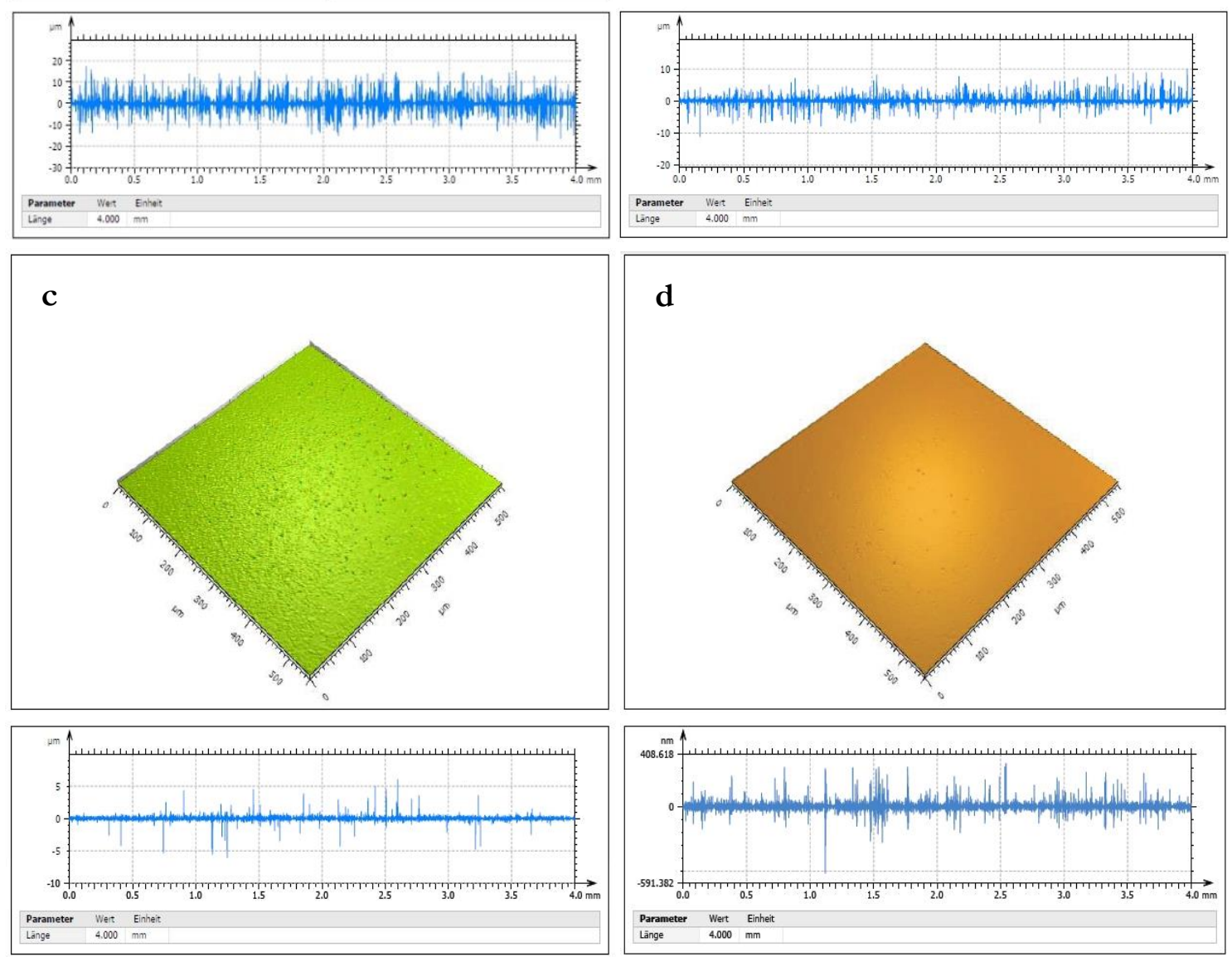

Abbildung 14: Oberflächenmorphologie Grandio Voco A3 in 3D und 2D nach Behandlung mit $110 \mu \mathrm{m}$ Aluminiumoxid (a), Sandpapier der Körnung 400 (b), Sandpapier der Körnung 1200 (c) und Diamantpolierpaste der Körnung $1 \mu \mathrm{m}(\mathrm{d})$ 


\subsection{Freie Oberflächenenergie}

Bei den Messungen der Oberflächenenergien (Tabelle 17, Tabelle 27, Tabelle 37 und Abbildung 15) waren die Ergebnisse nicht so einheitlich wie bei den $\mathrm{R}_{\mathrm{a}}$-Messungen. Abgesehen davon zeigten sich deutlich niedrigeren Messungen der disperseren Komponente der Oberflächenenergien und dementsprechend höhere Messungen der polaren Komponente des Amalgams gegenüber der Materialien Voco Grandio A1-A4.

Tabelle 17: Median und Interquartilsabstand (IQR) der freien Oberflächenenergie (SFE) unterteilt nach Polierstufe und Farbe bzw. Material $(n=5$, jeweils)

\begin{tabular}{|c|c|c|c|c|c|}
\hline Farbe/Material & & 110 & 400 & 1200 & $\mathrm{HG}$ \\
\hline \multirow[t]{2}{*}{ A1 } & Median & 58.89 & 59.28 & 66.61 & 64.88 \\
\hline & IQR & 3.1 & 3.5 & 4.1 & 2.9 \\
\hline \multirow[t]{2}{*}{ A2 } & Median & 62.67 & 63.8 & 62.74 & 63.98 \\
\hline & IQR & 5.4 & 2.1 & 2.6 & 1.5 \\
\hline \multirow[t]{2}{*}{ A3 } & Median & 64.66 & 64.31 & 63.83 & 65.5 \\
\hline & IQR & 5.6 & 1.7 & 2.4 & 2.6 \\
\hline \multirow[t]{2}{*}{ A4 } & Median & 63.39 & 65.02 & 68.09 & 63.71 \\
\hline & IQR & 3.3 & 2.1 & 0.5 & 1 \\
\hline \multirow[t]{2}{*}{ AG } & Median & 61.08 & 64.74 & 62.06 & 67.54 \\
\hline & IQR & 1.4 & 1.9 & 5.2 & 4 \\
\hline
\end{tabular}



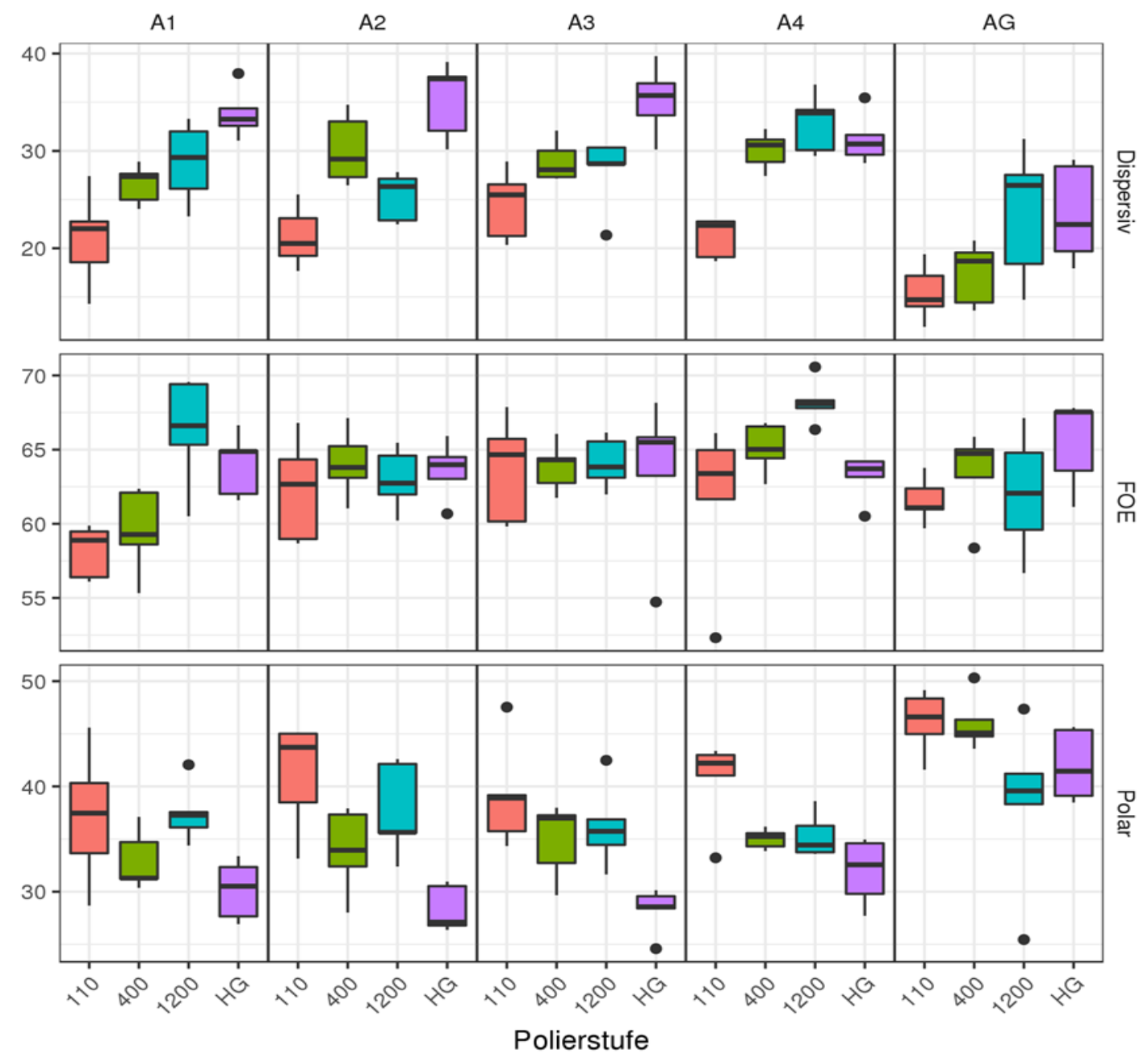

Abbildung 15: Boxplot der freien Oberflächenenergie- (FOE), Polar- und Dispersivmessungen gruppiert nach Polierstufe und Farbe bzw. Material

Aus den Tabelle 18 bis Tabelle 22 ist ersichtlich, dass sich die freie Oberflächenenergie bei A1 zwischen den Polierstufen 110 und 1200, 110 und HG sowie 400 und 1200 signifikant unterschied. Auch bei der Farbe A4 gab es einen bedeutenden Unterschied zwischen der Polierstufe 110 und 1200.

Tabelle 18: Differenzen (diff) und p-Werte (adjustiert) von SFE zwischen den einzelnen Polierstufen bei Grandio Voco A1

\begin{tabular}{|l|l|l|l|l|}
\hline A1 & & 110 & 400 & 1200 \\
\hline 400 & diff & 1.39 & & \\
\hline & p adj & 0.85 & & \\
\hline 1200 & diff & 8.13 & 6.75 & \\
\hline & p adj & $<\mathbf{0 . 0 1}$ & $<\mathbf{0 . 0 1}$ & -2.27 \\
\hline HG & diff & 5.86 & 4.47 & 0.56 \\
\hline & p adj & $\mathbf{0 . 0 2}$ & 0.08 & \\
\hline
\end{tabular}


Tabelle 19: Differenzen (diff) und p-Werte (adjustiert) von SFE zwischen den einzelnen Polierstufen bei Grandio Voco A2

\begin{tabular}{|c|c|c|c|c|}
\hline \multicolumn{2}{|l|}{$\mathrm{A} 2$} & 110 & 400 & 1200 \\
\hline \multirow[t]{2}{*}{400} & diff & 1.77 & & \\
\hline & $\mathrm{p}$ adj & 0.69 & & \\
\hline \multirow[t]{2}{*}{1200} & diff & 0.7 & -1.06 & \\
\hline & $\mathrm{p}$ adj & 0.97 & 0.91 & \\
\hline \multirow[t]{2}{*}{ HG } & diff & 1.33 & -0.44 & 0.62 \\
\hline & $\mathrm{p}$ adj & 0.84 & 0.99 & 0.98 \\
\hline
\end{tabular}

Tabelle 20: : Differenzen (diff) und p-Werte (adjustiert) von SFE zwischen den einzelnen Polierstufen bei Grandio Voco A3

\begin{tabular}{|l|l|l|l|l|}
\hline A3 & & 110 & 400 & \\
\hline 400 & diff & 0.21 & & \\
\hline & p adj & 1 & 0.27 & \\
\hline 1200 & diff & 0.48 & 1 & \\
\hline & p adj & 1 & -0.36 & -0.63 \\
\hline HG & diff & -0.15 & 1 & 0.99 \\
\hline & p adj & 1 & & \\
\hline
\end{tabular}

Tabelle 21: : Differenzen (diff) und p-Werte (adjustiert) von SFE zwischen den einzelnen Polierstufen bei Grandio Voco A4

\begin{tabular}{|l|l|l|l|l|}
\hline A4 & & 110 & 400 & 1200 \\
\hline 400 & diff & 3.4 & & \\
\hline & p adj & 0.33 & & \\
\hline 1200 & diff & 6.54 & 3.13 & \\
\hline & p adj & $\mathbf{0 . 0 2}$ & 0.4 & -5.07 \\
\hline HG & diff & 1.47 & -1.93 & 0.08 \\
\hline & p adj & 0.87 & 0.75 & \\
\hline
\end{tabular}


Tabelle 22: : Differenzen (diff) und p-Werte (adjustiert) von SFE zwischen den einzelnen Polierstufen bei Amalgam

\begin{tabular}{|l|l|l|l|l|}
\hline AG & \multicolumn{2}{|c|}{110} & 400 & 1200 \\
\hline 400 & diff & 1.84 & & \\
\hline & p adj & 0.78 & -1.37 & \\
\hline 1200 & diff & 0.47 & 0.89 & \\
\hline & p adj & 0.99 & 2.1 & 3.47 \\
\hline HG & diff & 3.94 & 0.7 & 0.31 \\
\hline & p adj & 0.22 & & 0.3 \\
\hline
\end{tabular}

Die Tabelle 23 bis Tabelle 26 zeigen den Vergleich der freien Oberflächenenergie der Farben bzw. Material einer Polierstufe. Dabei zeigte sich ein signifikanter Unterschied bei der Polierstufe 400 zwischen den Farben A1 und A2 und bei der Polierstufe 1200 zwischen A4 und Amalgam.

Tabelle 23: Differenzen (diff) und p-Werte (adjustiert) von SFE zwischen den einzelnen Farben / Materialien bei Polierstufe 110

\begin{tabular}{|c|c|c|c|c|c|}
\hline \multicolumn{2}{|l|}{110} & $\mathrm{~A} 1$ & $\mathrm{~A} 2$ & A3 & A4 \\
\hline \multirow[t]{2}{*}{ A2 } & diff & 4.14 & & & \\
\hline & $\mathrm{p}$ adj & 0.36 & & & \\
\hline \multirow[t]{2}{*}{ A3 } & diff & 5.5 & 1.35 & & \\
\hline & $\mathrm{p}$ adj & 0.13 & 0.97 & & \\
\hline \multirow[t]{2}{*}{ A4 } & diff & 3.54 & -0.6 & -1.96 & \\
\hline & $\mathrm{p}$ adj & 0.51 & 1 & 0.9 & \\
\hline \multirow[t]{2}{*}{$A G$} & diff & 3.43 & -0.71 & -2.06 & -0.11 \\
\hline & $\mathrm{p}$ adj & 0.54 & 1 & 0.88 & 1 \\
\hline
\end{tabular}


Tabelle 24: Differenzen (diff) und p-Werte (adjustiert) von SFE zwischen den einzelnen Farben / Materialien bei Polierstufe 400

\begin{tabular}{|c|c|c|c|c|c|}
\hline \multicolumn{2}{|l|}{400} & $\mathrm{~A} 1$ & $\mathrm{~A} 2$ & A3 & A4 \\
\hline \multirow[t]{2}{*}{ A2 } & diff & 4.52 & & & \\
\hline & $\mathrm{p}$ adj & 0.05 & & & \\
\hline \multirow{2}{*}{ A3 } & diff & 4.32 & -0.2 & & \\
\hline & $\mathrm{p}$ adj & 0.06 & 1 & & \\
\hline \multirow[t]{2}{*}{ A4 } & diff & 5.56 & 1.03 & 1.24 & \\
\hline & p adj & 0.01 & 0.96 & 0.92 & \\
\hline \multirow[t]{2}{*}{$\mathrm{AG}$} & diff & 3.89 & -0.63 & -0.43 & -1.67 \\
\hline & $\mathrm{p}$ adj & 0.11 & 0.99 & 1 & 0.8 \\
\hline
\end{tabular}

Tabelle 25: Differenzen (diff) und p-Werte (adjustiert) von SFE zwischen den einzelnen Farben / Materialien bei Polierstufe 1200

\begin{tabular}{|c|c|c|c|c|c|}
\hline 1200 & & A1 & $\mathrm{A} 2$ & A3 & A4 \\
\hline \multirow[t]{2}{*}{ A2 } & diff & -3.29 & & & \\
\hline & $\mathrm{p}$ adj & 0.39 & & & \\
\hline \multirow[t]{2}{*}{ A3 } & diff & -2.16 & 1.13 & & \\
\hline & p adj & 0.75 & 0.97 & & \\
\hline \multirow[t]{2}{*}{ A4 } & diff & 1.94 & 5.23 & 4.1 & \\
\hline & $\mathrm{p}$ adj & 0.81 & 0.06 & 0.19 & \\
\hline \multirow[t]{2}{*}{$\mathrm{AG}$} & diff & -4.23 & -0.95 & -2.07 & -6.17 \\
\hline & $\mathrm{p}$ adj & 0.17 & 0.98 & 0.78 & 0.02 \\
\hline
\end{tabular}

Tabelle 26: Differenzen (diff) und p-Werte (adjustiert) von SFE zwischen den einzelnen Farben / Materialien bei Polierstufe HG

\begin{tabular}{|c|c|c|c|c|c|}
\hline \multicolumn{2}{|l|}{$\mathrm{HG}$} & A1 & \multirow[t]{2}{*}{$\mathrm{A} 2$} & \multirow[t]{2}{*}{ A3 } & \multirow[t]{2}{*}{$\mathrm{A} 4$} \\
\hline A2 & diff & -0.39 & & & \\
\hline & $\mathrm{p}$ adj & 1 & & & \\
\hline \multirow[t]{2}{*}{ A3 } & diff & -0.52 & -0.13 & & \\
\hline & $\mathrm{p}$ adj & 1 & 1 & & \\
\hline \multirow[t]{2}{*}{ A4 } & diff & -0.85 & -0.46 & -0.33 & \\
\hline & $\mathrm{p}$ adj & 0.99 & 1 & 1 & \\
\hline \multirow[t]{2}{*}{$\mathrm{AG}$} & diff & 1.52 & 1.9 & 2.03 & 2.37 \\
\hline & $\mathrm{p}$ adj & 0.93 & 0.86 & 0.83 & 0.74 \\
\hline
\end{tabular}


Tabelle 27: Median und Interquartilsabstand (IQR) der disperseren Komponente unterteilt nach Polierstufe und Farbe bzw. Material ( $\mathrm{n}=5$, jeweils)

\begin{tabular}{|l|l|l|l|l|l|}
\hline Farbe/Material & \multicolumn{2}{|l}{110} & 400 & 1200 & HG \\
\hline A1 & Median & 22.01 & 27.36 & 29.33 & 33.26 \\
\hline A2 & IQR & 4.2 & 2.7 & 5.9 & 1.8 \\
\hline A3 & Median & 20.49 & 29.16 & 26.34 & 37.4 \\
\hline & IQR & 3.9 & 5.7 & 4.3 & 5.5 \\
\hline A4 & Median & 25.49 & 28.07 & 28.68 & 35.69 \\
\hline & IQR & 5.3 & 2.7 & 1.7 & 3.3 \\
\hline AG & Median & 22.35 & 30.61 & 33.89 & 30.71 \\
\hline & IQR & 3.6 & 2.3 & 4.1 & 2 \\
\hline & Median & 14.72 & 18.68 & 26.46 & 22.45 \\
\hline
\end{tabular}

In den Tabelle 28 bis Tabelle 32 sind die Vergleiche der disperseren Komponente der Polierstufen einer Farbe bzw. eines Materials aufgetragen. Als signifikant stellten sich bei A1 die Polierstufen 110 zu 1200 und 110 zu HG dar. Bei der Farbe A2 und A3 zeigten sich 110 zu HG und 1200 zu HG signifikant. Die Farbe A4 zeigte Signifikanzen von der Polierstufe $110 \mathrm{zu}$ allen anderen Polierstufen. Bei Amalgam gab es keine signifikanten Unterschiede zwischen den Polierstufen für den disperseren Anteil.

Tabelle 28: Differenzen (diff) und p-Werte (adjustiert) der disperseren Komponente zwischen den einzelnen Polierstufen bei Grandio Voco A1

\begin{tabular}{|l|l|l|l|l|}
\hline A1 & \multicolumn{2}{|c|}{110} & & \\
\hline 400 & diff & 5.58 & & \\
\hline & p adj & 0.11 & & \\
\hline 1200 & diff & 7.8 & 2.22 & \\
\hline & p adj & $\mathbf{0 . 0 2}$ & 0.77 & 5.04 \\
\hline HG & diff & 12.84 & 7.26 & 0.16 \\
\hline & p adj & $<\mathbf{0 . 0 1}$ & 0.03 & \\
\hline
\end{tabular}


Tabelle 29: Differenzen (diff) und p-Werte (adjustiert) der disperseren Komponente zwischen den einzelnen Polierstufen bei Grandio Voco A2

\begin{tabular}{|l|l|l|l|l|}
\hline A2 & & 110 & 400 & 1200 \\
\hline 400 & diff & 8.94 & & \\
\hline & p adj & $\mathbf{< 0 . 0 1}$ & & \\
\hline 1200 & diff & 4.13 & -4.81 & \\
\hline & p adj & 0.24 & 0.14 & 9.94 \\
\hline HG & diff & 14.07 & 5.13 & $<\mathbf{0 . 0 1}$ \\
\hline
\end{tabular}

Tabelle 30: Differenzen (diff) und p-Werte (adjustiert) der disperseren Komponente zwischen den einzelnen Polierstufen bei Grandio Voco A3

\begin{tabular}{|l|l|l|l|l|}
\hline A3 & & 110 & 400 & 1200 \\
\hline 400 & diff & 4.42 & & \\
\hline 1200 & p adj & 0.2 & & \\
\hline & diff & 3.37 & -1.05 & \\
\hline HG & p adj & 0.41 & 0.96 & 7.35 \\
\hline & diff & 10.72 & 6.3 & $\mathbf{0 . 0 1}$ \\
\hline
\end{tabular}

Tabelle 31: Differenzen (diff) und p-Werte (adjustiert) der disperseren Komponente zwischen den einzelnen Polierstufen bei Grandio Voco A4

\begin{tabular}{|l|l|l|l|l|}
\hline A4 & \multicolumn{2}{|c|}{110} & 400 & \\
\hline 400 & diff & 8.94 & & \\
\hline & p adj & $<\mathbf{0 . 0 1}$ & 2.83 & \\
\hline 1200 & diff & 11.77 & 0.3 & \\
\hline & p adj & $<\mathbf{0 . 0 1}$ & 1.17 & -1.66 \\
\hline HG & diff & 10.11 & 0.87 & 0.71 \\
\hline & p adj & $<\mathbf{0 . 0 1}$ & & \\
\hline
\end{tabular}


Tabelle 32: Differenzen (diff) und p-Werte (adjustiert) der disperseren Komponente zwischen den einzelnen Polierstufen bei Amalgam

\begin{tabular}{|c|c|c|c|c|}
\hline \multicolumn{2}{|l|}{$\mathrm{AG}$} & 110 & 400 & 1200 \\
\hline \multirow[t]{2}{*}{400} & diff & 1.96 & & \\
\hline & $\mathrm{p}$ adj & 0.91 & & \\
\hline \multirow[t]{2}{*}{1200} & diff & 8.22 & 6.25 & \\
\hline & $\mathrm{p}$ adj & 0.06 & 0.2 & \\
\hline \multirow[t]{2}{*}{$\mathrm{HG}$} & diff & 8.07 & 6.1 & -0.15 \\
\hline & $\mathrm{p}$ adj & 0.07 & 0.22 & 1 \\
\hline
\end{tabular}

Die Tabelle 33 bis Tabelle 36 zeigen die Vergleiche der einzelnen Farben bzw. Materialien für die disperseren Komponenten von jeweils einer Polierstufe. Dabei zeigte sich bei der Polierstufe 110 eine Signifikanz zwischen A3 und Ag. Bei der Polierstufe 400 und HG stellten sich Signifikanzen zwischen jeder Farbe A1 - A4 zu dem Material AG dar. Bei Polierstufe 1200 gab es einen bedeutenden Unterschied zwischen A4 und AG.

Tabelle 33:Differenzen (diff) und p-Werte (adjustiert) der disperseren Komponente zwischen den einzelnen Farben / Materialien bei Polierstufe 110

\begin{tabular}{|l|l|l|l|l|l|}
\hline 110 & & A1 & A2 & A3 & A4 \\
\hline A2 & diff & 0.19 & & & \\
\hline A3 & p adj & 1 & & & \\
\hline & diff & 3.51 & 3.31 & & \\
\hline A4 & p adj & 0.51 & 0.56 & -3.39 & \\
\hline & diff & 0.12 & -0.07 & 0.54 & \\
\hline AG & p adj & 1 & 1 & -9.06 & -5.68 \\
\hline & diff & -5.56 & -5.75 & $<0.01$ & 0.11 \\
\hline
\end{tabular}


Tabelle 34: Differenzen (diff) und p-Werte (adjustiert) der disperseren Komponente zwischen den einzelnen Farben / Materialien bei Polierstufe 400

\begin{tabular}{|c|c|c|c|c|c|}
\hline \multicolumn{2}{|l|}{400} & $\mathrm{~A} 1$ & $\mathrm{~A} 2$ & \multirow[t]{2}{*}{ A3 } & \multirow{2}{*}{ A4 } \\
\hline A2 & diff & 3.55 & & & \\
\hline & $\mathrm{p}$ adj & 0.25 & & & \\
\hline \multirow[t]{2}{*}{ A3 } & diff & 2.34 & -1.21 & & \\
\hline & $\mathrm{p}$ adj & 0.64 & 0.95 & & \\
\hline \multirow[t]{2}{*}{ A4 } & diff & 3.48 & -0.08 & 1.13 & \\
\hline & $\mathrm{p}$ adj & 0.27 & 1 & 0.96 & \\
\hline \multirow[t]{2}{*}{$A G$} & diff & -9.17 & -12.73 & -11.52 & -12.65 \\
\hline & $\mathrm{p}$ adj & $<0.01$ & $<0.01$ & $<0.01$ & $<0.01$ \\
\hline
\end{tabular}

Tabelle 35: Differenzen (diff) und p-Werte (adjustiert) der disperseren Komponente zwischen den einzelnen Farben / Materialien bei Polierstufe 1200

\begin{tabular}{|c|c|c|c|c|c|}
\hline 1200 & & $\mathrm{~A} 1$ & $\mathrm{~A} 2$ & A3 & $\mathrm{A} 4$ \\
\hline \multirow[t]{2}{*}{ A2 } & diff & -3.48 & & & \\
\hline & $\mathrm{p}$ adj & 0.71 & & & \\
\hline \multirow[t]{2}{*}{ A3 } & diff & -0.92 & 2.56 & & \\
\hline & $\mathrm{p}$ adj & 1 & 0.88 & & \\
\hline \multirow[t]{2}{*}{ A4 } & diff & 4.09 & 7.57 & 5.01 & \\
\hline & $\mathrm{p}$ adj & 0.58 & 0.08 & 0.39 & \\
\hline \multirow[t]{2}{*}{$\mathrm{AG}$} & diff & -5.14 & -1.66 & -4.22 & -9.23 \\
\hline & $\mathrm{p}$ adj & 0.36 & 0.97 & 0.55 & 0.02 \\
\hline
\end{tabular}

Tabelle 36: Differenzen (diff) und p-Werte (adjustiert) der disperseren Komponente zwischen den einzelnen Farben / Materialien bei Polierstufe HG

\begin{tabular}{|l|l|l|l|l|l|}
\hline HG & \multicolumn{2}{|c|}{ A1 } & A2 & A3 & \\
\hline A2 & diff & 1.43 & & & \\
\hline & p adj & 0.97 & -0.04 & & \\
\hline A3 & diff & 1.39 & 1 & -4 & \\
\hline A4 & p adj & 0.97 & -4.04 & 0.44 & \\
\hline & diff & -2.61 & 0.43 & -11.72 & -7.71 \\
\hline AG & diff & -10.33 & -11.75 & $<\mathbf{0 . 0 1}$ & $\mathbf{0 . 0 2}$ \\
\hline
\end{tabular}


Tabelle 37: Median und Interquartilsabstand (IQR) der polaren Komponente unterteilt nach Polierstufe und Farbe bzw. Material ( $\mathrm{n}=5$, jeweils)

\begin{tabular}{|c|c|c|c|c|c|}
\hline \multicolumn{2}{|l|}{ Farbe/Material } & \multirow{2}{*}{$\begin{array}{l}110 \\
37.46\end{array}$} & \multirow{2}{*}{$\begin{array}{l}400 \\
31.29\end{array}$} & \multirow{2}{*}{$\begin{array}{l}1200 \\
37.27\end{array}$} & \multirow{2}{*}{$\begin{array}{l}\text { HG } \\
30.52\end{array}$} \\
\hline A1 & Median & & & & \\
\hline & IQR & 6.7 & 3.5 & 1.5 & 4.7 \\
\hline A2 & Median & 43.72 & 33.94 & 35.64 & 27.1 \\
\hline & IQR & 6.5 & 4.9 & 6.5 & 3.7 \\
\hline A3 & Median & 38.9 & 36.99 & 35.74 & 28.56 \\
\hline & IQR & 3.4 & 4.5 & 2.4 & 1.1 \\
\hline A4 & Median & 42.21 & 35.24 & 34.43 & 32.56 \\
\hline & IQR & 1.9 & 1.2 & 2.5 & 4.8 \\
\hline AG & Median & 46.6 & 45.08 & 39.58 & 41.45 \\
\hline & IQR & 3.4 & 1.6 & 2.9 & 6.2 \\
\hline
\end{tabular}

Die Tabelle 38 bis Tabelle 42 zeigen den Vergleich der polaren Komponente der einzelnen Polierstufen bei einer Farbe bzw. eines Materials. Bei der Farbe A1und AG gibt es keine bedeutenden Unterschiede. Die Farben A2 und A3 zeigten Signifikanzen zwischen HG und 110 sowie HG und 1200. Einen signifikanten Unterschied bei der Farbe A4 stellte sich zwischen 110 und HG dar.

Tabelle 38: Differenzen (diff) und p-Werte (adjustiert) der polaren Komponente zwischen den einzelnen Polierstufen bei Grandio Voco A1

\begin{tabular}{|l|l|l|l|l|}
\hline A1 & & 110 & 400 & 1200 \\
\hline 400 & diff & -4.2 & & \\
\hline & p adj & 0.39 & & \\
\hline 1200 & diff & 0.34 & 4.53 & \\
\hline \multirow{2}{*}{ HG } & p adj & 1 & 0.32 & -7.31 \\
\hline & diff & -6.98 & -2.78 & 0.05 \\
\hline
\end{tabular}


Tabelle 39: Differenzen (diff) und p-Werte (adjustiert) der polaren Komponente zwischen den einzelnen Polierstufen bei Grandio Voco A2

\begin{tabular}{|c|c|c|c|c|}
\hline \multicolumn{2}{|l|}{$\mathrm{A} 2$} & 110 & 400 & 1200 \\
\hline \multirow[t]{2}{*}{400} & diff & -7.18 & & \\
\hline & $\mathrm{p}$ adj & 0.06 & & \\
\hline \multirow[t]{2}{*}{1200} & diff & -3.43 & 3.75 & \\
\hline & p adj & 0.57 & 0.5 & \\
\hline \multirow[t]{2}{*}{$\mathrm{HG}$} & diff & -12.75 & -5.57 & -9.32 \\
\hline & $\mathrm{p}$ adj & $<0.01$ & 0.18 & 0.01 \\
\hline
\end{tabular}

Tabelle 40: Differenzen (diff) und p-Werte (adjustiert) der polaren Komponente zwischen den einzelnen Polierstufen bei Grandio Voco A3

\begin{tabular}{|l|l|l|l|l|}
\hline A3 & \multicolumn{1}{|l|}{110} & 400 & 1200 \\
\hline 400 & diff & -4.21 & & \\
\hline & p adj & 0.34 & & \\
\hline 1200 & diff & -2.9 & 1.31 & \\
\hline & p adj & 0.64 & 0.95 & -7.98 \\
\hline HG & diff & -10.88 & -6.67 & $\mathbf{0 . 0 2}$ \\
\hline
\end{tabular}

Tabelle 41: Differenzen (diff) und p-Werte (adjustiert) der polaren Komponente zwischen den einzelnen Polierstufen bei Grandio Voco A4

\begin{tabular}{|l|l|l|l|l|}
\hline A4 & \multicolumn{2}{|c|}{110} & 400 & \\
\hline 400 & diff & -5.54 & & \\
\hline & p adj & 0.03 & 0.3 & \\
\hline 1200 & diff & -5.24 & 1 & \\
\hline & p adj & 0.05 & -3.1 & -3.4 \\
\hline HG & diff & -8.64 & 0.35 & 0.28 \\
\hline
\end{tabular}


Tabelle 42: Differenzen (diff) und p-Werte (adjustiert) der polaren Komponente zwischen den einzelnen Polierstufen bei Amalgam

\begin{tabular}{|l|l|l|l|l|}
\hline AG & \multicolumn{1}{|l|}{110} & 400 & \\
\hline 400 & diff & -0.12 & & \\
\hline & p adj & 1 & & \\
\hline 1200 & diff & -7.75 & -7.63 & \\
\hline & p adj & 0.09 & 0.09 & 3.63 \\
\hline HG & diff & -4.13 & -4.01 & 0.64 \\
\hline & p adj & 0.54 & 0.56 & \\
\hline
\end{tabular}

Der Vergleich der polaren Komponente der Zahnfarben und Amalgam bei den einzelnen Polierstufen ist in den Tabelle 43 bis Tabelle 46 dargestellt. Bei der Polierstufen 110 und 1200 stellten sich keine Unterschiede zwischen den Farben bzw. Materialien dar. Bei den Polierstufen 400 und HG zeigten sich signifikante Unterschiede zwischen A1 - A4 zu Amalgam.

Tabelle 43: Differenzen (diff) und p-Werte (adjustiert) der polaren Komponente zwischen den einzelnen Farben / Materialien bei Polierstufe 110

\begin{tabular}{|l|l|l|l|l|l|}
\hline 110 & & A1 & A2 & A3 & A4 \\
\hline A2 & diff & 3.96 & & & \\
\hline A3 & p adj & 0.71 & & & \\
\hline & diff & 1.99 & -1.96 & & \\
\hline A4 & p adj & 0.97 & 0.97 & 1.43 & \\
\hline & diff & 3.42 & -0.53 & 0.99 & \\
\hline AG & p adj & 0.81 & 1 & 7 & 5.57 \\
\hline & diff & 8.99 & 5.04 & 0.2 & 0.41 \\
\hline
\end{tabular}


Tabelle 44: Differenzen (diff) und p-Werte (adjustiert) der polaren Komponente zwischen den einzelnen Farben / Materialien bei Polierstufe 400

\begin{tabular}{|c|c|c|c|c|c|}
\hline \multicolumn{2}{|l|}{400} & A1 & \multicolumn{2}{|l|}{$\mathrm{A} 2$} & \multirow[t]{2}{*}{$\mathrm{A} 4$} \\
\hline A2 & diff & 0.98 & & & \\
\hline & $\mathrm{p}$ adj & 0.98 & & & \\
\hline A3 & diff & 1.98 & 1 & & \\
\hline & $\mathrm{p}$ adj & 0.83 & 0.98 & & \\
\hline A4 & diff & 2.08 & 1.11 & 0.1 & \\
\hline & $\mathrm{p}$ adj & 0.8 & 0.98 & 1 & \\
\hline$A G$ & diff & 13.07 & 12.09 & 11.09 & 10.99 \\
\hline & $\mathrm{p}$ adj & $<0.01$ & $<0.01$ & $<0.01$ & $<0.01$ \\
\hline
\end{tabular}

Tabelle 45: Differenzen (diff) und p-Werte (adjustiert) der polaren Komponente zwischen den einzelnen Farben / Materialien bei Polierstufe 1200

\begin{tabular}{|c|c|c|c|c|c|}
\hline \multicolumn{2}{|l|}{1200} & A1 & $\mathrm{A} 2$ & A3 & A4 \\
\hline \multirow[t]{2}{*}{ A2 } & diff & 0.19 & & & \\
\hline & $\mathrm{p}$ adj & 1 & & & \\
\hline \multirow[t]{2}{*}{ A3 } & diff & -1.24 & -1.44 & & \\
\hline & $\mathrm{p}$ adj & 0.99 & 0.99 & & \\
\hline \multirow[t]{2}{*}{ A4 } & diff & -2.15 & -2.34 & -0.91 & \\
\hline & $\mathrm{p}$ adj & 0.95 & 0.93 & 1 & \\
\hline \multirow[t]{2}{*}{$\mathrm{AG}$} & diff & 0.9 & 0.71 & 2.14 & 3.05 \\
\hline & $\mathrm{p}$ adj & 1 & 1 & 0.95 & 0.85 \\
\hline
\end{tabular}

Tabelle 46: Differenzen (diff) und p-Werte (adjustiert) der polaren Komponente zwischen den einzelnen Farben / Materialien bei Polierstufe HG

\begin{tabular}{|c|c|c|c|c|c|}
\hline \multicolumn{2}{|l|}{$\mathrm{HG}$} & $\mathrm{A} 1$ & A2 & A3 & \multirow[t]{2}{*}{ A4 } \\
\hline A2 & diff & -1.81 & & & \\
\hline & p adj & 0.84 & & & \\
\hline A3 & diff & -1.91 & -0.09 & & \\
\hline & $\mathrm{p}$ adj & 0.81 & 1 & & \\
\hline A4 & diff & 1.76 & 3.58 & 3.67 & \\
\hline & $\mathrm{p}$ adj & 0.85 & 0.29 & 0.27 & \\
\hline $\mathrm{AG}$ & diff & 11.84 & 13.66 & 13.75 & 10.08 \\
\hline & $\mathrm{p}$ adj & $<0.01$ & $<0.01$ & $<0.01$ & $<0.01$ \\
\hline
\end{tabular}




\subsection{Korrelation von Rauheit und freier Oberflächenenergie}

Um einen möglichen Einfluss der Rauheit $\left(\mathrm{R}_{\mathrm{a}}\right)$ auf die freie Oberflächenenergie (FOE, Dispersiv, Polar) und vice versa darzustellen, wurden die entsprechenden Messungen korreliert (nach Pearson). Als dimensionsloses Maß zeigt der Korrelationskoeffizient nach Perason ( $r$ ) an, wie stark der lineare Zusammenhang zwischen zwei Variablen ist. Der Korrelationskoeffizient kann Werte zwischen +1 und -1 annehmen. Je näher $r$ an Null liegt, desto schwächer ist der lineare Zusammenhang (Tabelle 47).

Tabelle 47: Interpretation der Korrelationswerte nach Pearson

\begin{tabular}{|l|l|}
\hline Werte des Korrelationskoeffizienten & Linearer Zusammenhang \\
\hline $0,0 \leq \mathrm{r} \leq \pm 0,2$ & kein bis gering \\
\hline $\pm 0,2<\mathrm{r} \leq \pm 0,5$ & mäßig \\
\hline $\pm 0,5<\mathrm{r} \leq \pm 0,8$ & deutlich \\
\hline $\pm 0,8<\mathrm{r} \leq \pm 1,0$ & hoch \\
\hline
\end{tabular}

Die Ergebnisse sind der Tabelle 48 zu entnehmen und in der Abbildung 16 dargestellt. Auf der Diagonalen sind die Dichteschätzungen aller Polierstufen übereinandergelegt abgebildet. Die zugehörigen Boxplots sind an dem rechten Rand zu finden. Unterhalb der Diagonalen sind die Scatterplots aufgetragen und in der oberen Dreiecksmatrix die dazugehörigen Korrelationen ( $r$ ) sowie p-Werte (p) und mit der Holm-Methode adjustierte p-Werte (p.adj). Eine blaue Einfärbung deutet hierbei auf eine negative und eine rote Einfärbung auf eine positive Korrelation hin. Die statistische Bewertung zeigte eine hohe negative Korrelation zwischen der polaren Komponente und der disperseren Komponente. Zwischen der disperseren Komponente und $\mathrm{R}_{\mathrm{a}}$ besteht eine deutliche negative Korrelation. 
Tabelle 48: Korrelation r (nach Pearson) von Rauheit, der freien Oberflächenenergie (FOE), Dispersiv, Polar (tWert nach $\mathrm{t}$-Test; $\mathrm{p}$-Wert $=$ Signifkanzwahrscheinlichkeit) für alle Materialen

\begin{tabular}{|c|c|c|c|c|c|}
\hline Variable & Wert & Methode & $\mathrm{r}$ & $\mathrm{t}$ & p-Wert \\
\hline \multirow[t]{4}{*}{$\mathbf{R}_{\mathbf{a}}$} & $\mathrm{R}_{\mathrm{a}}$ & Pearson & 1.00 & Inf & $<0.01$ \\
\hline & FOE & Pearson & -0.27 & -2.80 & $<0.01$ \\
\hline & Dispersiv & Pearson & -0.58 & -7.04 & $<0.01$ \\
\hline & Polar & Pearson & 0.46 & 5.13 & $<0.01$ \\
\hline \multirow[t]{4}{*}{ FOE } & $\mathrm{R}_{\mathrm{a}}$ & Pearson & -0.27 & -2.80 & $<0.01$ \\
\hline & FOE & Pearson & 1.00 & Inf & $<0.01$ \\
\hline & Dispersiv & Pearson & 0.37 & 3.89 & $<0.01$ \\
\hline & Polar & Pearson & 0.17 & 1.75 & 0.08 \\
\hline \multirow[t]{4}{*}{ Dispersiv } & $\mathrm{R}_{\mathrm{a}}$ & Pearson & -0.58 & -7.04 & $<0.01$ \\
\hline & FOE & Pearson & 0.37 & 3.89 & $<0.01$ \\
\hline & Dispersiv & Pearson & 1.00 & Inf & $<0.01$ \\
\hline & Polar & Pearson & -0.85 & -16.15 & $<0.01$ \\
\hline \multirow[t]{4}{*}{ Polar } & $\mathrm{R}_{\mathrm{a}}$ & Pearson & 0.46 & 5.13 & $<0.01$ \\
\hline & FOE & Pearson & 0.17 & 1.75 & 0.08 \\
\hline & Dispersiv & Pearson & -0.85 & -16.15 & $<0.01$ \\
\hline & Polar & Pearson & 1.00 & Inf & $<0.01$ \\
\hline
\end{tabular}


Korrelation: Alle Materialien
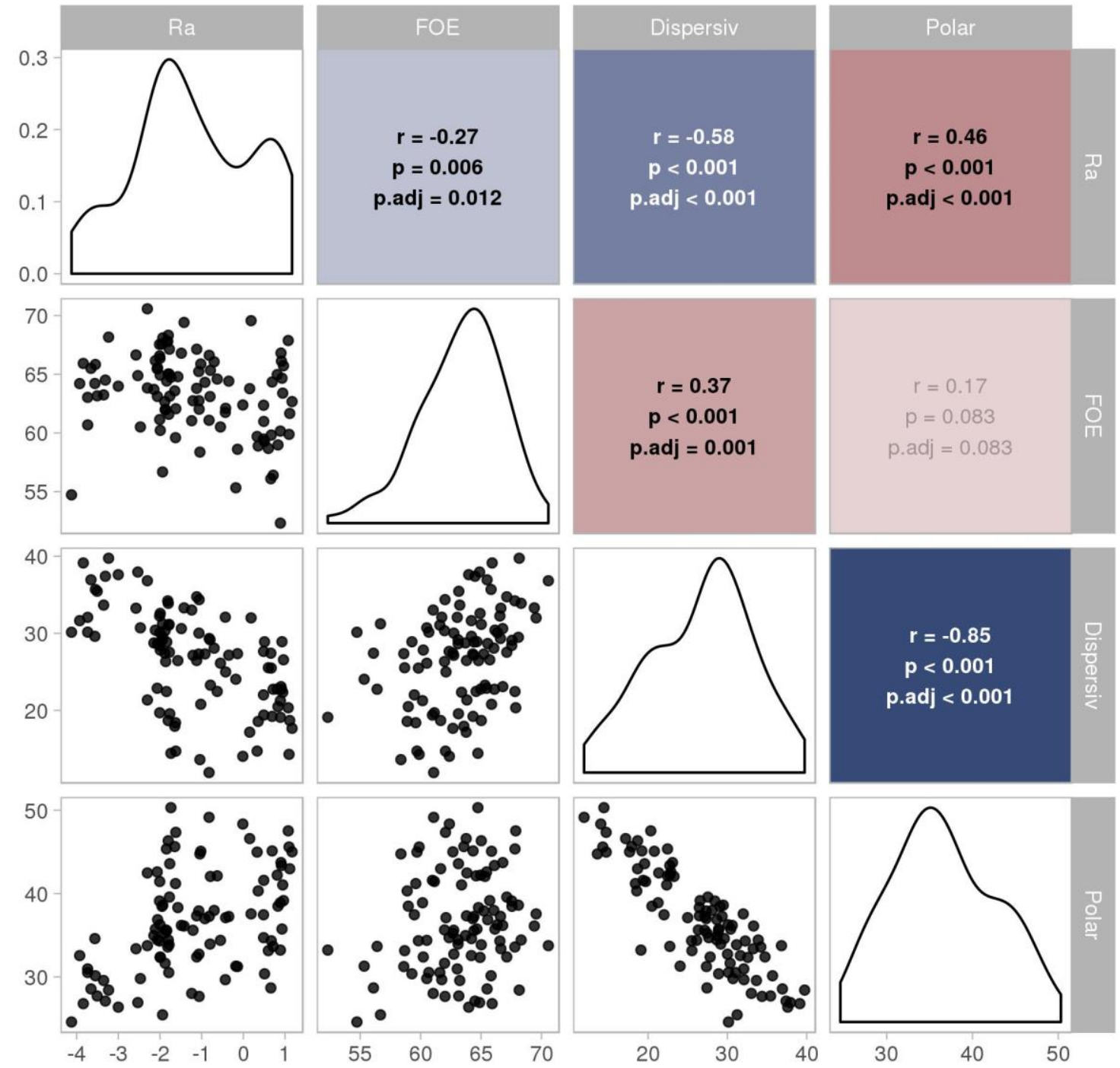

Abbildung 16: Korrelation (nach Pearson) von Rauheit $\left(\mathbf{R}_{\mathrm{a}}\right)$ und der freien Oberflächenenergie (FOE, Dispersiv, Polar) für alle Materialien 
Anschließend wurden die Scatterplots und Korrelationen unterteilt nach Material durchgeführt. Wie in der Abbildung 17 dargestellt, zeigten sich deutliche negative Korrelationen zwischen FOE - $R_{a}$, Dispersiv - $R_{a}$ und Polar - Dispersiv sowie eine positive Korrelation zwischen Dispersiv - FOE bei den verschiedenen Polierstufen der Farbe A1 von Grandio Voco.

\section{Korrelation: A1}
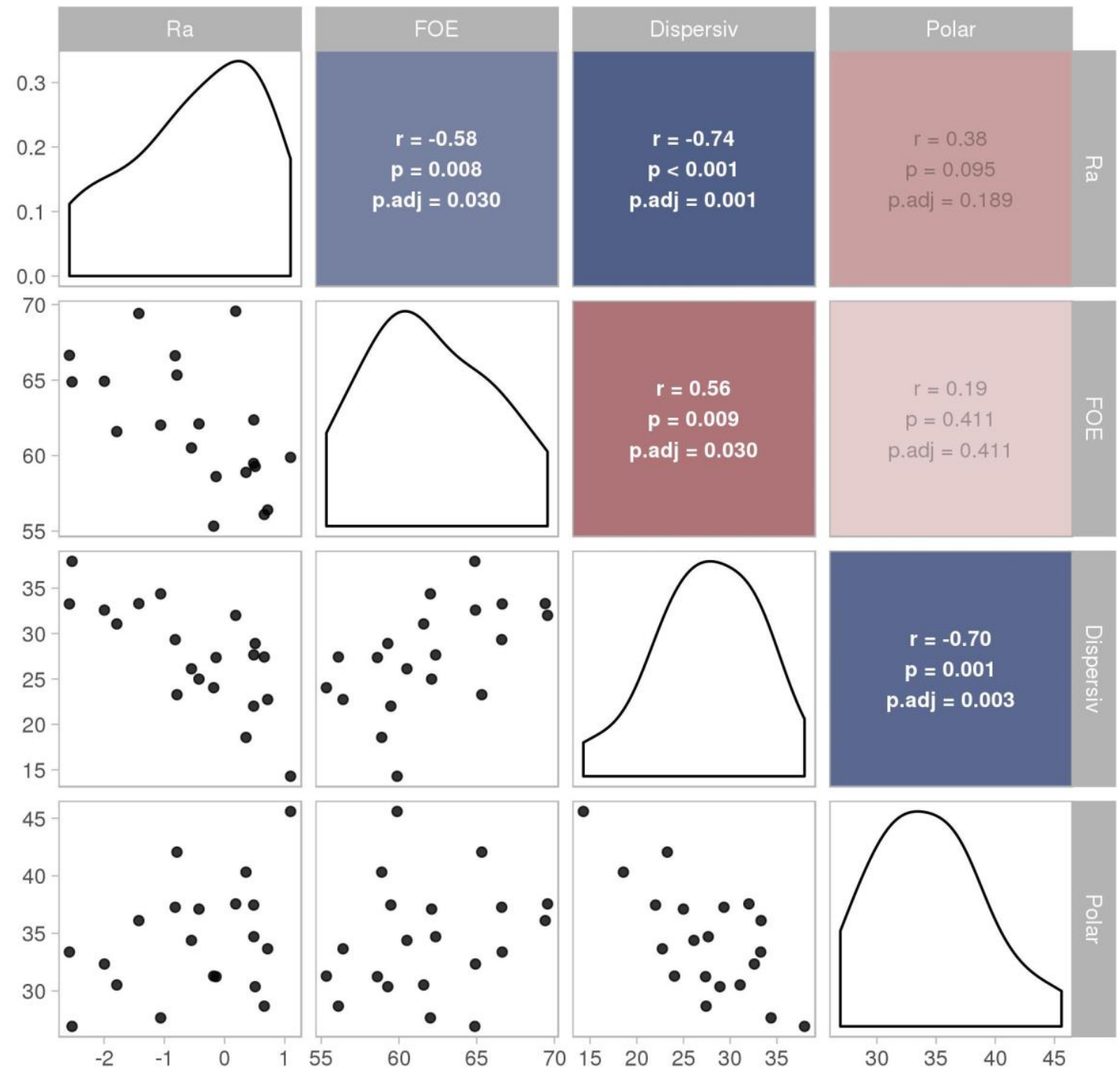

Abbildung 17: Korrelation (nach Pearson) von Rauheit $\left(\mathbf{R}_{\mathrm{a}}\right)$ und der freien Oberflächenenergie (FOE, Dispersiv, Polar) für Grandio Voco A1 
Aus der Abbildung 18 ist ersichtlich, dass eine deutliche Korrelation zwischen Dispersiv $-R_{a}$, Polar $-R_{a}$ und Polar - Dispersiv bei verschiedenen Polierstufen der Farbe A2 von Grandio Voco bestand.

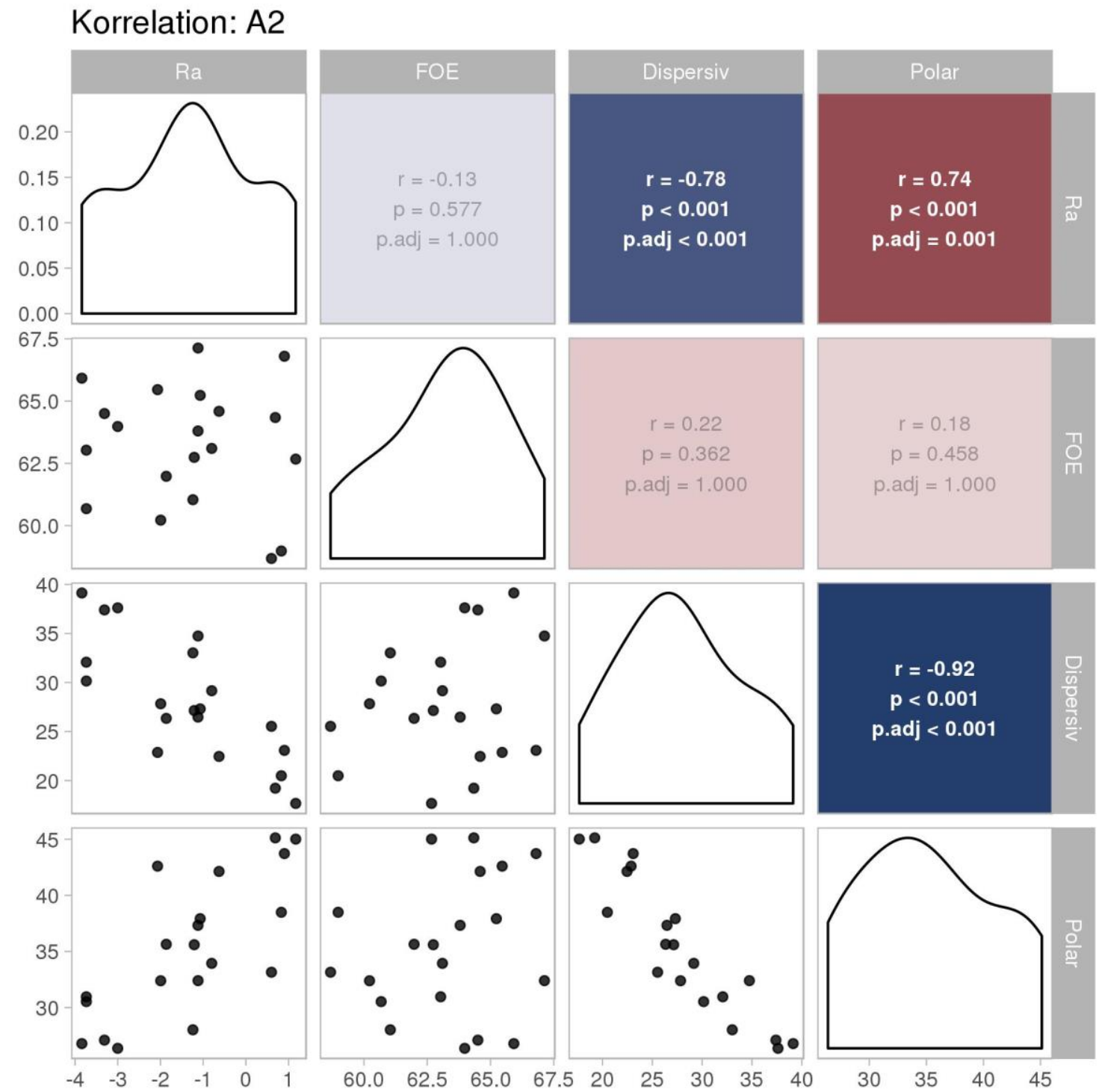

Abbildung 18: Korrelation (nach Pearson) von Rauheit $\left(\mathbf{R}_{\mathrm{a}}\right)$ und der freien Oberflächenenergie (FOE, Dispersiv, Polar) für Grandio Voco A2 
Bei der Farbe A3 ergab die Untersuchung dasselbe Korrelationsbild wie bei der Farbe A2 (Abbildung 19).

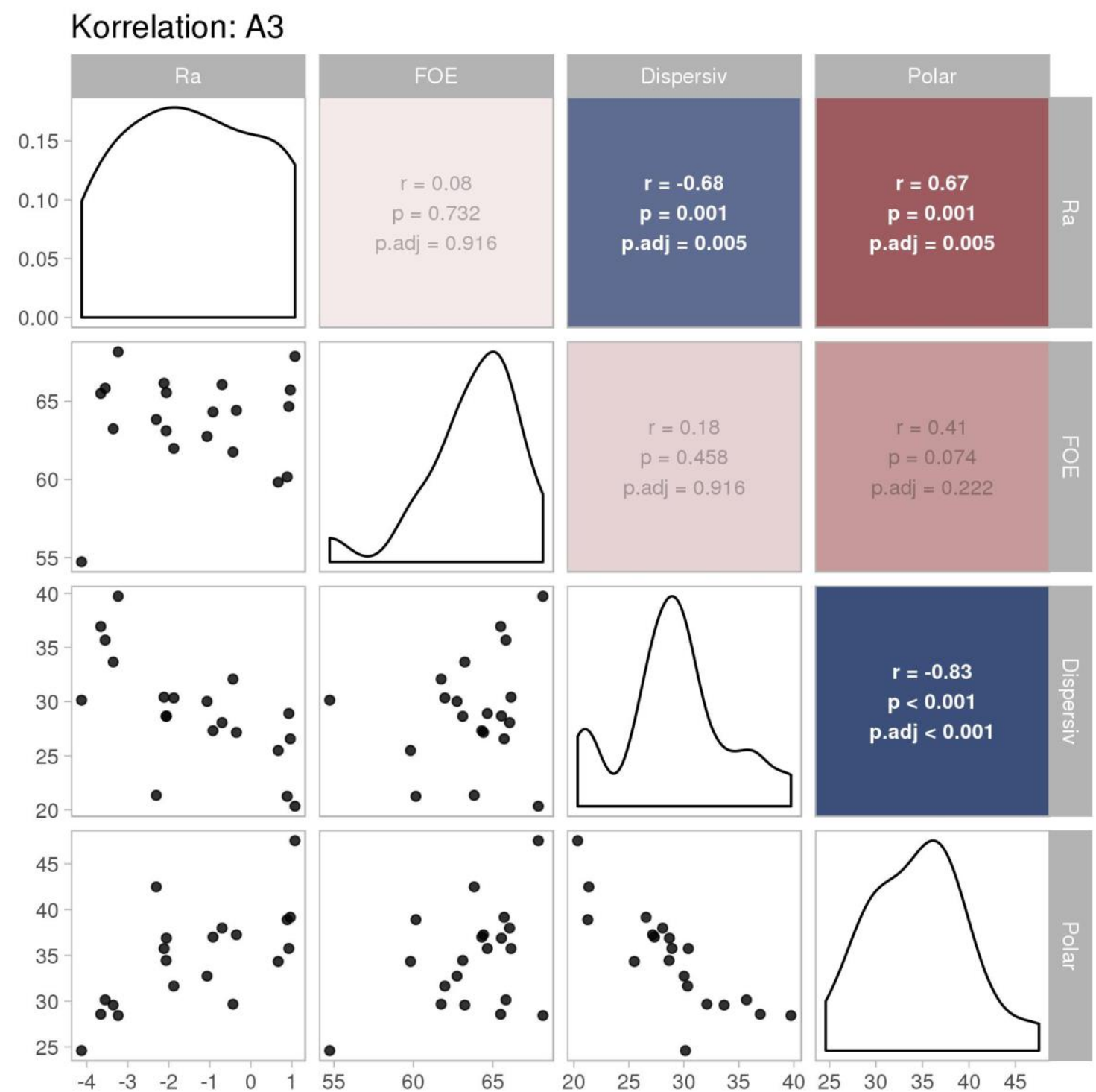

Abbildung 19: Korrelation (nach Pearson) von Rauheit $\left(\mathbf{R}_{\mathrm{a}}\right)$ und der freien Oberflächenenergie (FOE, Dispersiv, Polar) für Grandio Voco A3 
Eine hohe negative Korrelation zwischen den Polierstufen von A4 zeigte sich zwischen Dispersiv $-\mathrm{R}_{\mathrm{a}}$. Polar $-\mathrm{R}_{\mathrm{a}}$ und Dispersiv $-\mathrm{FOE}$ zeigte eine deutliche positive und Polar - Dispersiv eine deutlich negative Korrelation (Abbildung 20).

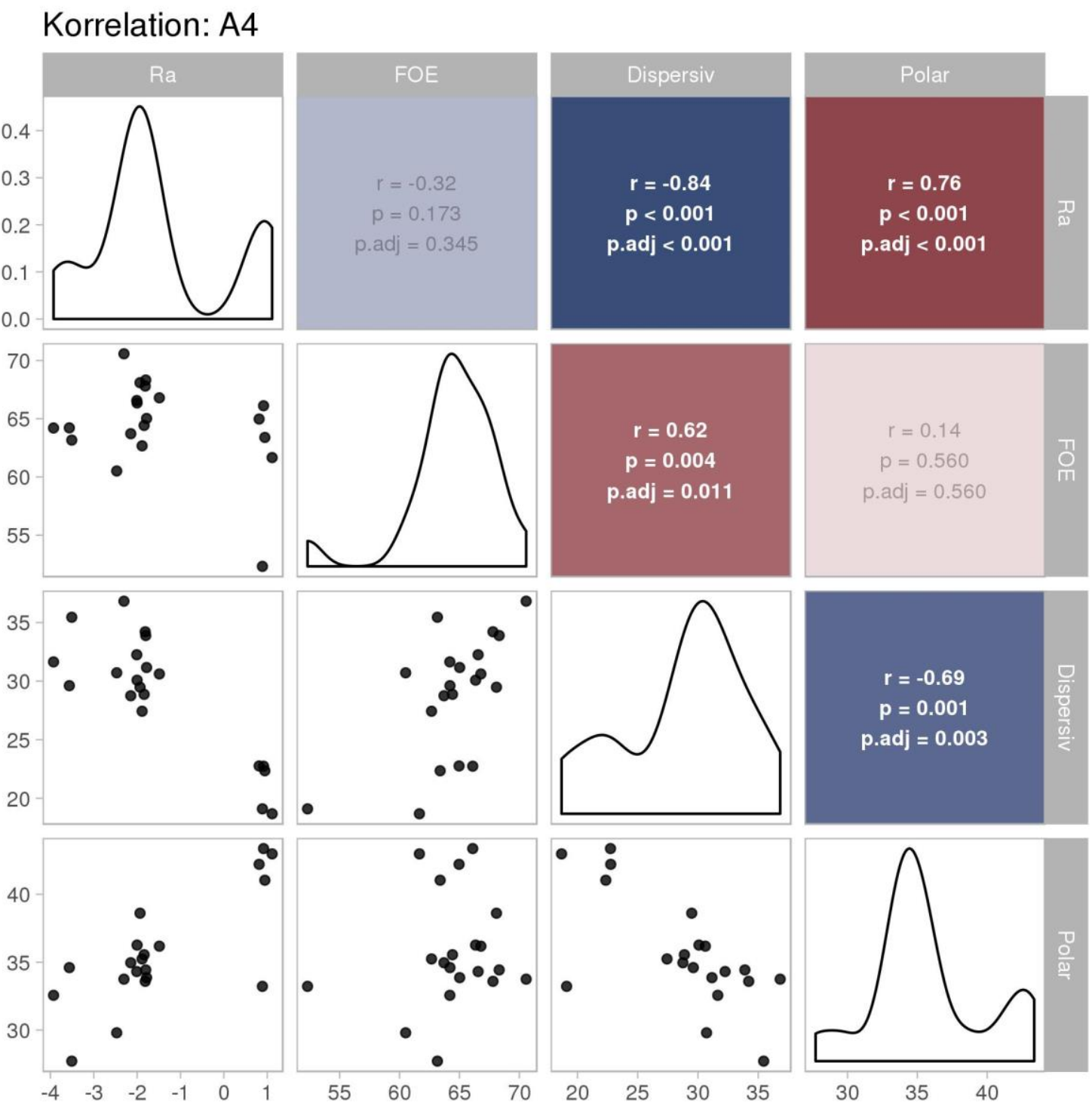

Abbildung 20: Korrelation (nach Pearson) von Rauheit $\left(\mathbf{R}_{\mathrm{a}}\right)$ und der freien Oberflächenenergie (FOE, Dispersiv, Polar) für Grandio Voco A4 
Die Auswertung des Materials Amalgam ergab eine hohe negative Korrelation $(r=-0.84)$ zwischen Polar - Dispersiv Messungen (Abbildung 21).

\section{Korrelation: AG}

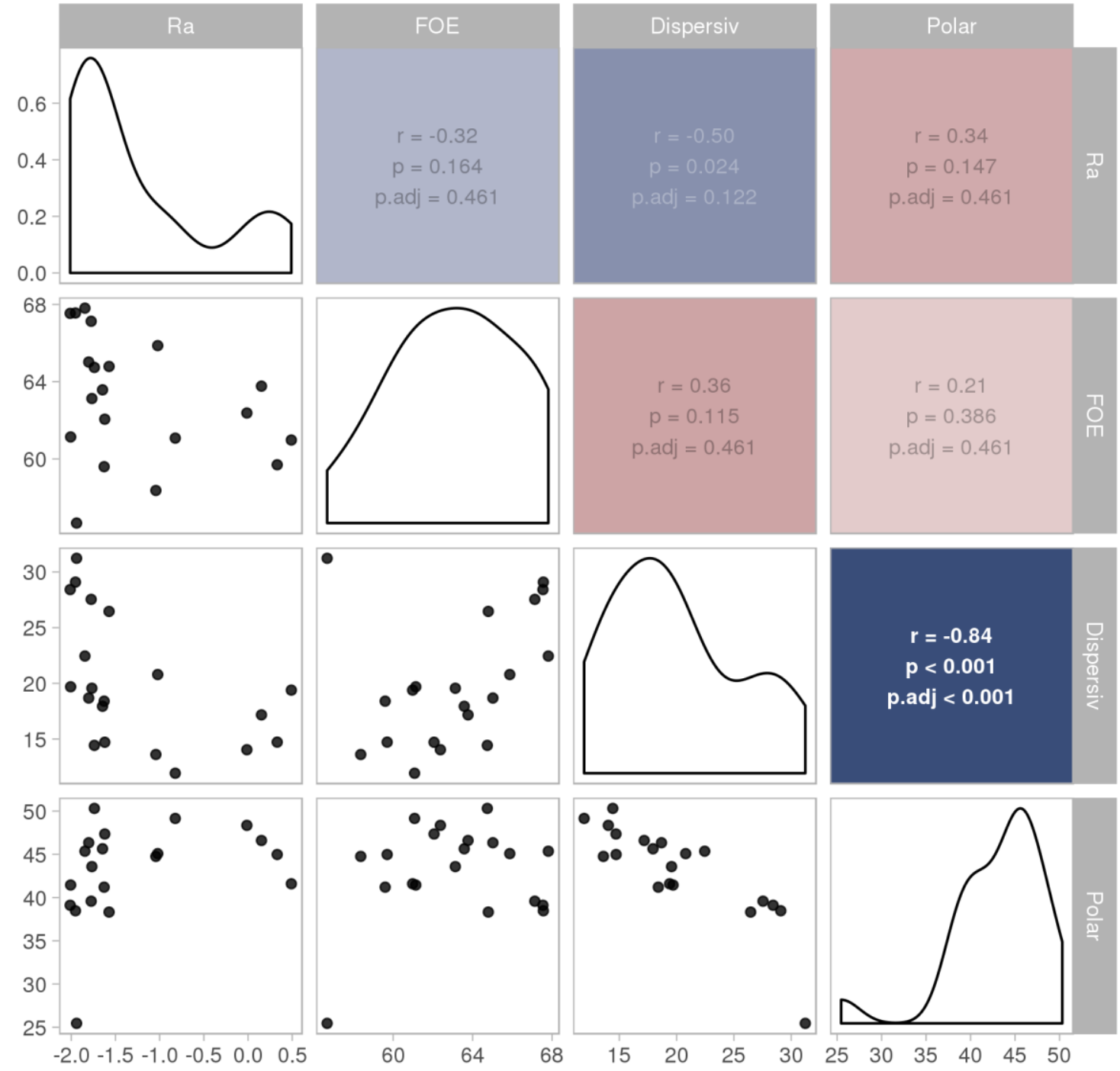

Abbildung 21: Korrelation (nach Pearson) von Rauheit $\left(\mathbf{R}_{\mathrm{a}}\right)$ und der freien Oberflächenenergie (FOE, Dispersiv, Polar) für Amalgam 


\subsection{Vorversuch}

Die gemessene mittlere Rauheit $\left(\mathrm{R}_{\mathrm{a}}\right)$ von Grandio Voco BL im Vorversuch ist in Abbildung 22 dargestellt. Es zeigte sich eine große Streuung der Messwerte bei den Probekörpern, welche mit $110 \mu \mathrm{m}$ Alumiumoxid behandelt wurden.

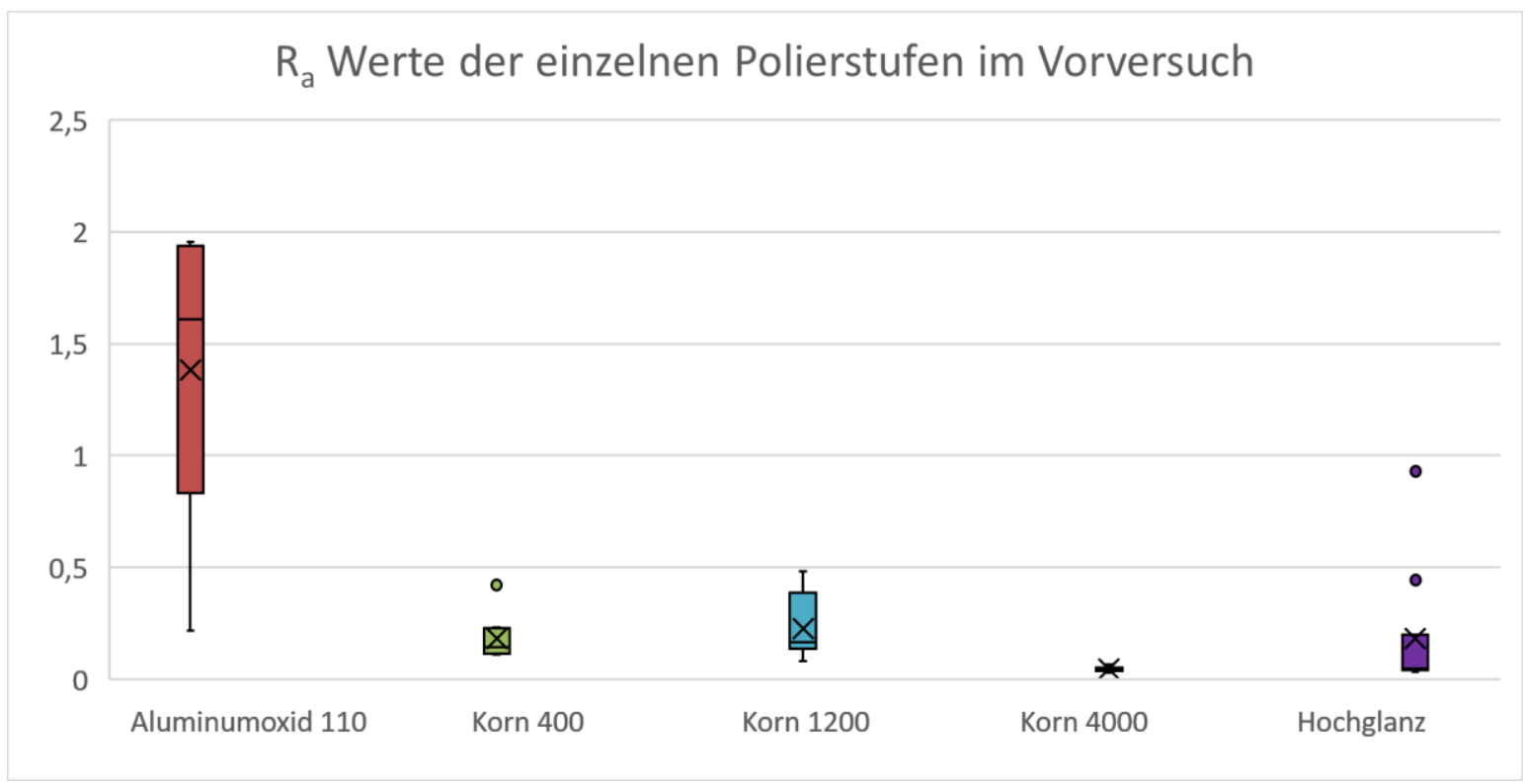

Abbildung 22: $\mathbf{R}_{\mathrm{a}}$-Werte von Grandio Voco BL im Vorversuch

Bei den Kontaktwinkelmessungen im Vorversuch zeigte sich, dass die freie Energie der Oberfläche und deren dispersere Komponente die gleiche Tendenz hatten und sich die polare Komponente entgegengesetzt verhielt (Abbildung 23).

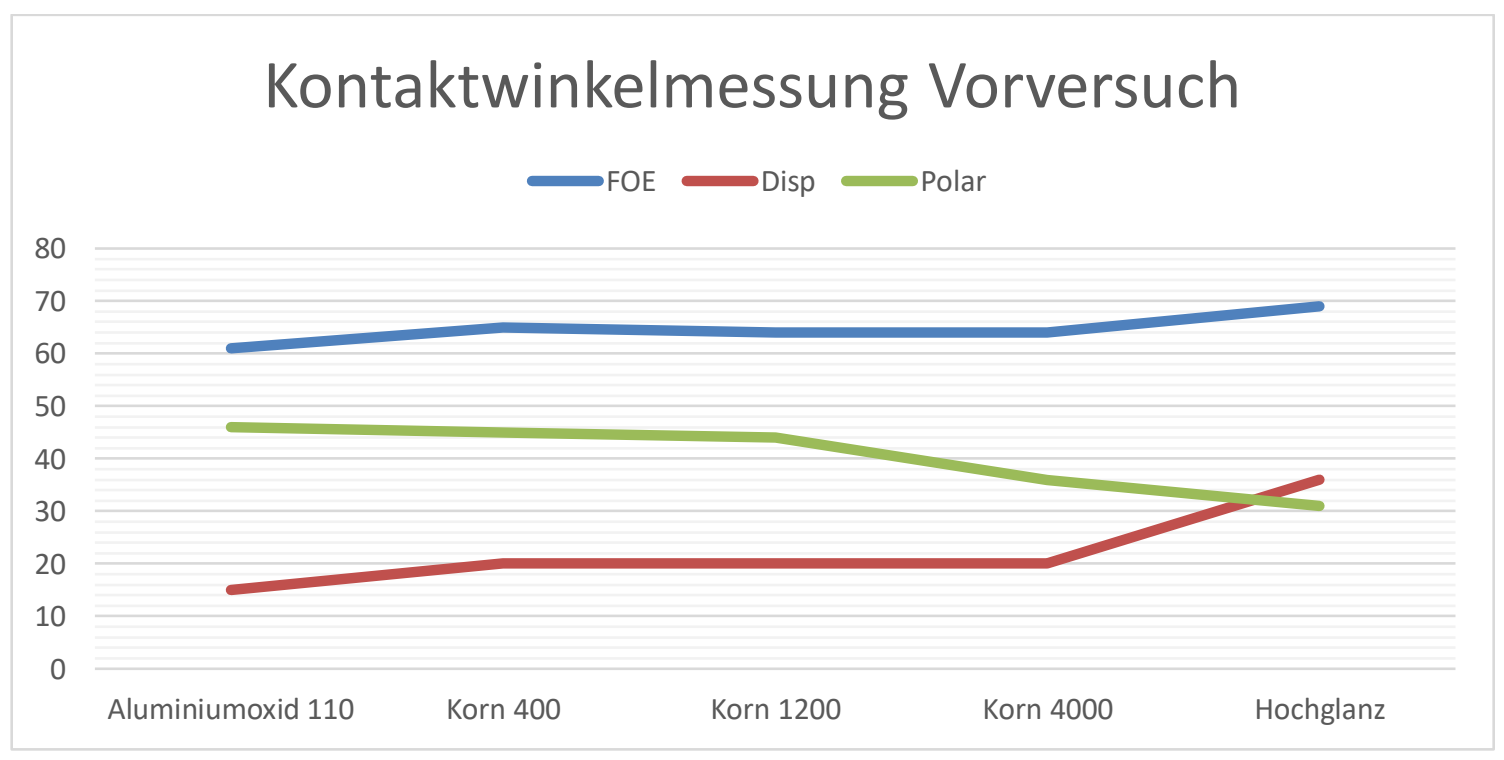

Abbildung 23: Kontaktwinkelmessungen Grandio Voco BL im Vorversuch 


\subsubsection{Zytotoxizität}

Die Zytotoxizitätsmesswerte vom Vorversuch sind in Abbildung 24 dargestellt. Hier zeigten sich geringfügige Unterschiede zwischen den einzelnen Polierstufen. Dabei wurde festgestellt, dass die Zytotoxizitätswerte der einzelnen Polierstufen bedeutende Unterschiede gegenüber den Glaswerten zeigten.

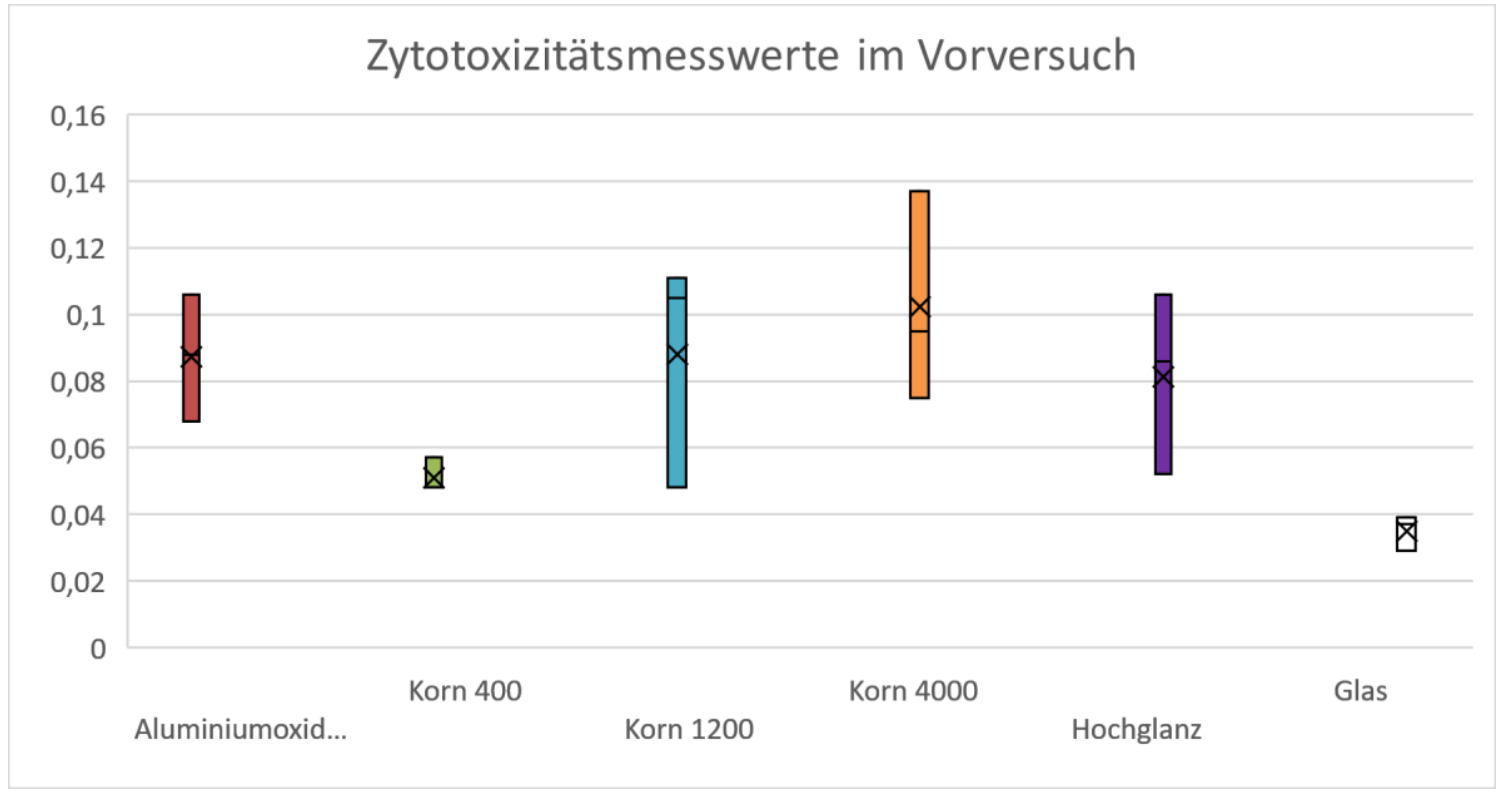

Abbildung 24: Zytotoxizitätsmesswerte von Grandio Voco BL im Vorversuch 


\subsubsection{Zellviabilität}

Bei den Messwerten der Zellviabilität von L929 auf Grandio Voco BL zeigten sich unterschiedliche Werte bei den einzelnen Polierstufen (Abbildung 25). Dabei zeigte sich eine breite Streuung der Polierstufe 4000. Die Messwerte für die Viabilität der Zellen für die Glasprobekörper waren am höchsten.

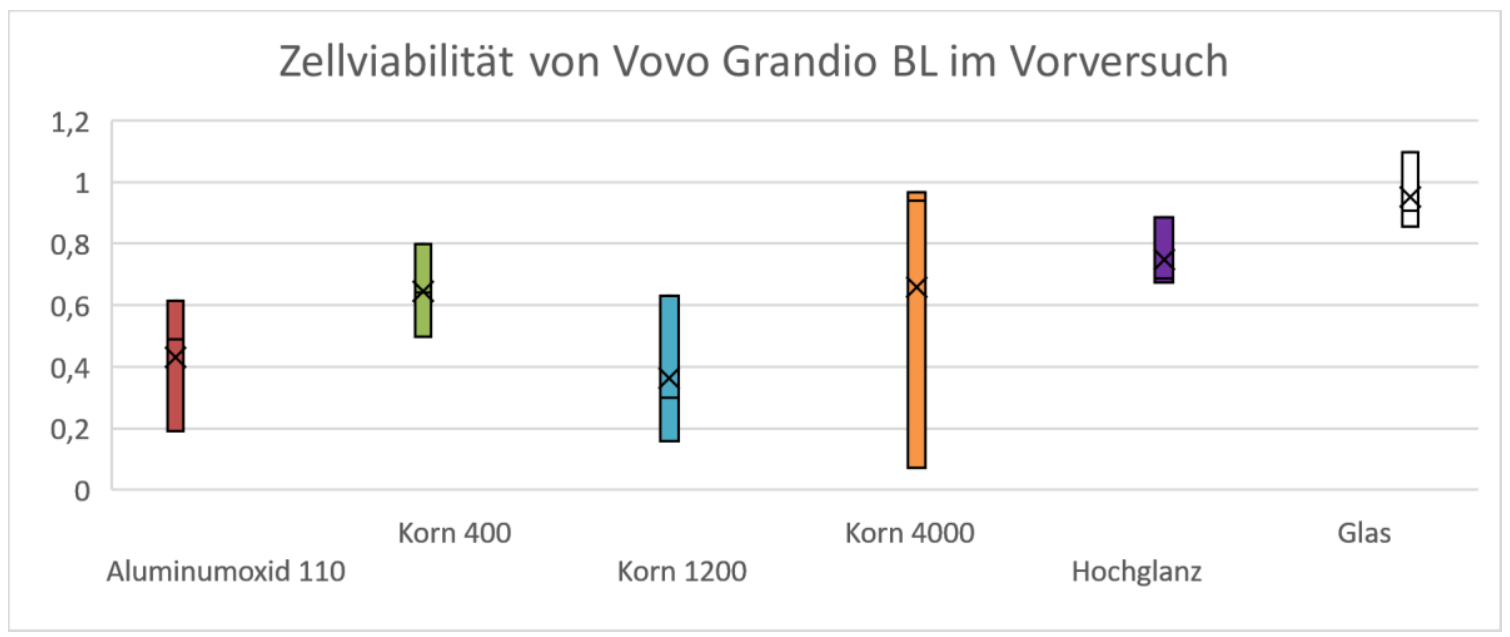

Abbildung 25: Zellviabilität von Vovo Grandio BL im Vorversuch

\subsection{Hauptversuch}

Die Auswertung der Zytotoxizität und Viabilität erfolgte für jede Zelllinie jeweils mittels einer ANOVA. Abschließende Paarvergleiche wurden mit einem t-Test durchgeführt. Alle Analysen wurden mit der Bonferoni-Holm-Methode angepasst, sodass die family-wise error rate von $\alpha=5 \%$ eingehalten wurde. Da sich die Kontrollmessungen auf dem Glas zwischen den Polierstufen stark unterschieden, wurden die Messungen an die jeweilige Zellpassage adjustiert. Bei der schrittweisen Analyse wurde zunächst das globale Modell untersucht mit allen Materialien und Polierstufen sowie deren Interaktion (Material - Polierstufe). Bei einer Signifikanz der Interaktion Polierstufe zu Material, wurde der Datensatz aufgeteilt in Amalgam und die vier Stufen A1-A4. Diese wurden wiederum mit einer Two-Way-ANOVA für Grandio Voco bzw. One-Way-ANOVA für Amalgam analysiert. Ist bei der Two-Way-ANOVA die Interaktion nicht signifikant, verhalten sich die Materialien A1-A4 statistisch nicht unterschiedlich über die Polierstufen. Die Paarvergleiche wurden dann für die zusammengeführte Gruppe A1-A4 durchgeführt. Anhand der Paarvergleiche lässt sich erkennen, bei welchem Material ein Unterschied zwischen welchen Polierstufen besteht. 


\subsubsection{Zytotoxizität}

Die Messwerte der Zytotoxizitätsmessungen sind zur Übersicht in Abbildung 26 dargestellt. Je höher die Werte der y-Achse sind, desto höher die relative Zytotoxizität.

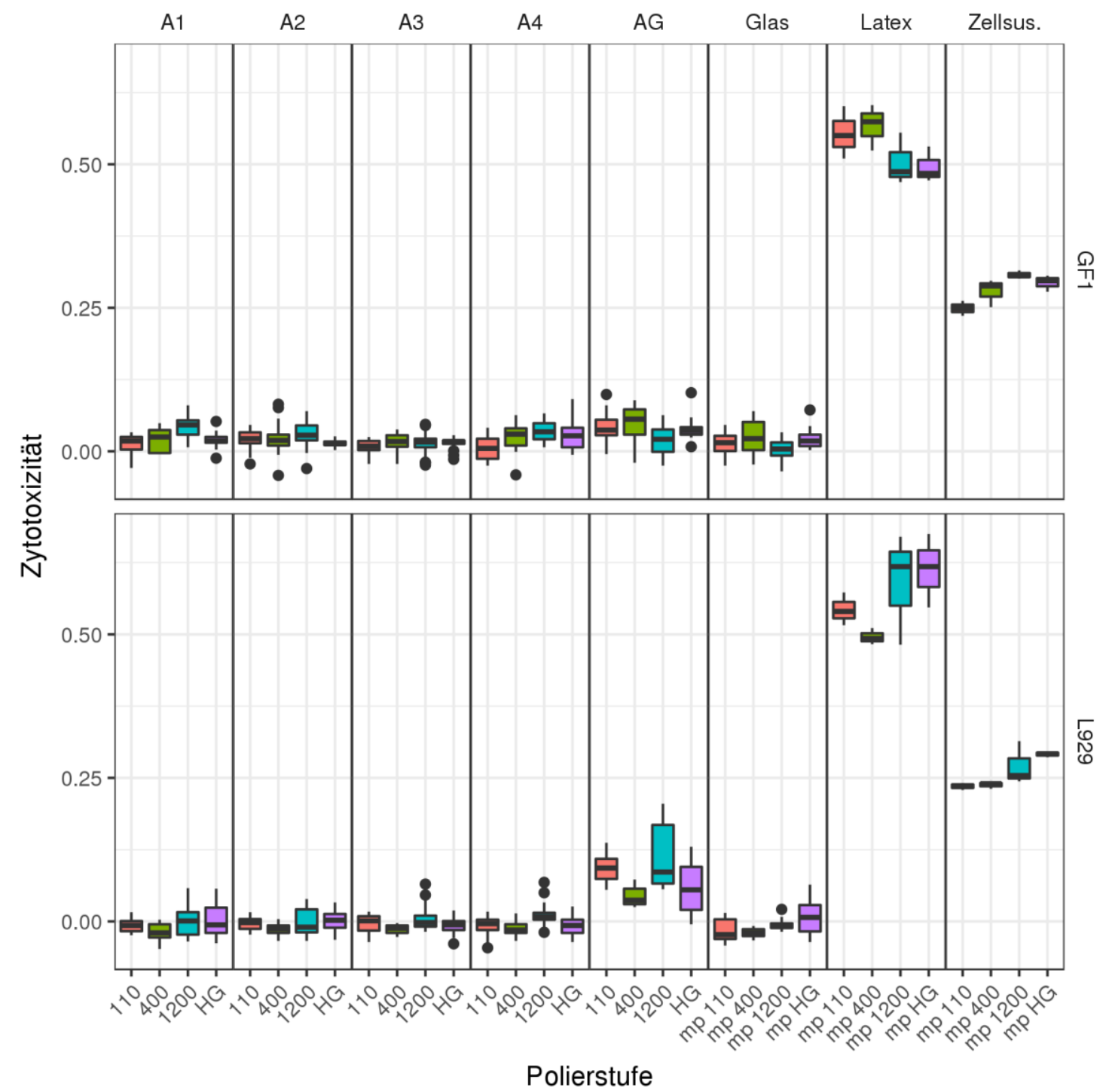

Abbildung 26: Boxplot der Zytotoxizitäts-Messungen gruppiert nach Zelllinie, Polierstufe und Farbe bzw. Material $(\mathrm{mp}=$ mit Polierstufe $)$

In Abbildung 27 sind die Zytotoxizitätsmessungen, welche an die Glas-Werte adjustiert wurden, dargestellt. 


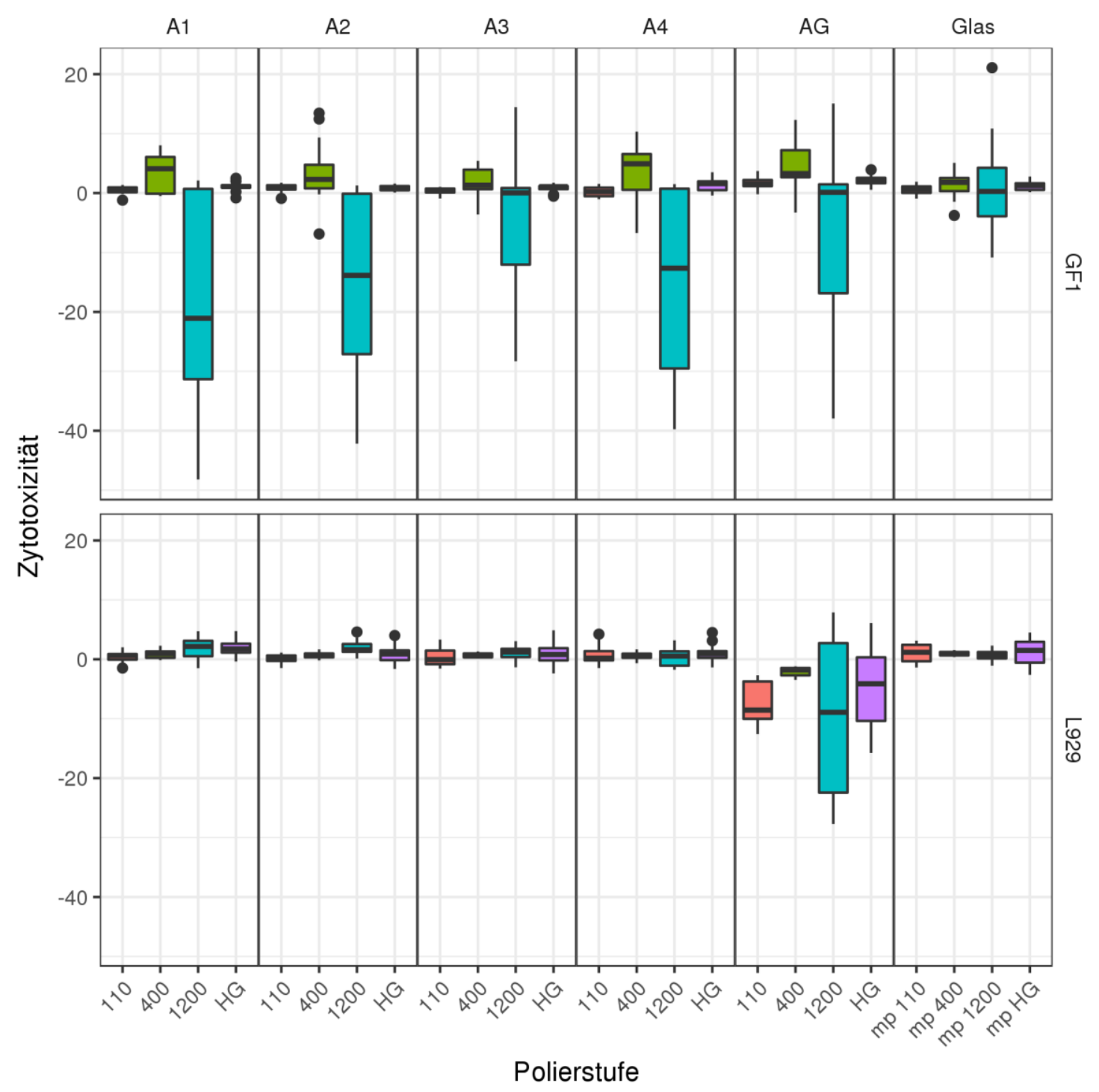

Abbildung 27: An die Glas-Werte adjustierte Zytotoxizitätsmessungen gruppiert nach Polierstufe und Zelllinie $(\mathrm{mp}=$ mit Polierstufe $)$

Bei der globalen Untersuchung der Zelllinie GF1 hat sich gezeigt, dass es sowohl eine Signifikanz zwischen den einzelnen Polierstufen als auch zwischen den Materialien bzw. unterschiedlichen Zahnfarben von Grandio Voco gab (Tabelle 49). 
Tabelle 49: Two-Way-ANOVA für die Zytotoxizität der Zellline GF1 mit den Faktoren Polierstufen und Farbe/Material $(\operatorname{Pr}>$ F, der Signifikanzwahrscheinlichkeitswert, der dem F-Wert zugeordnet ist)

\begin{tabular}{|l|l|}
\hline GF1 auf allen Materialien/Farben & $\mathrm{Pr}>\mathrm{F}$ \\
\hline Polierstufe & $\mathbf{< 0 . 0 0 1}$ \\
\hline Farbe/Material & $\mathbf{0 . 0 0 7}$ \\
\hline Polierstufe: Farbe/Material & $\mathbf{< 0 . 0 0 1}$ \\
\hline
\end{tabular}

Daraufhin wurde in Grandio Voco und Amalgam unterschieden, und die Werte von Grandio Voco A1 - A4 sind zuerst analysiert worden. Dabei stellte sich heraus, dass die Polierstufe und die Polierstufe zur Farbe einen signifikanten Einfluss auf die Zytotoxizität der Zelllinie GF1 hat, aber nicht die Farbe (Tabelle 50).

Tabelle 50: Two-Way-ANOVA für Grandio Voco A1 - A4 für die Zytotoxizität des Keimes GF1 mit den Faktoren Polierstufen und Farbe

\begin{tabular}{|l|l|}
\hline GF1 auf Grandio Voco & Pr> F \\
\hline Polierstufe & $<\mathbf{0 . 0 0 1}$ \\
\hline Farbe & 0.086 \\
\hline Polierstufe: Farbe & $\mathbf{< 0 . 0 0 1}$ \\
\hline
\end{tabular}

Um zu erschließen, zwischen welchen Polierstufen sich signifikante Unterschiede ergaben, wurden Paarvergleiche zwischen den einzelnen Polierstufen der einzelnen Farben durchgeführt. Bei der Farbe A1 gab es signifikante Unterschiede zwischen den Polierstufen 1200 $110 \mu \mathrm{m}, 1200$ - 400 und HG - 1200. Bei der Farbe A2 zeigte sich eine Signifikanz bei den Polierstufen 1200 - 110, 1200 - 400 und HG - 1200. Bei der Farbe A3 gab es einen bedeutenden Unterschied zwischen Polierstufen 1200 - 400. Bei der Farbe A4 stellten sich Signifikanzen zwischen 1200 - 110, 1200 - 400 und HG - 1200 dar (Tabelle 51). 
Tabelle 51: Paarvergleiche zwischen allen Polierstufen der Zytotoxizität der Zelllinie GF1 auf Grandio Voco (die p-Werte wurden mit der Tukey-Methode angeglichen, um den Fehler 1. Art einzuhalten) (p-Werte)

\begin{tabular}{|lllllll|l|}
\hline GF1 & $400-110$ & $1200-110$ & HG-110 & $1200-400$ & HG-400 & HG-1200 \\
\hline A1 & 0.76 & $<\mathbf{0 . 0 1}$ & 1 & $<\mathbf{0 . 0 1}$ & 0.86 & $<\mathbf{0 . 0 1}$ \\
\hline A2 & 0.72 & $<\mathbf{0 . 0 1}$ & 1 & $<\mathbf{0 . 0 1}$ & 0.72 & $<\mathbf{0 . 0 1}$ \\
\hline A3 & 0.87 & $\mathbf{0 . 0 2}$ & 0.99 & $\mathbf{0}$ & 0.95 & $\mathbf{0 . 0 1}$ \\
\hline A4 & 0.47 & $<\mathbf{0 . 0 1}$ & 0.96 & $<\mathbf{0 . 0 1}$ & 0.77 & $<\mathbf{0 . 0 1}$ \\
\hline
\end{tabular}

Anhand der Paarvergleiche, welche in der Tabelle 52 dargestellt sind, zeigte sich, dass es besonderen Unterschiede in der zytotoxischen Wirkung auf die Zelllinie GF1 bei der Polierstufe 110 und den Farben A4 - A2 und 1200 bei den Farben A3 - A1gab.

Tabelle 52: Paarvergleiche zwischen allen Polierstufen der Zytotoxizität der Zellline GF1 auf Grandio Voco A1 A4 (p-Werte)

\begin{tabular}{|l|l|l|l|l|l|l|}
\hline & $\mathrm{A} 2-\mathrm{A} 1$ & $\mathrm{~A} 3-\mathrm{A} 1$ & $\mathrm{~A} 4-\mathrm{A} 1$ & $\mathrm{~A} 3-\mathrm{A} 2$ & $\mathrm{~A} 4-\mathrm{A} 2$ & $\mathrm{~A} 4-\mathrm{A} 3$ \\
\hline 110 & 0.59 & 0.82 & 0.32 & 0.15 & $\mathbf{0 . 0 2}$ & 0.82 \\
\hline 400 & 1.00 & 0.60 & 0.99 & 0.64 & 0.99 & 0.42 \\
\hline 1200 & 0.87 & $\mathbf{0 . 0 2}$ & 0.71 & 0.13 & 0.99 & 0.24 \\
\hline HG & 0.68 & 0.82 & 0.55 & 0.99 & 0.08 & 0.13 \\
\hline
\end{tabular}

Bei der One-Way-ANOVA der Amalgamprobekörper zeigte sich ein signifikanter Unterschied zwischen den Polierstufen (Tabelle 53). Bei den darauffolgenden Paarvergleichen zeigte sich die Signifikanz zwischen den Polierstufen 1200 - 110 und 1200 - 400 (Tabelle 54).

Tabelle 53: One-Way-ANOVA für die Viabilität der Zelllinie GF1 mit dem Faktor Polierstufen auf AG

\begin{tabular}{|l|l|}
\hline GF1 auf Amalgam & Pr $>$ F \\
\hline Polierstufe & $\mathbf{< 0 . 0 0 1}$ \\
\hline
\end{tabular}


Tabelle 54: Paarvergleiche zwischen allen Polierstufen der Viabilität der Zelllinie GF1 auf Amalgam (die p-Werte wurden mit der Tukey-Methode angeglichen um den Fehler 1. Art einzuhalten)

\begin{tabular}{|c|c|c|c|c|}
\hline GF1 auf Amalgam & 110 & 400 & 1200 & $\mathrm{HG}$ \\
\hline 110 & & 0.65 & 0.01 & 1 \\
\hline 400 & & & $<0.001$ & 0.77 \\
\hline 1200 & & & & $<0.001$ \\
\hline HG & & & & \\
\hline
\end{tabular}

Bei der Zelllinie L929 zeigte sich bei der globalen Untersuchung eine Signifikanz zwischen den Polierstufen, den Materialien und den Polierstufen zu Farbe/Material (Tabelle 55).

Tabelle 55: Two-Way-ANOVA für die Viabilität der Zelllinie L929 mit den Faktoren Polierstufen und Farbe/

Material

\begin{tabular}{|l|l|}
\hline L929 auf allen Materialien/Farben & $\operatorname{Pr}>$ F \\
\hline Polierstufe & $<\mathbf{0 . 0 0 1}$ \\
\hline Farbe/Material & $\mathbf{< 0 . 0 0 1}$ \\
\hline Polierstufe: Farbe/Material & $\mathbf{< 0 . 0 0 1}$ \\
\hline
\end{tabular}

Es wurden Grandio Voco A1 - A4 und das Amalgam gesplittet. Zuerst wurde der Komposit analysiert. Die Varianzanalyse zeigte, dass sich die unterschiedlichen Polierstufen, die Farben und die Polierstufen zur Farbe des Komposits signifikant unterschieden (Tabelle 56).

Tabelle 56: One-Way-ANOVA für die Zytotoxizität der Zelllinie L929 mit dem Faktor Polierstufen auf Farben A1-A4

\begin{tabular}{|l|l|}
\hline L929 auf Grandio Voco A1 - A4 & Pr> F \\
\hline Polierstufe & $<\mathbf{0 . 0 0 1}$ \\
\hline Farbe & $\mathbf{0 . 0 0 6}$ \\
\hline Polierstufe: Farbe & $\mathbf{0 . 0 0 6}$ \\
\hline
\end{tabular}

Bei den Paarvergleichen stellte sich heraus, dass bei den Farben A3 und A4 keine Signifikanz zwischen den unterschiedlichen Polierstufen besteht. Bei der Farbe A1 gab es einen signifikanten Unterschied zwischen 1200 - 110 und HG - 110. Die Farbe A2 zeigte bedeutende Unterschiede zwischen den Polierstufen 1200 - 110 und 1200 - 400 für die Zytotoxizität der Zelllinie L929 (Tabelle 57). 
Tabelle 57: Paarvergleiche zwischen allen Polierstufen der Zytotoxizität der Zelllinie L929 auf Grandio Voco A1 - A4 (die p-Werte wurden mit der Tukey-Methode angeglichen, um den Fehler 1. Art einzuhalten)

\begin{tabular}{|l|lllllll|}
\hline L929 & $400-110$ & $1200-110$ & HG-110 & $1200-400$ & HG-400 & HG-1200 \\
\hline A1 & 0.56 & $<\mathbf{0 . 0 1}$ & $\mathbf{0}$ & 0.05 & 0.07 & 1 \\
\hline A2 & 0.28 & $<\mathbf{0 . 0 1}$ & 0.11 & $<\mathbf{0 . 0 1}$ & 0.96 & $\mathbf{0}$ \\
\hline A3 & 0.8 & 0.11 & 0.39 & 0.51 & 0.9 & 0.89 \\
\hline A4 & 1 & 0.89 & 0.78 & 0.96 & 0.65 & 0.35 \\
\hline
\end{tabular}

Bei den Paarvergleichen von der Zelllinie L929 zwischen allen Polierstufen auf Grandio Voco A1 - A4 stellte sich eine Signifikanz bei der Polierstufe 1200 und den Farben A4 zu A1 und A4 zu A2 dar (Tabelle 58).

Tabelle 58: Paarvergleiche zwischen allen Polierstufen der Zytotoxizität des Zellline L929 auf Grandio Voco A1 A4 (p-Werte)

\begin{tabular}{|l|l|l|l|l|l|l|}
\hline L929 & A2-A1 & A3-A1 & A4-A1 & A3-A2 & A4-A2 & A4-A3 \\
\hline 110 & 0.82 & 0.99 & 0.91 & 0.95 & 0.43 & 0.75 \\
\hline 400 & 0.38 & 0.39 & 0.22 & 1.00 & 0.99 & 0.99 \\
\hline 1200 & 1.00 & 0.30 & $\mathbf{0 . 0 0}$ & 0.35 & $\mathbf{0 . 0 0}$ & 0.26 \\
\hline HG & 0.08 & 0.14 & 0.28 & 1.00 & 0.93 & 0.98 \\
\hline
\end{tabular}

Die ANOVA für Amalgam zeigte eine Signifikanz zwischen den Polierstufen (Tabelle 59).

Tabelle 59: One-Way-ANOVA für die Zytotoxizität der Zelllinie L929 mit dem Faktor Polierstufen auf AG

\begin{tabular}{|l|l|}
\hline L929 auf Amalgam & Pr $>$ F \\
\hline Polierstufe & $\mathbf{0 . 0 0 1}$ \\
\hline
\end{tabular}

Die Paarvergleiche beim Amalgam zeigten, dass zwischen den Polierstufen 1200 - 400 bedeutende Unterschiede bestehen (Tabelle 60).

Tabelle 60: Paarvergleiche zwischen allen Polierstufen der Zytotoxizität der Zelllinie L929 auf Grandio Voco (die p-Werte wurden mit der Tukey-Methode angeglichen, um den Fehler 1. Art einzuhalten) (p-Werte)

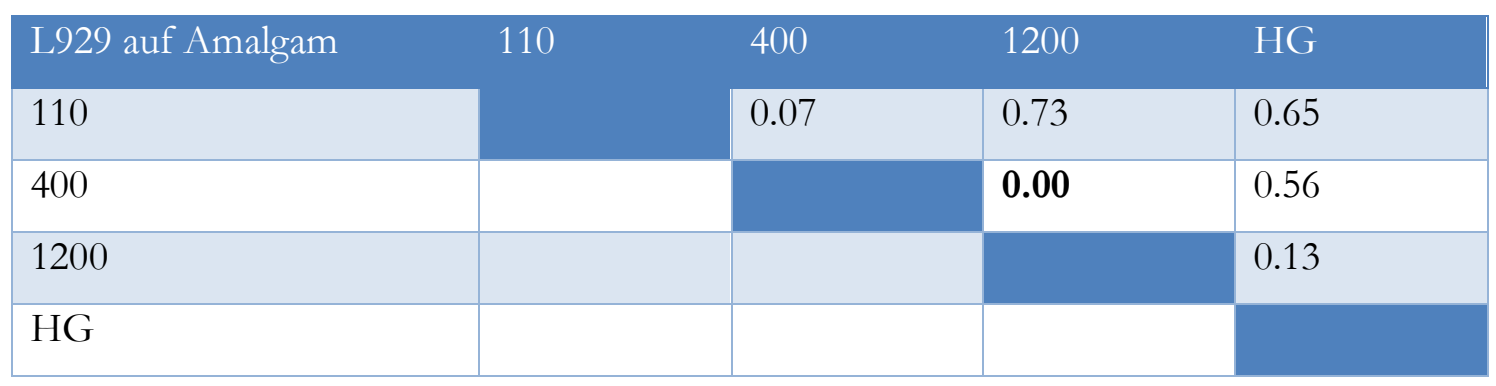




\subsubsection{Zellviabilität}

Die Messwerte der Viabilitätsmessungen sind in Abbildung 28 dargestellt. Die Auswertung der Viabilität erfolgte für jede Zelllinie jeweils mit einer ANOVA und wurde zum Schluss mit Paarvergleichen mit einem t-Test durchgeführt. Die Analysen wurden mit der BonferoniHolm-Methode angepasst, sodass die family-wise error rate von $\alpha=5 \%$ eingehalten wurde. Da sich die Kontrollmessungen auf dem Glas zwischen den Polierstufen stark unterschieden, wurden die Messungen an die jeweilige Zellpassage adjustiert (Abbildung 29).

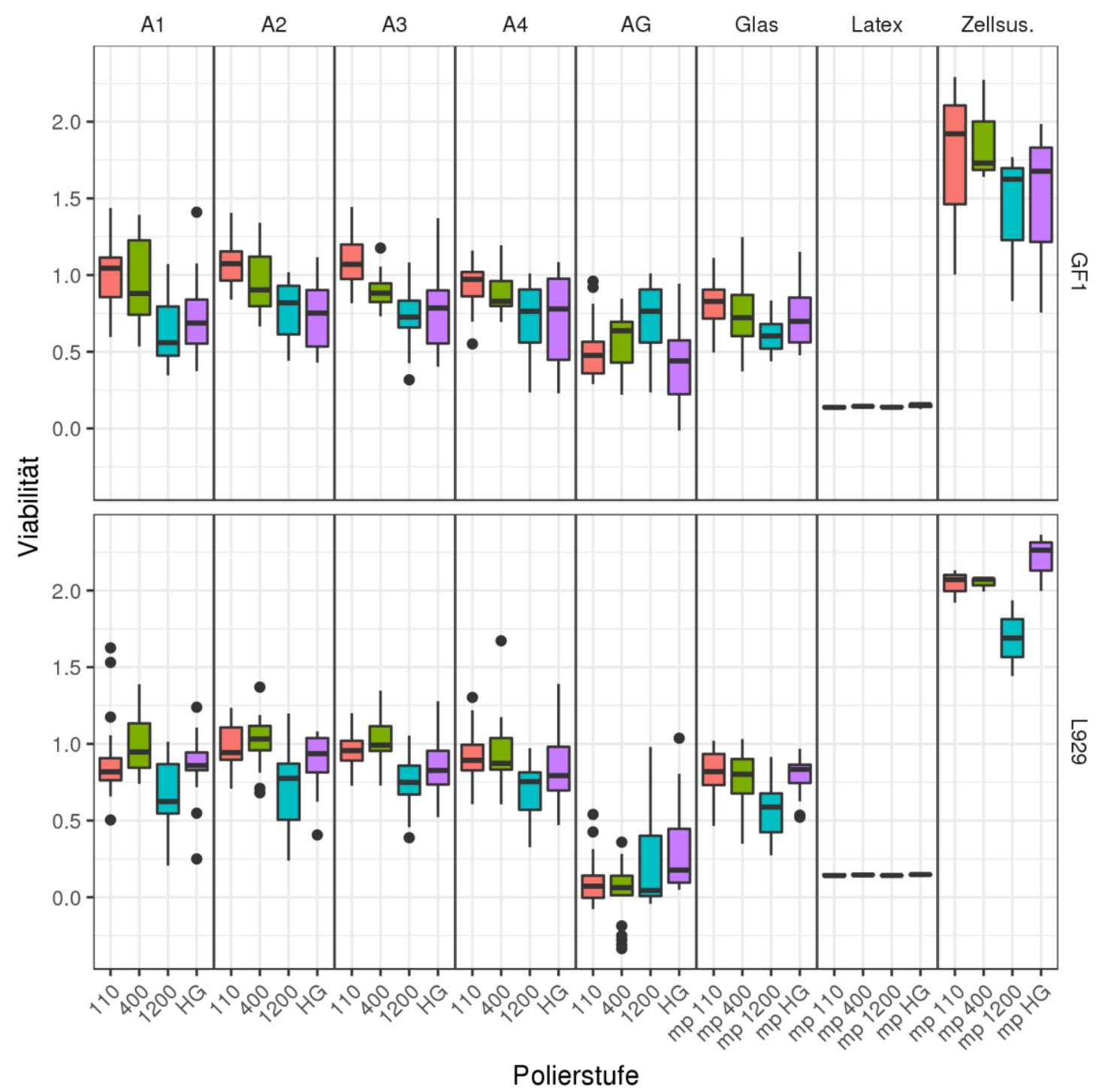

Abbildung 28: Boxplot der Viabilitätsmessungen gruppiert nach Zelllinie, Polierstufe und Farbe bzw. Material $(\mathrm{mp}=$ mit Polierstufe) 


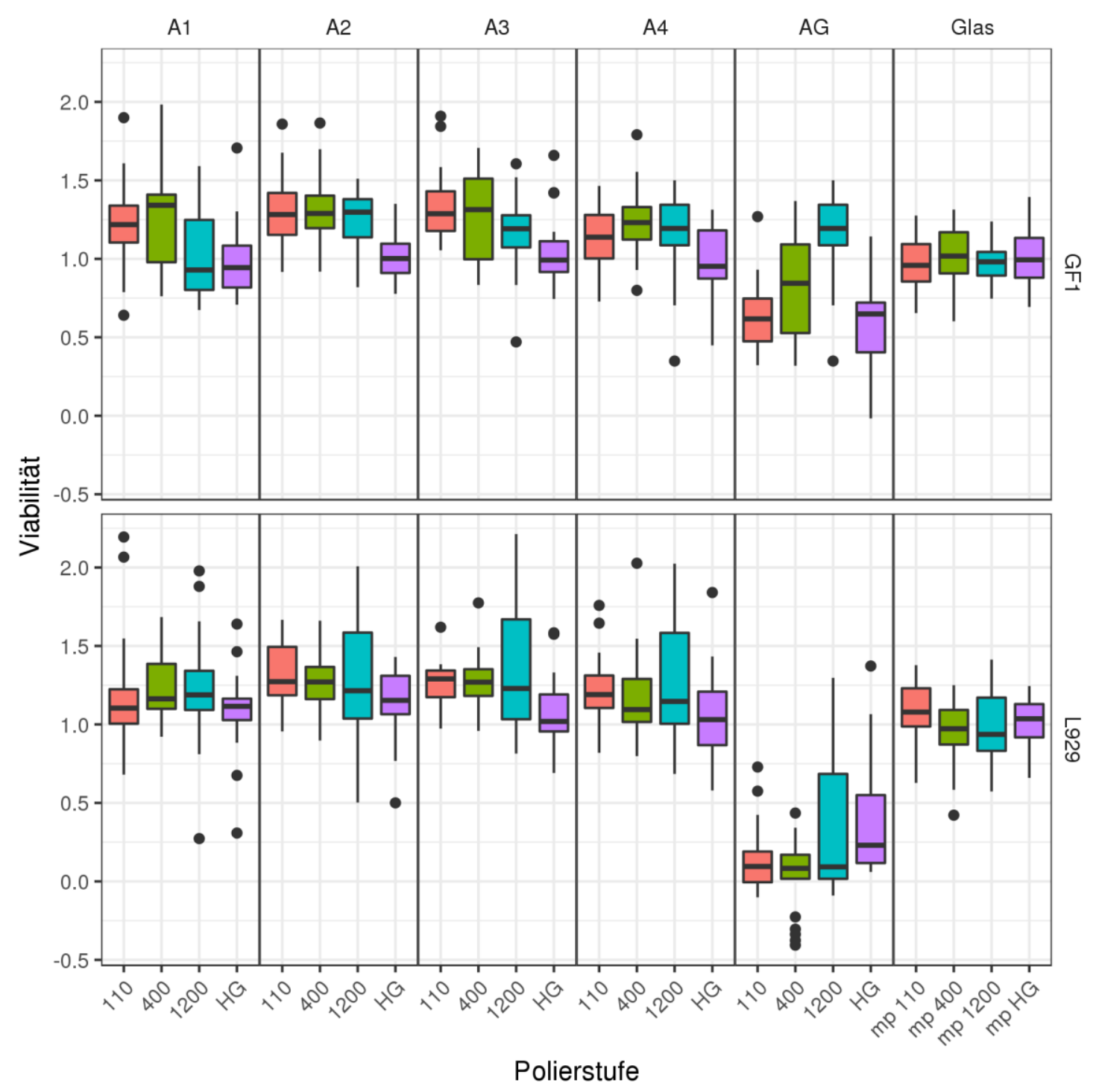

Abbildung 29: An die Glas-Werte adjustierte Viabilitätsmessungen gruppiert nach Polierstufe und Zelllinie $(\mathrm{mp}=$ mit Polierstufe $)$

Die globale Untersuchung der Viabilität der Zelllinie GF1 zeigte einen signifikanten Unterschied sowohl zwischen den Polierstufen und Farben/Materialien als auch zwischen den Polierstufen zu Farben/Materialien (Tabelle 61). 
Tabelle 61: Two-Way-ANOVA für die Viabilität der Zelllinie GF1 mit den Faktoren Polierstufen und Farbe/

Material zu dem Niveau $\alpha=0.05$

\begin{tabular}{|l|l|}
\hline GF1 auf allen Materialien/Farben & Pr $>$ F \\
\hline Polierstufe & $<\mathbf{0 . 0 0 1}$ \\
\hline Farbe/Material & $<\mathbf{0 . 0 0 1}$ \\
\hline Polierstufe: Farbe/Material & $<\mathbf{0 . 0 0 1}$ \\
\hline
\end{tabular}

Nach dem Split von Amalgam und Grandio Voco A1-A4 wurde die Komposite mit einer One-Way-ANOVA untersucht und zeigte einen signifikanten Unterschied zwischen den Polierstufen. Eine Signifikanz stellte sich auch zwischen den unterschiedlichen Farben dar (Tabelle 62).

Tabelle 62: One-Way-ANOVA für die Viabilität des Keimes GF1 mit dem Faktor Polierstufen gemittelt über die Level A1 - A4 von Farbe zu dem Niveau $\alpha=0.05 / 2=0.025$

\begin{tabular}{|l|l|}
\hline GF1 auf Grandio Vovo A1 - A4 & Pr $>$ F \\
\hline Polierstufe & $<\mathbf{0 . 0 0 1}$ \\
\hline Farbe & $\mathbf{0 . 0 1 3}$ \\
\hline Polierstufe: Farbe & 0.514 \\
\hline
\end{tabular}

Bei den folgenden Paarvergleichen zwischen den Polierstufen gab es signifikante Unterschiede zwischen den Polierstufen HG-110, 1200-400, HG-400 und HG-1200 (Tabelle 63).

Tabelle 63: Paarvergleiche zwischen allen Polierstufen der Viabilität der Zelllinie GF1 auf Grandio Voco. Die pWerte wurden mit der Tukey-Methode angeglichen, um den Fehler 1 . Art zu dem Niveau $\alpha=0.025$ einzuhalten

\begin{tabular}{|c|c|c|c|c|}
\hline GF1 auf Grandio Voco A1 - A4 & 110 & 400 & 1200 & $\mathrm{HG}$ \\
\hline 110 & & 0.93 & 0.04 & $<0.001$ \\
\hline 400 & & & 0.01 & $<0.001$ \\
\hline 1200 & & & & 0 \\
\hline $\mathrm{HG}$ & & & & \\
\hline
\end{tabular}

Der Paarvergleich der Zellviabilität der Zelllinie GF1 aufgetrennt nach Polierstufen ergab keine signifikanten Unterschiede (Tabelle 64). 
Tabelle 64: Paarvergleiche der Viabilität zwischen den Farben von Grandio Voco des Zelllinie GF1 aufgetrennt nach Polierstufen (p-Werte)

\begin{tabular}{|c|c|c|c|c|}
\hline GF1 auf Grandio Voco A1 - A4 & A1 & A2 & A3 & A4 \\
\hline A1 & & 0.12 & 0.24 & 1.00 \\
\hline A2 & & & 0.99 & 0.08 \\
\hline A3 & & & & 0.17 \\
\hline A4 & & & & \\
\hline
\end{tabular}

Die ANOVA von Amalgam stellte eine Signifikanz der Viabilität von GF1 zwischen den Polierstufen dar (Tabelle 65). Der darauffolgende Paarvergleich zeigt eine Signifikanz zwischen den Polierstufen 1200 - 110, 1200 - 400, HG- 400 und HG-1200 (Tabelle 66).

Tabelle 65: One-Way-ANOVA für die Viabilität der Zelllinie GF1 mit dem Faktor Polierstufen Amalgam

\begin{tabular}{|l|l|}
\hline GF1 auf Amalgam & Pr $>$ F \\
\hline Polierstufe & $<\mathbf{0 . 0 0 1}$ \\
\hline
\end{tabular}

Tabelle 66: Paarvergleiche zwischen allen Polierstufen der Viabilität der Zelllinie GF1 auf Amalgam (p-Werte)

\begin{tabular}{|c|c|c|c|c|}
\hline GF1 auf Amalgam & 110 & 400 & 1200 & $\mathrm{HG}$ \\
\hline 110 & & 0.08 & $<0.001$ & 0.9 \\
\hline 400 & & & 0.01 & 0.01 \\
\hline 1200 & & & & $<0.001$ \\
\hline $\mathrm{HG}$ & & & & \\
\hline
\end{tabular}

Die Two-Way-ANOVA für die Viabilität der Zelllinie L929 zeigte in Polierstufe, Farbe/Material und Polierstufe zu Farbe/Material eine Signifikanz (Tabelle 67).

Tabelle 67: Two-Way-ANOVA für die Viabilität der Zelllinie L929 mit den Faktoren Polierstufen und Farbe/Material zu dem Niveau $\alpha=0.05$

\begin{tabular}{|l|c|}
\hline L929 auf allen Farben/Materialien & Pr $>$ F. \\
\hline Polierstufe & $<\mathbf{0 . 0 0 1}$ \\
\hline Farbe/Material & $<\mathbf{0 . 0 0 1}$ \\
\hline Polierstufe: Farbe/Material & $<\mathbf{0 . 0 0 1}$ \\
\hline
\end{tabular}

Bei der One-Way-ANOVA für die Viabilität der Zelllinie L929 mit dem Faktor Polierstufen auf Grandio Voco A1 - A4 zeigte sich ein hervorstechender Unterschied bei den Polierstufen (Tabelle 68). 
Tabelle 68: One-Way-ANOVA für die Viabilität der Zelllinie L929 mit dem Faktor Polierstufen auf Grandio Voco zu dem Niveau $\alpha=0.05 / 2=0.025$

\begin{tabular}{|l|l|}
\hline L929 auf Grandio Voco A1 - A4 & Pr> F. \\
\hline Polierstufe & $\mathbf{< 0 . 0 0 1}$ \\
\hline Farbe & 0.284 \\
\hline Polierstufe: Farbe/Material & 0.969 \\
\hline
\end{tabular}

Bei den folgenden Paarvergleichen von Grandio Voco zeigte sich eine Signifikanz zwischen HG - 110, HG - 400 und HG - 1200. Keine Unterschiede zeigten sich bei $400-110$, 1200 - 110 und 1200 - 400 (Tabelle 69).

Tabelle 69: Paarvergleiche zwischen allen Polierstufen der Viabilität der Zelllinie L929 auf Grandio Voco (die pWerte wurden mit der Tukey-Methode angeglichen, um den Fehler 1 . Art $\alpha=0.025$ einzuhalten)

\begin{tabular}{|c|c|c|c|}
\hline L929 auf Grandio Voco A1 - A4 & 400 & 1200 & $\mathrm{HG}$ \\
\hline 110 & 1 & 0.9 & 0 \\
\hline 400 & & 0.84 & 0 \\
\hline 1200 & & & $<0.001$ \\
\hline $\mathrm{HG}$ & & & \\
\hline
\end{tabular}

Die One-Way-ANOVA für die Viabilität der Zelllinie L929 mit dem Faktor Polierstufen auf Amalgam zeigt eine Signifikanz zwischen den Polierstufen (Tabelle 70). Bei den folgenden Paarvergleichen stellte sich der Unterschied zwischen 1200 - 400 und HG - 400 als signifikant dar (Tabelle 71).

Tabelle 70: One-Way-ANOVA für die Viabilität der Zelllinie L929 mit dem Faktor Polierstufen auf AG zu dem Niveau $\alpha=0.05 / 2=0.025$

\begin{tabular}{|l|l|}
\hline L929 auf Amalgam & Pr $>$ F. \\
\hline Polierstufe & $\mathbf{0 . 0 0 3}$ \\
\hline
\end{tabular}

Tabelle 71: Paarvergleiche zwischen allen Polierstufen der Viabilität der Zelllinie L929 auf Amalgam (p-Werte)

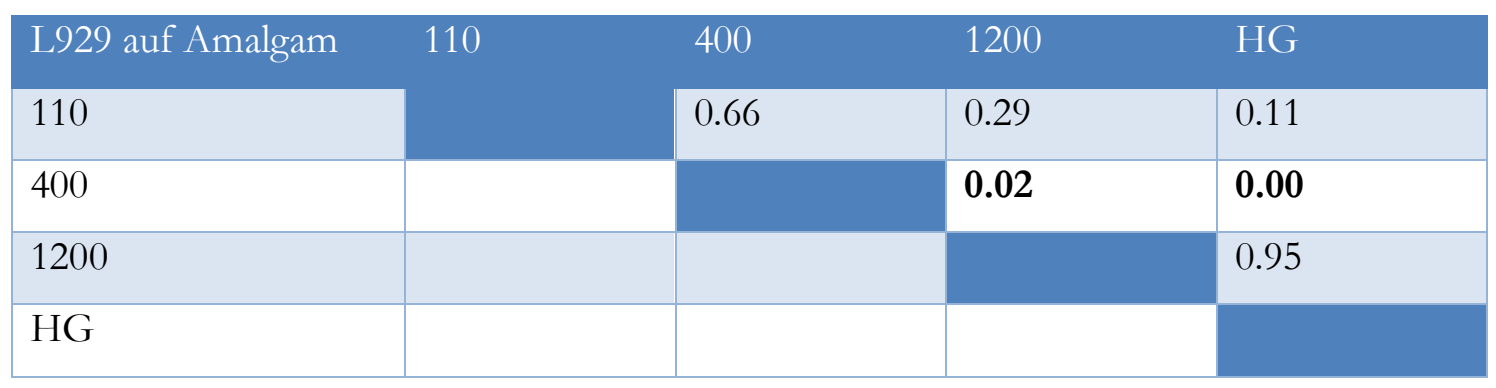




\subsubsection{Zusammenfassung der Ergebnisse}

Die $\mathrm{R}_{\mathrm{a}}$-Messwerte zeigten, dass sich das Polieren unterschiedlich auf die Testmaterialien auswirkte. Bei den Farben A1 und A2 unterscheiden sich alle Polierstufen, und es ist ein positiver Verlauf für $\mathrm{R}_{\mathrm{a}}$ von HG über $1200 \mathrm{zu} 400$ bis zu 110 zu erkennen. Dieser Korrelation fiel bei dem Material A1 am deutlichsten aus. Ein entsprechender Verlauf ist bei A3, A4 und AG auch zu erkennen, wobei die Polierstufen 1200 und HG kaum zu unterscheiden sind. Die Messungen der freien Energie der Oberfläche waren nicht so einheitlich wie die Messungen der arithmetischen Rauheit. Erkennbar waren die höheren Messwerte für die polare Komponente und die niedrigeren Messwerte für die disperse Komponente des Amalgams gegenüber Grandio Voco A1 - A4.

Bei den Zytotoxizitätsmessungen zeigten sich signifikante Unterschiede des zytotoxischen Potenzials der verschiedenen Polierstufen. Dabei ist auffällig, dass bei zehn Unterschieden der Zytotoxizität von GF1 zwischen den einzelnen Polierformen immer die Körnung 1200 involviert ist. Auch beim Amalgam waren die Vergleiche mit Körnung 1200 die Paarvergleiche, die sich als signifikant herausstellten. Bei der Zelllinie L929 gab es nur vier signifikante Unterschiede bei Grandio Voco. Diese bezogen sich bei drei bedeutenden Unterschieden auch auf die Polierstufe der Körnung 1200. Bei den Paarvergleichen von der Zelllinie L929 zwischen allen Polierstufen auf Grandio Voco A1 - A4 stellte sich eine Signifikanz bei der Polierstufe 1200 und den Farben A4 zu A1 und A4 zu A2 dar. Auch beim Amalgam gab es einen signifikanten Wert beim Paarvergleich und zwar zwischen den Polierstufen 1200 - 400. Viabilitätsmessungen der Zellline GF1 zeigten zwischen den Polierstufen von Grandio Voco vier signifikante Unterschiede, bei denen auffällig ist, dass bei drei Unterschieden die Hochglanzpolitur eine Rolle spielt. Der Paarvergleich aufgetrennt nach Polierstufen auf Grandio Voco ergab keine signifikanten Unterschiede. Die Viabilität von GF1 auf Amalgam zeigte beim Paarvergleich zwischen den Polierstufen viermal eine Relevanz, wobei hier die Polierstufe mit der Körnung 1200 dreimal inbegriffen ist.

Bei der Untersuchung der Messergebnisse für die Viabilität der Zelllinie L929 zeigten sich bei dem Paarvergleich zwischen den Polierstufen auf Grandio Voco A1-A4 drei bedeutende Unterschiede, an denen immer die Hochglanzpolitur beteiligt war. Die Paarvergleiche auf Amalgam zeigten zwei Signifikanzen, wobei immer die Polierstufe der Körnung 400 beteiligt war. 


\section{DISKUSSION}

\subsection{Diskussion der Methoden}

In der vorliegenden Arbeit sollte untersucht werden, ob und inwieweit sich geringfügige Differenzen in der Zusammensetzung von dentalen Kompositen auf die physiko-chemischen Oberflächencharakteristika und auf die Zellviabilität anhaftender Maus- und humaner Gingivafibroblasten auswirken. Um sich nicht zu sehr von der klinischen Realität zu entfernen, wurden verschiedenfarbige Füllungskomposite als Testmaterialien verwendet, die sich nur minimal in der Zusammensetzung im Hinblick auf Farbpigmente unterscheiden. Im Rahmen der Untersuchung sollte also auch geklärt werden, ob handelsübliche Farbmischungen unterschiedliche Wirkungen auf die umliegenden biotischen Gewebe haben können und ob damit bestimmte Farbmischungen bei entsprechenden Indikationen bevorzugt werden sollten, z. B. als Unterfüllung im ästhetisch nicht relevanten Bereich, aber im Kontakt zur Gingiva.

Beimischungen für die Farbgebung resultieren in geringen Unterschieden in der Zusammensetzung der vier untersuchten Komposittestmaterialien (Grandio Voco, A1, A2, A3 und A4). Als Vergleichsmaterial wurde zusätzlich Amalgam verwendet, weil es über Jahrzehnte der Gold-Standard in der direkten Füllungstherapie war und aufgrund seiner vermeintlichen zytotoxischen Eigenschaften durch Alternativmaterialien wie Komposite ersetzt wurde. Es gibt bereits verschiedene experimentelle Modelle, um zellbasierte Untersuchungen zur Zytotoxizität von Biomaterialien durchzuführen. Dabei werden grundsätzlich In-vivo-Untersuchungen und In-vitro-Untersuchungen unterschieden. In-vivo-Modelle sind realitätsnah, unterliegen aber auch multiplen Einflussvariablen und Störfaktoren, wie z. B. interindividuellen Unterschieden bei den Testpersonen durch abweichende orale Mikrobiome oder abweichende Speichelmenge und -zusammensetzung, unterschiedliche Nahrungsaufnahme oder variierenden Mundhygienemaßnahmen (Lebeaux et al. 2013; Bürgers et al. 2010b; Papavasileiou et al. 2015). Bei In-vitro-Modellen lassen sich diese Parameter kontrollieren und wirtsspezifische Störfaktoren ausschalten, es herrschen deshalb standardisierte und reproduzierbare Bedingungen (Coenye and Nelis 2010; Bürgers et al. 2010a; Bürgers et al. 2009b). Die Übertragbarkeit von gewonnenen In-vitro-Erkenntnissen auf die entsprechende In-vivo-Situation ist mit spezifischen Einschränkungen trotzdem möglich, weil grundsätzliche Tendenzen so relativ suffizient erfasst werden können (Syrjänen et al. 1985; Souza et al. 2006). Damit ein möglicher Effekt von unterschiedlichen Farbzusätzen bei dentalen Kunststoff- 
füllmaterialien sichtbar wird, wurden in der vorliegenden Studie vier unterschiedliche Farbvarianten eines handelsüblichen Füllungskomposits eingesetzt. Dabei wurde jede In-vitroMessreihe insgesamt dreimal durchgeführt, um die Reproduzierbarkeit der Ergebnisse zu gewährleisten.

Durch das Medizinproduktegesetz (MPG) sind Sicherheit, Qualitätssicherung und Feststellung der Unbedenklichkeit von medizinischen Produkten geregelt, dies betrifft auch dentale Füllungskompositen. Das MPG gibt aber auch vor, dass nicht alle Inhaltsstoffe von Medizinprodukten in den entsprechenden Sicherheitsdatenblättern aufgelistet sein müssen. Die Angaben zu Farbpigmenten und deren Beimengungen sind bei allen gängigen Herstellern knapp und nicht umfassend, weil die Mischungsrezepte Betriebsgeheimnisse sind, die den Hersteller vor Nachahmung durch Konkurrenten schützen sollen. Deswegen konnten im Rahmen der vorliegenden Untersuchung etwaige Unterschiede in der Zytotoxizität nicht auf spezifische Mischungsbestandteile zurückgeführt werden. Im Allgemeinen handelt es sich aber um anorganische Pigmente wie Titan-, Eisen- oder Aluminiumdioxid (Rosentritt et al. 2018).

Nach dem Deutsches Institut für Normung (2009), welches biologische Prüfungen von Medizinprodukten auf Zytotoxizität normiert, gilt ein Stoff als zytotoxisch, wenn im Rahmen einer Untersuchung weniger als $70 \%$ der Zellen mit Kontakt zum Werkstoff vital verbleiben. Für den klinischen Anwender ist es aber bisher unmöglich, genaue Aussagen über die Zytotoxizität vom Hersteller oder durch Sicherheitsdatenblätter in Erfahrung zu bringen.

\subsubsection{Testmaterialien, Positiv- und Negativkontrollen}

Für die Untersuchung wurde der Füllungskunstoff Grandio der Firma Voco in den Farben A1, A2. A3 und A4 und Amalgam der Firma Pluradent verwendet. Es handelt sich bei den verschiedenfarbigen Kompositen um typische und handelsübliche Materialien. Beide Materialgruppen, die Komposite und Amalgam gehören zu den direkten Füllungsmaterialien und finden breite Anwendung in der Therapie von kleineren Kavitäten (Mjör und Jokstad 1993; Alptekin et al. 2010; Opdam et al. 2010; Alhareky und Tavares 2016). Ausgewählt wurde die Materialgruppe der Füllungskomposite, weil sie häufig in der klinischen Anwendung im direkten Kontakt zu den zahnumgebenden Weichgeweben stehen. Das verwendete Komposit Grandio ist als Testmaterial geeignet, weil es in Zusammensetzung und Farbvarianten den zurzeit verfügbaren Kompositmaterialien entspricht, mögliche Schlussfolgerungen können mit geringen Einschränkungen auf ähnliche Produkte übertragen werden. Komposite werden für ästhetisch relevante Bereiche in verschiedenen Farbvarianten angewendet und sind 
auch heute noch ein Alternativwerkstoff zum Amalgam, das eine breite Indikation vor allem im Seitenzahngebiet hatte (Dunne et al. 1997; Opdam et al. 2007; Moraschini et al. 2015). Amalgam verschwindet aufgrund seiner vermeintlich toxischen Eigenschaften zunehmend vom Markt und eignet sich deshalb bei der Einordnung von Zytotoxizitäten hervorragend als Vergleichsmaterial für die marktdominanten „modernen“ bzw. vermeintlich „biokompatibleren" Füllungskomposite. Sowohl die Komposite als auch das Amalgam wurden streng nach Herstellerangaben eingesetzt. Durch das korrekte Verarbeiten nach Herstellerangaben konnte der negative Einfluss von reduzierten Materialeigenschaften und der Anteil von zytoxischen Restmonomeren auf den Versuchsaufbau signifikant reduziert werden(Schedle et al. 1998; Kedjarune et al. 1999).

Die Herstellung und Verwendung von Probekörpern unterschiedlicher Größe war aufgrund der verschiedenen Versuchsanordnungen notwendig, wobei sich unterschiedlich große Probekörper in ihrer relativen Zytotoxizität nicht unterscheiden. Die Kontaktwinkelmessung erfolgte an Probekörpern mit $10 \mathrm{~mm}$ Durchmesser, da das Auftropfen von Deionat und Methyleniodid aus parallel angeordneten Öffnungen erfolgt. Methyleniodid ist bekanntermaBen zytotoxisch und deshalb wurden die einmal verwendeten Probekörper alle verworfen, da es auf die Zelllinien eine zytotoxische Wirkung gehabt hätte (Smola 2018). Für ein besseres Handling und zur Reduktion der Mengen der Versuchsmaterialien wurden für den Hauptversuch Probekörper mit 6 mm Durchmesser in 48-Well-Platten eingesetzt. Zur Untersuchung der Effekte der physiko-chemischen Oberflächencharakteristika von Kompositen auf Zelllinien war eine konstante Größe, d. h. Höhe und Durchmesser der Probekörper wichtig.

Die verwendeten Probekörper und klinisch (in situ) verarbeitete Komposite unterscheiden sich in ihren physiko-chemischen Oberflächencharakteristika. Direkte Kompositrestaurationen werden im Mund des Patienten polymerisiert, bearbeitet und poliert. Die Rauheit und Strukturierung der Oberflächen hängen dabei von vielen - nicht reproduzierbaren - Faktoren ab. Das klinische Ergebnis bezogen auf die messbaren physiko-chemischen Eigenschaften ändert sich durch Lokalisation der Füllung, Geschick und Erfahrung des Behandlers und Störfaktoren wie Speichelzutritt während der Polymerisation (Ozgünaltay et al. 2003; Bashetty and Joshi 2010; Berger et al. 2011; Chour et al. 2016). Durch eine vollautomatische Schleif- und Poliermaschine mit vorgegebenen Bearbeitungszeiten und konstantem Anpressdruck werden absolut konstante und reproduzierbare Oberflächen erzielt. Zuerst wurden alle Probekörper auf Hochglanz poliert und dann die abschließenden Rauheiten eingestellt, um eine definierte gleichmäßige Oberfläche zu erhalten. Durch die manuelle Bearbeitung von 
Probekörpern dagegen ist eine unterschiedliche Güte der Oberfläche nicht auszuschließen (Jung et al. 2007). Unterschiedliche Zytotoxizitäten könnten dann auch lediglich auf abweichenden Rauheiten oder Hydrophobizitäten basieren. Der geringfügig unterschiedliche Anpressdruck der 10-mm-zu den 6-mm-Probekörpern ist dabei zu vernachlässigen, da er durch die Anzahl der auf den Halter aufgebrachten Menge kompensiert wurde. Es wurden auf einem Halter entweder fünf 10-mm- oder zwölf 6-mm-Probekörper fixiert. Daraus resultiert eine Probekörperfläche von $392 \mathrm{~mm}^{2}$ für 10-mm- und $339 \mathrm{~mm}^{2}$ für 6-mm-Probekörper je Halter.

Als Negativkontrolle wurde Glas eingesetzt, welches industriell gefertigt und nicht weiterbearbeitet wurde. Glasprobekörper haben keinen stimulierenden oder wachstumshemmenden Effekt auf diverse Zelllinien, ebenfalls verhalten sie sich in Untersuchungen zur Zytotoxizität neutral (Schmid-Schwap et al. 2009; Gosau et al. 2016; Viden 2018). Als Positivkontrolle wurde Latex $(5 \times 5 \mathrm{~mm})$ eingesetzt, welches sich nachweislich negativ auf die Zelllinien auswirkt (Stellet Lourenço et al. 2014).

\subsubsection{Herstellung und Konditionierung der Probekörper}

Das Herstellungsverfahren von Probekörpern mittels Silikon-Dublierformen wird standardmäßig von vielen Arbeitsgruppen für die Herstellung von Kompositprobekörpern eingesetzt (Prudil 2010; Johanning 2018). Dadurch konnten die Probekörper in gleicher Stärke und Durchmesser erstellt werden. Alle Probekörper wurden exakt nach Herstellerangaben verarbeitetet und polymerisiert. Durch die anschließenden Schleif- und Polierprozesse wurde die Sauerstoffinhibitionsschicht komplett entfernt, welche aufgrund der enthaltenden nicht-polymerisierten Restmonomere zytotoxisch wirkt. Der Polierprozess erfolgte standardisiert, um eine gute Vergleichbarkeit der unterschiedlichen Testmaterialien und Einzelprobekörper zu ermöglichen. Um die Probekörper zu desinfizieren und mögliche Bakterienkontamination zu verhindern, wurden sie in 70 \% igem Ethanol gewaschen. Die Probekörper wurden zusätzlich in der Sterilbank und unter Vakuum hergestellt, um eine vorzeitige Bakterienbesiedelung auszuschließen. Laut dem Deutschen Institut für Normung (2009) ist eine Sterilisation vorgesehen, welche aber bei der vorliegenden Studie nicht zweckmäßig erschien. Durch eine Heißsterilisation hätten sich die Komposite in ihrer Form und auch in den Zytotoxizitätswerten verändert. Die Sterilisation mit ultraviolettem Licht kam nicht in Frage, da auch hier die Zytotoxizitätswerte des lichthärtenden Komposits hätten beeinflusst werden können. In der Arbeit wurden minimale Unterschiede in der Zusammensetzung bei möglichst 
konstanten Oberflächen untersucht, deswegen sollten solche potentielle Einflussfaktoren vermieden werden.

\subsubsection{Auswahl der Zellkulturen}

Die Hauptvorteile der In-vitro-Bedingungen mit einzelnen Zelllinien sind - ohne Wertung durch die Reihenfolge - eine reproduzierbare standardisierte Durchführbarkeit und der Ausschluss ethischer Fragestellungen beim Einsatz von Versuchstieren oder Probanden. Die L929 Mausfibroblasten sind der Klon 929 von Stamm L, der vor 75 Jahren von einer männlichen $\mathrm{C} 3 \mathrm{H} /$ An-Maus abgeleitet wurde (Earle et al. 1943). Die Zellen wachsen adhärent und werden zur Testung von Zytotoxizitäten herangezogen und empfohlen (Deutsches Institut für Normung 2009). Diese Zelllinie wurde schon in mehreren Studien zur Zytotoxizitätsbewertung von dentalen Kunststoffen verwendet (Schweikl und Schmalz 1996; Kostoryz et al. 1999; Kaga et al. 2001; Thonemann et al. 2002; Malkoc et al. 2010; Bal et al. 2011; Ashraf et al. 2012; Heravi et al. 2013). Da diese Fibroblasten aber weder aus dem oralen Bereich kommen noch dem eigentlich zu testenden Organismus angehören, wurde die humane Zelllinie GF1 hinzugefügt. Die Zelllinie GF1 der AG Orale Biologie und Geweberegeneration der Abteilung für Zahnärztliche Prothetik der Universitätsmedizin Göttingen sind Fibroblasten der humanen Gingiva, und sie passten so genau auf das Anforderungsprofil für die Studie (Schubert et al. 2018). Von anderen Arbeitsgruppen werden für eine Reihe von ähnlichen Fragestellungen auch humane Gingivafibroblasten verwendet (Tipton and Dabbous 1995; Key et al. 2006; Asgary et al. 2012).

\subsubsection{Mess- und Testmethoden}

Die Messung der Oberflächentopographie und Rauheit von abiotischen Oberflächen kann mit unterschiedlichen Methoden durchgeführt werden. Es ist möglich, die Oberfläche mechanisch abzutasten oder auch optisch zu erfassen (Duparre et al. 2002; Canabarro et al. 2009; Koch et al. 2013; Hahnel et al. 2010b; Bürgers et al. 2009a; Hahnel et al. 2009b; GünayBulutsuz et al. 2018). Die zweidimensionale Darstellung kann mit Hilfe der 2D-Profilometrie erfolgen, und zwar durch das Abtasten einer vorher definierten Strecke der Oberfläche. Dabei wird nur ein bestimmter Ausschnitt der Oberfläche untersucht. Der arithmetische Mittenrauwert $\left(\mathrm{R}_{\mathrm{a}}\right)$ wird als darstellender Parameter der Rauheit in der Literatur angegeben (Kocher et al. 2002; Hosoya et al. 2003; Vrochari et al. 2017; Ruschel et al. 2018). Um biologische 
Prozesse zu bewerten, ist die dreidimensionale Bildgebung besser geeignet, da man nicht in die Prozesse eingreifen muss, z. B. durch Ablösen von adhärenten Zellen (Stäubert 2018). Weitfeld-Konfokalmikroskope, wie das hier verwendete Smartproof 5, können durch Aufnahmen in mehreren Ebenen eine dreidimensionale Oberfläche darstellen und die Oberflächenparameter berechnen (Haus 2014; Borlinghaus 2016). Die Messgenauigkeiten zwischen dem mechanischen und optischen Verfahren unterscheiden sich kaum, die optische Variante hat die Vorteile, die Oberfläche dreidimensional darstellen zu können und schnell alle Oberflächenparameter erfassen zu können (Gyurkovics et al. 2017). Die Weitfeld-Konfokalmikroskopie war für die vorliegende Studie gut geeignet, da sie schnell und in einer guten Detailschärfe alle Oberflächenparameter errechnet und die Oberflächenmorphologie dreidimensional darstellen kann.

Die Kontaktwinkelmessung ist eine oft angewandte Untersuchung bei der Ermittlung der freien Energie der Oberfläche (Busscher et al. 1984; Bürgers et al. 2009a; Hahnel et al. 2009a; Winkler et al. 2014). Um die freie Oberflächenenergie zu ermitteln, werden auf einen Festkörper mindestens zwei Flüssigkeiten mit komplementären Eigenschaften getropft, meist Wasser (polare Eigenschaften) und Methyleniodid (unpolare Eigenschaften). Es kann bei andersgearteten Formen des gleichen Testmaterials oder bei der Position der aufgetropften Flüssigkeiten zu unterschiedlichen Messergebnissen kommen (Chibowski und Perea-Carpio 2002). Schon die Oberflächenverunreinigungen mit kleinsten Staubkörnern reicht aus, um divergierende Messergebnisse zu erhalten (Yuan und Lee 2013). Weiterhin kann die Bewegung der Tropfen beim Aufbringen auf das Testmaterial zu verschiedenen Messergebnissen führen (Lam et al. 2002; Korhonen et al. 2013). Der Kontaktwinkel wird mit Hilfe der Young'schen Gleichung ermittelt, welche den Kontaktwinkel bei idealen Verhältnissen angibt, d. h. die Gleichung beschreibt eine reine Flüssigkeit, welche auf einen chemisch und topographisch gleichartigen Körper appliziert wird und von einer homogenen Gasphase umgeben ist. Alle Probekörper sind dagegen reale Feststoffe, und damit unterliegt der Kontaktwinkel einer zeitlichen und örtlichen Veränderung (Starov et al. 2003; Farris et al. 2011). Um diesem Effekt Rechnung zu tragen, wurden bei dieser Studie nach dem Auftragen der Flüssigkeit im Abstand von jeweils einer Sekunde mehrere Messungen anhand eines Livebildes durchgeführt, und aus den gewonnenen Messergebnissen wurde ein Mittelwert sowohl für die freie Energie der Oberfläche als auch für den Kontaktwinkel berechnet (Girault et al. 1984; Lin et al. 1996). Diese Methodik scheint die annähernd korrekte freie Energie der Oberfläche darzustellen und hat sich daher als reproduzierbar, präzise und anwenderfreundlich etabliert (Uyama et al. 1991; Yuan und Lee 2013). 
Für den durchgeführten Versuch ist WST-8 geeignet, da der Test selbst nicht zytotoxisch auf Zellen wirkt (Schmitz 2011), XT'T und MT'T werden vom Deutschen Institut für Normung zur Zytotoxizitätsmessung vorgeschlagen (Deutsches Institut für Normung 2009). Die meisten aktuellen Studien zur Zytotoxizitätsuntersuchung von dentalen Materialien verwenden MTT (Jan et al. 2014; Goiato et al. 2015; Madhyastha et al. 2015; Shin et al. 2016; Milheiro et al. 2016). Der WST-8-Test hat gegenüber dem MTT den entscheidenden Vorteil, dass das Formazan außerhalb der Zelle lokalisiert und wasserlöslich ist und deshalb keine Zerstörung der Zellen notwendig wird (Gstraunthaler und Lindl 2013). Ein weiterer Vorteil für diese Studie ist auch die Tatsache, dass der WST-8 gegenüber anderen Methoden bedeutend sensitiver ist, weil die Zellviabilität gemessen wird (Tominaga et al. 1999; Ginouves et al. 2014). Der Test ist zudem einfach durchführbar und zeigt schnell verfügbare Ergebnisse, wodurch es möglich war, den hohen Probendurchsatz dieser Studie in angemessener Zeit zu bewältigen.

Die Zytotoxizität wurde mit einem LDH-basierten Test gemessen. Dabei wird Resazurin verwendet, welches als ein Redoxindikator in die Zelle eindringt und im Zellinneren zu Resorufin reduziert wird (Rodríguez-Corrales and Josan 2017; Präbst et al. 2017). Die Handhabung und Auswertung ist sehr anwenderfreundlich, man gibt das tiefblaue Resazurin zu den Zellkulturen und nur metabolisch aktive Zellen können das Resazurin zu rosa Resorufin reduzieren (Riss et al. 2011). Durch den entsprechenden Farbumschlag im Photometer konnten sehr schnell und einfach die zytotoxischen Effekte der Testmaterialien bestimmt werden.

\subsection{Diskussion der Ergebnisse}

\subsubsection{Rauheit}

Die verschiedenen Polierstufen hatten unterschiedliche starke Auswirkungen auf die Rauheit der verschiedenen Testmaterialien von Grandio Voco und das Amalgam. Die erwartete Korrelation zwischen den sukzessiven Polierstufen und den daraus resultierenden abnehmenden Mittenrauheitswerten zeigte sich am deutlichsten bei der Farbe A1. Bei der Farbe A2 ist diese Tendenz auch zu erkennen, bei den Farben A3, A4 und AG sind die Unterschiede zwischen den Polierstufen 1200 und HG geringer. Die leicht abweichende Wirkung der unterschiedlichen Polierstufen auf die Testmaterialien begründet sich wahrscheinlich in abweichenden Füllkörpern und/oder Pigmenten bei den verwendeten Kompositen (der Farbe A3 und A4). 
Makroskopische Oberflächendefekte, wie z. B. Kratzer und Mulden, welche zu Verfälschungen der Messergebnisse hätten führen können, wurden durch visuelle Inspektion ausgeschlossen. Die Vermeidung von Defekten ist auf die standardisierte Oberflächenbearbeitung zurückzuführen. Die Literaturrecherche zeigte, dass die Oberflächenrauheit von Kompositen abhängig vom benutzten Poliersystem ist (Berastegui et al. 1992; Baseren 2004; Abzal et al. 2016).

Die Rauheit und Topographie von dentalen Kompositen beeinflussen adhärente humane Gingivafibroblasten (Trubiani et al. 2012). In der genannten Studie zeigte sich bei raueren Oberflächen im Gegensatz zu einer hochglanzpolierten Oberfläche eine Verringerung der Zellviabilität. Dies konnte in der vorliegenden Untersuchung nicht bestätigt werden, da die Viabilität der Gingivafibroblasten auf der Polierstufe 400 höher war als auf der HochglanzPolierstufe. Die höhere Zellviabilität auf strukturierteren Substraten zeigte sich auch bei der Untersuchung von Brunette (1986), bei der sich Gingivafibroblasten bevorzugt im Verlauf von vorhandenen Rillen anlagerten.

\subsubsection{Freie Oberflächenenergie}

Bei der freien Oberflächenenergie gab es nur bei A1 einen signifikanten Unterschied zwischen den Polierstufen 110 und 1200 sowie 400 und 1200. Weiterhin waren die niedrigeren Messungen der disperseren Komponente der Oberflächenenergien und dementsprechend höheren Messungen der polaren Komponente des Amalgams gegenüber der Materialien Grandio Voco A1-A4 auffällig.

Nach der Methode von Owens, Wendt, Kaelble und Rabel wird die freie Energie der Oberfläche von einem Festkörper aus dem Kontaktwinkel mit unterschiedlichen Flüssigkeiten errechnet. Dabei wird die freie Oberflächenenergie in zwei Anteile aufgeteilt, den polaren und dispersen Anteil. Nach diesem Modell hängt die Grenzflächenspannung zwischen den Flüssigkeiten und der Probe davon ab, ob der Probekörper entsprechende disperse oder polare Anteile besitzt und damit Wechselwirkungen mit der entsprechenden Flüssigkeit ausgebildet werden (Owens und Wendt 1969; Kaelble 1970; Rabel 1971). Dies erklärt auch die unterschiedlichen Messungen bei Amalgam und Komposit, da die beiden Materialien zu völlig verschiedenen Stoffklassen gehören. Komposite sind zusammengesetzt aus einer organischen Matrix und anorganischen Füllstoffen (Janda 2008a, 2008b, 2008c; Ilie et al. 2007). Amalgame wiederum bestehen aus verschiedenen Metallen und ist damit eine Zusammen- 
führung aus mehreren anorganischen Stoffen (Richardson et al. 2011; Miler 2017). Eine abweichende Wirkung von unterschiedlichen Oberflächenenergien auf die Zellviabilität von adhärenten Zellen ist allerdings nur bei extrem unterschiedlichen Oberflächenenergien zu erwarten, weil die Effekte - ähnlich der Wirkung auf Biofilme - durch stärkere Parameter wie Rauheit und Topographie maskiert werden.

\subsubsection{Korrelation von Rauheit und freier Oberflächenenergie}

Die Untersuchungen der Materialien bzw. Farben zeigte eine hohe negative Korrelation zwischen der polaren Komponente und der dispersen Komponente. Zwischen der dispersen Komponente und $\mathrm{R}_{\mathrm{a}}$ bestand eine deutliche negative Korrelation. Dabei ist zu bedenken, dass die Berechnung der freien Energie der Oberfläche durch die Young'sche Gleichung erfolgte. Die Gleichung beschreibt die Beziehung einer reinen Flüssigkeit mit einem chemisch homogenen und glatten Probekörper. Dieser Körper muss von einer gleichförmigen Gasphase umgeben sein. Die getesteten Probekörper wiederum sind reale Feststoffe und damit unterliegt der Kontaktwinkel einem zeitlichen und örtlichen Wandel.

Der wechselseitige Einfluss von Rauheit und Hydrophobizität ist in der Literatur nachvollziehbar beschrieben, wobei sich aufgrund der abweichenden chemischen Zusammensetzung von Testsubstraten keine allgemeingültigen physikalischen Gesetzmäßigkeiten ableiten lassen (Crawford et al. 2012; Webb et al. 2012; Lafuma und Quéré 2003). Ziel der Untersuchung war es also, möglichst konstante Oberflächenrauheiten und -energien zu produzieren, um dann mögliche Unterschiede in der Zytotoxizität alleine mit abweichenden Mischungen zu begründen. Die unterschiedlichen Rauheiten haben grundsätzlich Einfluss auf die freie Energie der Oberfläche, dürfen aber nicht mehr mit der chemischen Zusammensetzung des Probekörpers korreliert werden. Trotzdem bestätigt das Ergebnis durch die Auswertung nach Owens, Wendt, Kaelble und Rabel die unterschiedlichen polaren und dispersen Wechselwirkungen einer rauen mit einer glatten Oberfläche (Fowkes 1964; Kaelble 1970; Rabel 1971; Owens und Wendt 1969). 


\subsubsection{Zytotoxizität und Zellviabilität}

Die Zytotoxizitätsmessungen der Zelllinie GF1 zeigten signifikante Unterschiede bei der Polierstufe 1200 zwischen den untersuchten Testmaterialien. Auch bei der Zelllinie L929 gab es signifikante Unterschiede, wobei die Polierstufe der Körnung 1200 häufig vertreten war. Bei den Paarvergleichen von der Zelllinie L929 zwischen allen Polierstufen auf Grandio Voco A1 - A4 stellte sich eine Signifikanz bei der Polierstufe 1200 bei den Farben A4 zu A1 und A4 zu A2 dar. Bei den Messwerten fiel auf, dass deren Streuung bei der Polierstufe 1200 besonders ausgeprägt war und deshalb die Bereiche der anderen Polierstufen überlappten. Auch beim Amalgam gab es einen signifikanten Wert (d. h. Unterschied) beim Paarvergleich, und zwar zwischen den Polierstufen 1200 - 400. Des Weiteren ließ sich beobachten, dass die Zytotoxizität von Amalgam höher war als die von den Kompositen, was sich besonders deutlich bei der Zelllinie L929 zeigte. Dass Zellen hinsichtlich ihrer Vitalität unterschiedlich auf spezifische Komposite reagieren, zeigten schon Geurtsen et al. (1998). Die zytotoxischen Potenziale der verschiedenen Komposite der einzelnen Farben unterscheiden sich in den einzelnen Polierstufen kaum, und die Werte sind den Werten auf Glas sehr ähnlich. Amalgam wiederum war signifikant zytotoxischer als die Komposite und Glas. Die unterschiedlichen Farben hatten keinen Einfluss auf das zytotoxische Potenzial der getesteten Komposite, die chemischen Unterschiede durch die verschiedene Zusammensetzung und Konzentration von Pigmenten scheint keinen Einfluss auf die zytotoxische Wirkung der Materialien zu haben. In einer nachfolgenden Studie könnte geklärt werden, in welcher Konzentration Farbpigmente die Zellviabilität beeinflussen, dafür müssten experimentelle Komposite erstellt werden. Aufgrund der unbekannten Rezeptur der Hersteller war eine entsprechende Untersuchung im Rahmen dieser Studie nicht möglich.

Rauere bzw. strukturierte Oberflächen können vereinfacht als gefaltete glatte Oberflächen angesehen werden (Bos et al. 1999; Boulangé-Petermann et al. 1997). Durch die Veränderung der Oberflächenmorphologie und der damit verbundenen Oberflächenvergrößerung bei den Kompositen wäre es denkbar, dass verschieden stark exponierte Restmonomere für die unterschiedlichen Zytotoxizitätswerte bei den verschiedenen Polierstufen verantwortlich sein könnten (Kedjarune et al. 1999). Nach Goldberg (2008) ist aufgrund der intensiven Bemühungen der Entwickler von Kompositen der Anteil an ungebundenen Monomeren in den letzten 10 Jahren verringert worden, aber das Problem ist noch nicht beseitigt. Bis jetzt gibt es praktisch keinen vollständigen Umsatz während der Polymerisation, aber trotzdem reagieren in der initialen Polymerisation die meisten der Monomere mit dem Polymernetzwerk, 
und die Menge an Restmonomeren beträgt weniger als ein Zehntel der verbleibenden Methacrylgruppen, die somit nicht mehr als 1,5-5\% ausmachen. Diese Restmonomere bestimmen dann maßgeblich das zytotoxische Potenzial des Komposits. Nach Stanislawski et al. (1999) beeinträchtigen die Ionen, welche an der Farbgebung des Füllungsmaterials beteiligt sind, die Biokompatibilität des Komposit, da sie an der Fenton-Reaktion beteiligt sind, die wiederum reaktive (d. h. zytotoxische) Sauerstoffspezies (ROS) produziert. Elemente wie $\mathrm{Cu}^{2+}, \mathrm{Al}^{3+}$ und $\mathrm{Fe}^{2+}$ können ebenfalls in toxischen Konzentrationen vorhanden sein. In der Studie wurde gezeigt, dass die zytotoxische Kaskade durch Metalle, wie Aluminium und Eisen, verstärkt wird. Die Menge dieser Additiva variiert in unterschiedlichen Kompositen und harzmodifizierten Glasionomerzementen. Diese Beobachtung konnte in der vorliegenden Studie nicht bestätigt werden, da sich zwischen den einzelnen Zahnfarben keine signifikanten Unterschiede hinsichtlich der Zytotoxizität zeigten.

Bei den Viabilitätsmessungen der Zellline GF1 zeigte der Paarvergleich zwischen den Polierstufen von Grandio Voco insgesamt nur vier signifikante Unterschiede. Auffällig war, dass bei drei der identifizierten Unterschiede die Hochglanzpolitur einen negativen Einfluss auf die Viabilität hatte. Bei der Untersuchung der Messergebnisse für die Viabilität der Zelllinie L929 ergaben sich bei den Paarvergleichen zwischen den Polierstufen auf Grandio Voco A1A4 drei signifikante Unterschiede, immer auf Probekörpern mit Hochglanzpolitur. Die Paarvergleiche auf Amalgam zeigten zwei Signifikanzen, wobei immer die Polierstufe der Körnung 400 auftrat. Trubiani et al. (2012) beschreiben, dass die Oberflächenrauheit von Kompositen einen Einfluss auf die Zellviabilität von humanen Gingivafibroblasten hat. In der Studie wird dargestellt, das rauere Oberflächen eine verminderte Viabilität der Fibroblasten zur Folge haben. Dies bestätigte sich in der vorliegenden Untersuchung nicht. Die GF1Zellen zeigten sogar eine höhere Viabilität auf den raueren Oberflächen. Aufgrund der unterschiedlichen Versuchsprotokolle lassen sich die Ergebnisse allerdings auch nicht ohne Einschränkungen vergleichen, weitere Untersuchungen zum Einfluss der Oberflächenmorphologie auf die Zytotoxizität von dentalen Substraten wären deshalb sinnvoll. Die Untersuchung von rauen Oberflächen könnte allgemein von wissenschaftlichem Interesse sein, da sich potentielle zytotoxische Effekte aufgrund der Oberflächenvergößerung multiplizieren. Biokompatible Oberflächen bieten Zellen mehr Oberfläche zum Adhärieren, wogegen zytotoxisch wirksame Substrate mehr Wirkoberfläche haben und die Zellviabilität zusätzlich sinken wird.

Weiterhin fiel auf, dass die Viabilitätswerte der L929 Mausfibroblasten geringer waren als die Messwerte der Gingivafibroblasten (Abbildung 28). Andere Studien haben ebenfalls gezeigt, dass die Zelllinie L929 deutlich empfindlicher reagiert als andere Zelllinien (Thonemann et 
al. 2002; Schendel et al. 1992; Kwon et al. 2014; Eldeniz et al. 2007). Dies kann als Bestätigung der erhaltenen Ergebnisse gewertet werden und umgekehrt.

\subsection{Schlussfolgerung}

Die angewandte Methodik bestätigte die Eignung der eingesetzten Nachweistechniken zur Evaluierung der Zytotoxizität von Füllungsmaterialien (Komposite und Amalgam) mit abweichenden physiko-chemischen Eigenschaften. Erwartungsgemäß wurden die Mittenrauheitswerte $\left(\mathrm{R}_{\mathrm{a}}\right)$ durch das sukzessive Polieren in abgestimmten Stufen reduziert, das im Rahmen der Arbeit etablierte Prozedere zur Politur lieferte hierbei reproduzierbare Werte. Des Weiteren lag erwartungsgemäß eine hohe negative Korrelation zwischen der polaren Komponente und der dispersen Komponente der freien Oberflächenenergie vor. Eine deutlich negative Korrelation bestand auch zwischen den getesteten physiko-chemischen Parametern Rauheit und Oberflächenenergie, nämlich zwischen $\mathrm{R}_{\mathrm{a}}$ und der dispersen Komponente der freien Energie der Oberfläche. Die In-vitro-Untersuchung an den Kompositen zeigte, dass sich unterschiedliche Rauheiten durchaus auf die Zytotoxizität von humanen Gingivafibroblasten und L929 Fibroblasten auswirken können. Die Gründe hierfür bleiben auch unter Berücksichtigung der relevanten Literatur spekulativ. Die Farben der Komposite und damit minimale Unterschiede in der chemischen Zusammensetzung hatten keinen Einfluss auf die Zellviabilität und Zytotoxizität der getesteten Zelllinien. 


\section{ZUSAMMENFASSUNG}

In der zahnärztlichen Praxis werden zur Restauration von kleinen Defekten der Zahnhartsubstanzen heute hauptsächlich Komposite eingesetzt. Aufgrund der zahnähnlichen Farben und der besseren Biokompatibilität verdrängen diese den ehemaligen GoldStandard, die Amalgame, immer weiter. Dabei werden auch Füllungen im Zahnhalsbereich gelegt, wobei die verwendeten Materialien auch mit oralen Weichgeweben in Kontakt kommen. Im Rahmen dieser Studie sollte geklärt werden, ob und inwieweit minimale Unterschiede in der Zusammensetzung von Kompositen (durch abweichende Zusammensetzung und Konzentration von Farbpigmenten) das zytotoxische Potenzial der Testmaterialien beeinflussen können. Zusätzlich sollte bei jedem der Testmaterialien der Einfluss von physikochemischen Eigenschaften (Rauheit und Oberflächenenergie bzw. Hydrophobizität) auf die Zytotoxizität untersucht werden. Hierfür wurden vier unterschiedliche Farben eines konventionellen dentalen Füllungskunststoffes und Amalgam als Vergleichsmaterial begründet ausgewählt und untersucht.

Von den Farbvarianten bzw. Materialien wurden zylindrische Probekörper hergestellt und in mehreren Schritten - mittels eines festen Polierprotokolls - unterschiedliche Rauheiten eingestellt. Die Oberflächentopographie und der arithmetische Mittenrauwert wurden unter Zuhilfenahme der Weitfeld-Konfokalmikroskopie bestimmt. Weiterhin wurde die freie Energie der Oberfläche durch eine automatisierte Messung verschiedener Kontaktwinkel ermittelt. Es folgte die Inkubation der Probekörper mit Mausfibroblasten (L929) und humanen Gingivafibroblasten (GF1), entsprechend den Vorgaben des Deutschen Instituts für Normung hinsichtlich von Zytotoxizitätsuntersuchungen. Nach 48 Stunden wurden die Viabilitäten der adhärenten Zellen bzw. die Zytotoxizitäten der Testsubstrate bestimmt.

Die Auswertung der arithmetischen Mittenrauheit zeigte die erwartete positive Korrelation zwischen Politurstufe (von Hochglanz und Körnung 1200 über Körnung 400 zu $110 \mu \mathrm{m} /$ sandgestrahlt). Die freie Oberflächenenergie zeigte nur bei der Farbe A1 zwischen 400 und 1200 sowie 110 und 1200 signifikante Unterschiede. Ein allgemeiner über alle Vergleiche gültiger Zusammenhang lag nicht vor. Auffällig waren weiterhin die höheren Messungen der polaren Komponente und die niedrigeren Messwerte der dispersen Komponente des Amalgams gegenüber denen der Komposite, was durch die unterschiedliche Zusammensetzung der Materialien zu erwarten war.

Die Auswertungen der Zytotoxizitätsmessungen der GF1-Zellen zeigten signifikante Unterschiede bei der Polierstufe 1200 bei allen Materialien. Bei den L929-Zellen gab es signifikante 
Unterschiede bei der Polierstufe der Körnung 1200 und bei den darauffolgenden Paarvergleichen zeigte sich ein signifikanter Unterschied bei der Polierstufe 1200 und den Farben A4 zu A1 und A4 zu A2. Die Viabilitätsmessungen zeigten sowohl bei der Zelllinie L929 als auch bei der Zelllinie GF1 Signifikanzen im Hochglanzbereich. Aus den Messungen ist ersichtlich, dass die Viabilität der beiden adhärenten Zelllinien auf den rauen Oberflächen höher ausfiel als auf den hochglanzpolierten Oberflächen.

Zusammengefasst zeigte sich in der vorliegenden Studie kein signifikanter Einfluss des Materials per se auf die Zytotoxizität und damit Viabilität der humanen Gingivafibroblasten. Das bedeutet, dass minimale Unterschiede in der Zusammensetzung von ausgewählten verschiedenfarbigen Kompositen (in den kommerziell erhältlichen Mischungen) keine Auswirkung auf deren zytotoxisches Potenzial in vitro besitzen. Für die Rauheit dagegen wurde eine entsprechende Korrelation nachgewiesen, wobei rauere Substrate in der vorliegenden Versuchsanordnung eine geringere Zytotoxizität und eine höhere Viabilität adhärenter Zellen verursachten. Im Hinblick auf den anwendungsbezogenen Erkenntnisgewinn dieser Studie lässt sich aufgrund der vorliegenden In-vitro-Ergebnisse also festhalten, dass zur Präferenz bestimmter Kompositfarben bei möglichem Kontakt zu den Weichgeweben der Mundhöhle eine klinische Empfehlung nicht abgeleitet werden kann bzw. muss. 


\section{LITERATURVERZEICHNIS}

Aalto-Korte K, Alanko K, Kuuliala O, Jolanki R (2007): Methacrylate and acrylate allergy in dental personnel. Contact Dermatitis $\underline{57}, 324-330$

Abzal MS, Rathakrishnan M, Prakash V, Vivekanandhan P, Subbiya A, Sukumaran VG (2016): Evaluation of surface roughness of three different composite resins with three different polishing systems. J Conserv Dent 19, 171-174

Albert P, Dermann K, Rentsch H (2000): Amalgam und die Alternativen. Chemie in unserer Zeit $\underline{34}$, 300-305

Albuquerque PP, Moreira AD, Moraes RR, Cavalcante LM, Schneider LF (2013): Color stability, conversion, water sorption and solubility of dental composites formulated with different photoinitiator systems. J Dent 41 Suppl 3, e6

Alhareky M, Tavares M (2016): Amalgam vs Composite Restoration, Survival, and Secondary Caries. J Evid Based Dent Pract 16, 107-109

Alptekin T, Ozer F, Unlu N, Cobanoglu N, Blatz MB (2010): In vivo and in vitro evaluations of microleakage around Class I amalgam and composite restorations. Oper Dent $\underline{35}$, 641-648

Al-Radha ASD, Dymock D, Younes C, O'Sullivan D (2012): Surface properties of titanium and zirconia dental implant materials and their effect on bacterial adhesion. J Dent $\underline{40}, 146-153$

Altvater T, Hendrich C, Noth U, Rader CP, Stach R, Schutze N, Eulert J, Thull R (2000): Cytotoxicity study of high gold content Degutan surfaces of various degrees of roughness with fibroblasts (BALB 3T3) and osteoblasts (hFOB 1.19). Biomed Tech (Berl) 4도 , 238-242

Alves CBC, Segurado MN, Dorta MCL, Dias FR, Lenza MG, Lenza MA (2016): Evaluation of cytotoxicity and corrosion resistance of orthodontic mini-implants. Dental Press J Orthod 21, 3946

Anderson JM (2001): Biological Responses to Materials. Annu Rev Mater Res 31, 81-110

Anderson JM, Rodriguez A, Chang DT (2008): Foreign body reaction to biomaterials. Semin Immunol 20, 86-100

Asgary S, Moosavi SH, Yadegari Z, Shahriari S (2012): Cytotoxic effect of MTA and CEM cement in human gingival fibroblast cells. Scanning electronic microscope evaluation. N Y State Dent J $\underline{78}, 51-54$

Ashraf H, Moradimajd N, Mozayeni MA, Dianat O, Mahjour F, Yadegari Z (2012): Cytotoxicity evaluation of three resin-based sealers on an L929 cell line. Dent Res J (Isfahan) 9, 549-553

Ata SO, Yavuzyilmaz H (2009): In vitro comparison of the cytotoxicity of acetal resin, heat-polymerized resin, and auto-polymerized resin as denture base materials. J Biomed Mater Res Part

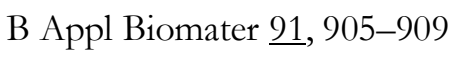

Atai M, Pahlavan A, Moin N (2012): Nano-porous thermally sintered nano silica as novel fillers for dental composites. Dent Mater 28, 133-145 
Attal JP, Asmussen E, Degrange M (1994): Effects of surface treatment on the free surface energy of dentin. Dent Mater 10, 259-264

Attik N, Hallay F, Bois L, Brioude A, Grosgogeat B, Colon P (2017): Mesoporous silica fillers and resin composition effect on dental composites cytocompatibility. Dent Mater $\underline{33}, 166-174$

Ausiello P, Cassese A, Miele C, Beguinot F, Garcia-Godoy F, Di Jeso B, Ulianich L (2013): Cytotoxicity of dental resin composites: An in vitro evaluation. J Appl Toxicol $\underline{33}, 451-457$

Aykent F, Yondem I, Ozyesil AG, Gunal SK, Avunduk MC, Ozkan S (2010): Effect of different finishing techniques for restorative materials on surface roughness and bacterial adhesion. $\mathrm{J}$ Prosthet Dent $\underline{103}, 221-227$

Bacchelli B, Giavaresi G, Franchi M, Martini D, Pasquale V de, Trirè A, Fini M, Giardino R, Ruggeri A (2009): Influence of a zirconia sandblasting treated surface on peri-implant bone healing: An experimental study in sheep. Acta Biomater $\underline{5}, 2246-2257$

Baek H-J, Kim E-K, Lee SG, Jeong S-H, Sakong J, Merchant AT, Im S-U, Song K-B, Choi Y-H (2016): Dental amalgam exposure can elevate urinary mercury concentrations in children. Int Dent J 66, 136-143

Bal BT, Sönmez N, Bavbek B, Akçaboy C (2011): Cytotoxicity of composite resins before and after expiration date. Preliminary report. N Y State Dent J $\underline{77}, 31-35$

Bandel A (2015): Gelungene Frontzahnästhetik. Freie Zahnarzt 모, 70-77

Baseren M (2004): Surface roughness of nanofill and nanohybrid composite resin and ormocer-based tooth-colored restorative materials after several finishing and polishing procedures. J Biomater Appl 19, 121-134

Bashetty K, Joshi S (2010): The effect of one-step and multi-step polishing systems on surface texture of two different resin composites. J Conserv Dent 13, 34-38

Battersby PD, Battersby SJ (2015): Measurements and modelling of the influence of dentine colour and enamel on tooth colour. J Dent $\underline{43}, 373-381$

Bayguinov PO, Oakley DM, Shih C-C, Geanon DJ, Joens MS, Fitzpatrick JAJ (2018): Modern Laser Scanning Confocal Microscopy. Curr Protoc Cytom 포, e39

Bedir Findik R, Celik HT, Ersoy AO, Tasci Y, Moraloglu O, Karakaya J (2016): Mercury concentration in maternal serum, cord blood, and placenta in patients with amalgam dental fillings: Effects on fetal biometric measurements. J Matern Fetal Neonatal Med 29, 3665-3669

Berastegui E, Canalda C, Brau E, Miquel C (1992): Surface roughness of finished composite resins. J Prosthet Dent 68, 742-749

Berger SB, Palialol ARM, Cavalli V, Giannini M (2011): Surface roughness and staining susceptibility of composite resins after finishing and polishing. J Esthet Restor Dent 23, 34-43

Bertau M, Müller A, Fröhlich P, Katzberg M: Industrielle Anorganische Chemie. John Wiley \& Sons, Weinheim 2013 
Bitter K, Paris S, Martus P, Schartner R, Kielbassa AM (2004): A Confocal Laser Scanning Microscope investigation of different dental adhesives bonded to root canal dentine. Int Endod $\mathrm{J} \underline{37}, 840-848$

Bollen CML, Papaioanno W, van Eldere J, Schepers E, Quirynen M, van Steenberghe D (1996): The influence of abutment surface roughness on plaque accumulation and peri-implant mucositis. Clin Oral Implants Res ㄱ, 201-211

Bollen CML, Lambrechts P, Quirynen M (1997): Comparison of surface roughness of oral hard materials to the threshold surface roughness for bacterial plaque retention: A review of the literature. Dental Materials $\underline{13}$, 258-269

Borlinghaus RT: Unbegrenzte Lichtmikroskopie: Über Auflösung und Super-Hochauflösung und die Frage, ob man Moleküle sehen kann (essentials). Springer Spektrum, Wiesbaden 2016

Bos R, van der Mei HC, Busscher HJ (1999): Physico-chemistry of initial microbial adhesive interactions-its mechanisms and methods for study. FEMS Microbiol Rev 23, 179-230

Boulangé-Petermann L, Rault J, Bellon-Fontaine M-N (1997): Adhesion of Streptococcus thermophilus to stainless steel with different surface topography and roughness. Biofouling $\underline{11}, 201-$ 216

Bowen RL (1959): Dental filling material comprising vinyl silane treated fused silica and a binder consisting of the reaction product of bis phenol and glycidyl acrylate. [URL: http://www.freepatentsonline.com/3066112.pdf] Zugriff 02.04.2018

Bowen RL (1963): Properties of a silica-reinforced polymer for dental restorations. J Am Dent Assoc 66, $57-64$

Bowen RL (1979): Compatibility of various materials with oral tissues. I: The components in composite restorations. J Dent Res $\underline{58}, 1493-1503$

Brackett MG, Bouillaguet S, Lockwood PE, Rotenberg S, Lewis JB, Messer RLW, Wataha JC (2007): In vitro cytotoxicity of dental composites based on new and traditional polymerization chemistries. J Biomed Mater Res Part B Appl Biomater 81, 397-402

Brunette DM (1986): Fibroblasts on micromachined substrata orient hierarchically to grooves of different dimensions. Exp Cell Res 164, 11-26

Brunetto PS, Slenters TV, Fromm KM (2011): In vitro Biocompatibility of New Silver(I) Coordination Compound Coated-Surfaces for Dental Implant Applications. Materials (Basel) 4, 355-367

Bumgardner JD, Lucas LC (1994): Corrosion and cell culture evaluations of nickel-chromium dental casting alloys. J Appl Biomater $\underline{5}, 203-213$

Bundesinstitut für Arzneimittel (BfArM): Amalgame in der zahnärztlichen Therapie. Bonn 2005

Buonocore MG (1955): A simple method of increasing the adhesion of acrylic filling materials to enamel surfaces. J Dent Res $\underline{34}$, 849-853

Buonocore MG, Matsui A, Gwinnett AJ (1968): Penetration of resin dental materials into enamel surfaces with reference to bonding. Arch Oral Biol $\underline{13}$, 61-67 
Bürgers R, Schneider-Brachert W, Rosentritt M, Handel G, Hahnel S (2009a): Candida albicans adhesion to composite resin materials. Clin Oral Investig 13, 293-299

Bürgers R, Cariaga T, Müller R, Rosentritt M, Reischl U, Handel G, Hahnel S (2009b): Effects of aging on surface properties and adhesion of Streptococcus mutans on various fissure sealants. Clin Oral Investig 13, 419-426

Bürgers R, Hahnel S, Reichert TE, Rosentritt M, Behr M, Gerlach T, Handel G, Gosau M (2010a): Adhesion of Candida albicans to various dental implant surfaces and the influence of salivary pellicle proteins. Acta Biomater $\underline{6}$, 2307-2313

Bürgers R, Gerlach T, Hahnel S, Schwarz F, Handel G, Gosau M (2010b): In vivo and in vitro biofilm formation on two different titanium implant surfaces. Clin Oral Implants Res 21, 156-164

Burke FJT (2004): Amalgam to tooth-coloured materials-implications for clinical practice and dental education: Governmental restrictions and amalgam-usage survey results. J Dent $\underline{32}, 343-350$

Busscher HJ, Weerkamp AH, van der Mei HC, van Pelt AW, Jong HP de, Arends J (1984): Measurement of the surface free energy of bacterial cell surfaces and its relevance for adhesion. Appl Environ Microbiol 48, 980-983

Buyukerkmen B, Ozturk AN (2013): Effect of polymerisation techniques on residual monomer amount released from different acrylic resins. Mat Res Innovat 14, 381-384

Cairovic A, Maksimovic V, Radovic K, Djurisic S (2016): The effect of recasting on biological properties of Ni-Cr dental alloy. Srp Arh Celok Lek 144, 574-579

Canabarro A, Figueiredo F, Paciornik S, De-Deus G (2009): Two- and three-dimensional profilometer assessments to determine titanium roughness. Scanning $\underline{31}, 174-179$

Can G, Akpinar G, Aydın A (2007): The Release of Elements from Dental Casting Alloy into CellCulture Medium and Artificial Saliva. Eur J Dent 1, 86-90

Caravaca C, Shi L, Balvay S, Rivory P, Laurenceau E, Chevolot Y, Hartmann D, Gremillard L, Chevalier J (2016): Direct silanization of zirconia for increased biointegration. Acta Biomater $\underline{46}$, 323-335

Carvalho RV de, Fernandez MR, Poli-Frederico RC, Guiraldo RD, Lopes MB, Berger SB, Moura SK, Demarco FF (2013): Influence of different photo-activation distances on cytotoxicity of a dental adhesive model resin. Minerva Stomatol 62, 199-205

Catelan A, Briso ALF, Sundfeld RH, Goiato MC, dos Santos PH (2011): Color stability of sealed composite resin restorative materials after ultraviolet artificial aging and immersion in staining solutions. J Prosthet Dent 105, 236-241

Cazzaniga G, Ottobelli M, Ionescu A, Garcia-Godoy F, Brambilla E (2015): Surface properties of resin-based composite materials and biofilm formation: A review of the current literature. Am J Dent $\underline{28}, 311-320$

Chadda H, Naveen SV, Mohan S, Satapathy BK, Ray AR, Kamarul T (2016): Cytotoxic evaluation of hydroxyapatite-filled and silica/hydroxyapatite-filled acrylate-based restorative composite resins: An in vitro study. J Prosthet Dent 116, 129-135 
Chiang H-J, Hsu H-J, Peng P-W, Wu C-Z, Ou K-L, Cheng H-Y, Walinski CJ, Sugiatno E (2016): Early bone response to machined, sandblasting acid etching (SLA) and novel surface-functionalization (SLAffinity) titanium implants: Characterization, biomechanical analysis and histological evaluation in pigs. J Biomed Mater Res A $\underline{104}$, 397-405

Chiaraviglio L, Kirby JE (2014): Evaluation of impermeant, DNA-binding dye fluorescence as a realtime readout of eukaryotic cell toxicity in a high throughput screening format. Assay Drug Dev Technol 12, 219-228

Chibowski E, Perea-Carpio R (2002): Problems of contact angle and solid surface free energy determination. Adv Colloid Interface Sci $\underline{98}, 245-264$

Chour RG, Moda A, Arora A, Arafath MY, Shetty VK, Rishal Y (2016): Comparative evaluation of effect of different polishing systems on surface roughness of composite resin: An in vitro study. J Int Soc Prev Community Dent $\underline{6}, 166-170$

Chu SJ, Trushkowsky RD, Paravina RD (2010): Dental color matching instruments and systems.

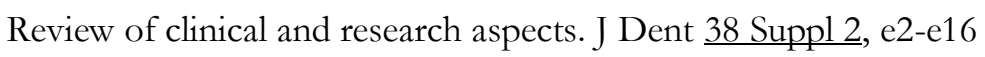

Cochis A, Azzimonti B, Della Valle C, Chiesa R, Arciola CR, Rimondini L (2015): Biofilm formation on titanium implants counteracted by grafting gallium and silver ions. J Biomed Mater Res A $\underline{103}, 1176-1187$

Coelho PG, Granato R, Marin C, Teixeira HS, Suzuki M, Valverde GB, Janal MN, Lilin T, Bonfante EA (2011): The effect of different implant macrogeometries and surface treatment in early biomechanical fixation: An experimental study in dogs. J Mech Behav Biomed Mater 4, 1974-1981

Coenye T, Nelis HJ (2010): In vitro and in vivo model systems to study microbial biofilm formation. J Microbiol Methods $\underline{83}, 89-105$

Conserva E, Menini M, Ravera G, Pera P (2013): The role of surface implant treatments on the biological behavior of SaOS-2 osteoblast-like cells. An in vitro comparative study. Clin Oral Implants Res $\underline{24}, 880-889$

Crawford RJ, Webb HK, Truong VK, Hasan J, Ivanova EP (2012): Surface topographical factors influencing bacterial attachment. Adv Colloid Interface Sci $\underline{179}, 142-149$

Cree IA, Andreotti PE (1997): Measurement of cytotoxicity by ATP-based luminescence assay in primary cell cultures and cell lines. Toxicol In Vitro 11, 553-556

Cucuruz AT, Andronescu E, Ghitulica CD, Cucuruz A (2017): The Effect of Silanization on Alumina for Improving the Compatibility with Poly (Methacrylic Acid) Matrix for Dental Restorative Materials. IJMSHR $\underline{11}, 111$

da Silva WJ, Leal CMB, Viu FC, Gonçalves LM, Barbosa CMR, Del Bel Cury AA (2015): Influence of surface free energy of denture base and liner materials on Candida albicans biofilms. J Investig Clin Dent $\underline{6}, 141-146$

Dafar MO, Grol MW, Canham PB, Dixon SJ, Rizkalla AS (2016): Reinforcement of flowable dental composites with titanium dioxide nanotubes. Dent Mater $\underline{32}, 817-826$

Demarco FF, Collares K, Correa MB, Cenci MS, Moraes RRd, Opdam NJ (2017): Should my composite restorations last forever? Why are they failing? Braz Oral Res $\underline{31}$, e56 
Deutsches Institut für Normung (2009): ISO 10993-5: 2009-10 Biologische Beurteilung von Medizinprodukten - Teil 5: Prüfungen auf In-vitro-Zytotoxizität [URL: https://www.beuth.de/de/norm/din-en-iso-10993-5/113571989] Zugriff 07.11.2017

Dunne SM, Gainsford ID, Wilson NHF (1997): Current materials and techniques for direct restorations in posterior teeth: Part 1: silver amalgam. Int Dent J $\underline{47}, 123-136$

Duparre A, Ferre-Borrull J, Gliech S, Notni G, Steinert J, Bennett JM (2002): Surface characterization techniques for determining the root-mean-square roughness and power spectral densities of optical components. Appl Opt $\underline{41}, 154-171$

Earle WR, Schilling EL, Stark TH, Straus NP, Brown MF, Shelton E (1943): Production of malignancy in vitro. IV. The mouse fibroblast cultures and changes seen in the living cells. J Natl Cancer Inst 4 , 165-212

Eldeniz AU, Mustafa K, Ørstavik D, Dahl JE (2007): Cytotoxicity of new resin-, calcium hydroxideand silicone-based root canal sealers on fibroblasts derived from human gingiva and L929 cell lines. Int Endod J 40, 329-337

Elsner P, Eyerer P, Hirth T (Hrsg): Kunststoffe: Eigenschaften und Anwendungen. 8. Auflage; Springer, Berlin, Heidelberg 2012

Elter C, Heuer W, Demling A, Hannig M, Heidenblut T, Bach F-W, Stiesch-Scholz M (2008): Supraand subgingival biofilm formation on implant abutments with different surface characteristics. Int J Oral Maxillofac Implants $\underline{23}, 327-334$

Ely C, Schneider LFJ, Ogliari FA, Schmitt CC, Corrêa IC, Lima GdS, Samuel SMW, Piva E (2012): Polymerization kinetics and reactivity of alternative initiators systems for use in light-activated dental resins. Dent Mater 28, 1199-1206

Engelhardt J, Knebel W (1993): Konfokale Laserscanning-Mikroskopie. Physik in unserer Zeit 24, $70-78$

Faber FJ (2006): Die Bestimmung der Zahnfarbe-Stellungnahme der DGZMK. [URL: http://www. dgzmk. de/uploads] Zugriff 23.06.18

Farris S, Introzzi L, Biagioni P, Holz T, Schiraldi A, Piergiovanni L (2011): Wetting of biopolymer coatings: Contact angle kinetics and image analysis investigation. Langmuir 27, 7563-7574

Feller L, Chandran R, Khammissa RAG, Meyerov R, Jadwat Y, Bouckaert M, Schechter I, Lemmer $J$ (2014): Osseointegration: Biological events in relation to characteristics of the implant surface. SADJ $\underline{69}, 112,114-7$

Ferracane JL (2011): Resin composite-state of the art. Dent Mater 27, 29-38

Ferracane JL (2016): Current Trends in Dental Composites. Critical Reviews in Oral Biology \& Medicine $\underline{6}, 302-318$

Ferracane JL, Moser JB, Greener EH (1985): Ultraviolet light-induced yellowing of dental restorative resins. J Prosthet Dent $\underline{54}, 483-487$ 
Ferreira JC, Pires PT, Azevedo ÁF de, Arantes-Oliveira S, Silva MJ, Melo PR de (2017): Morphology of the Dentin-resin Interface yielded by Two-step Etch-and-rinse Adhesives with Different Solvents. J Contemp Dent Pract $\underline{18}$, 947-958

Forss H, Widström E (2009): From amalgam to composite: Selection of restorative materials and restoration longevity in Finland. Acta Odontol Scand 59, 57-62

Fowkes FM (1964): Attractive forces at interfaces. Ind Eng Chem $\underline{56}, 40-52$

Frankenberger R (2009): Die adhäsive Seitenzahnversorgung - Komposit oder Keramik? ZWR $\underline{118}$, $187-190$

Gandhi G, Kalra JPS, Goyal A, Sharma A (2018): Microphotographic Assessment of Enamel Surface using Self-Etching Primer and Conventional Phosphoric Acid: An In vitro Study. Contemp Clin Dent $\underline{9}, 15-19$

Gardin C, Ferroni L, Bressan E, Calvo-Guirado JL, Degidi M, Piattelli A, Zavan B (2014): Adult stem cells properties in terms of commitment, aging and biological safety of grit-blasted and Acidetched ti dental implants surfaces. Int J Mol Cell Med $\underline{3}, 225-236$

Geurtsen W (2002): Biocompatibility of dental casting alloys. Crit Rev Oral Biol Med 13, 71-84

Geurtsen W, Lehmann F, Spahl W, Leyhausen G (1998): Cytotoxicity of 35 dental resin composite monomers/additives in permanent 3T3 and three human primary fibroblast cultures. J Biomed Mater Res $\underline{41}, 474-480$

Ghinea R, Pecho O, Herrera LJ, Ionescu AM, La Cardona JdC, Sanchez MP, Paravina RD, Perez MdM (2015): Predictive algorithms for determination of reflectance data from quantity of pigments within experimental dental resin composites. Biomed Eng Online 14 Suppl 2, S4

Ginouves M, Carme B, Couppie P, Prevot G (2014): Comparison of tetrazolium salts assays for evaluation of drug activity against Leishmania spp. J Clin Microbiol 52, 2131-2138

Girault HHJ, Schiffrin DJ, Smith BDV (1984): The measurement of interfacial tension of pendant drops using a video image profile digitizer. Journal of colloid and interface science 101, 257-266

Göbel W: 3D laser-scanning techniques for two-photon calcium imaging of neural network dynamics in vivo. ETH Zurich 2008

Goiato MC, Freitas E, dos Santos D, Medeiros R de, Sonego M (2015): Acrylic Resin Cytotoxicity for Denture Base-Literature Review. Adv Clin Exp Med 24, 679-686

Goldberg M (2008): In vitro and in vivo studies on the toxicity of dental resin components: A review. Clin Oral Investig $\underline{12}, 1-8$

Gosau M, Haupt M, Thude S, Strowitzki M, Schminke B, Buergers R (2016): Antimicrobial effect and biocompatibility of novel metallic nanocrystalline implant coatings. J Biomed Mater Res Part B Appl Biomater 104, 1571-1579

Griggs JA, Wataha JC, Kishen A (2003): Effect of hydrolyzed surface layer on the cytotoxicity and chemical resistance of a low fusing porcelain. Dent Mater 19, 353-358 
Grootjans S, Hassannia B, Delrue I, Goossens V, Wiernicki B, Dondelinger Y, Bertrand MJM, Krysko DV, Vuylsteke M, Vandenabeele P et al. (2016): A real-time fluorometric method for the simultaneous detection of cell death type and rate. Nat Protoc 11, 1444-1454

Gstraunthaler G, Lindl T: Zell-und Gewebekultur: Allgemeine Grundlagen und spezielle Anwendungen. Springer-Verlag, Wiesbaden 2013

Günay-Bulutsuz A, Berrak Ö, Yeprem HA, Arisan ED, Yurci ME (2018): Biological responses of ultrafine grained pure titanium and their sand blasted surfaces. Mater Sci Eng C Mater Biol Appl $\underline{91}, 382-388$

Guo G, Fan Y, Zhang J-F, Hagan JL, Xu X (2012): Novel dental composites reinforced with zirconiasilica ceramic nanofibers. Dent Mater 28, 360-368

Gupta A, Tavane P, Gupta PK, Tejolatha B, Lakhani AA, Tiwari R, Kashyap S, Garg G (2017): Evaluation of Microleakage with Total Etch, Self Etch and Universal Adhesive Systems in Class V Restorations: An In vitro Study. J Clin Diagn Res 11, ZC53-ZC56

Gyurkovics M, Baumann T, Carvalho TS, Assunção CM, Lussi A (2017): In vitro evaluation of modified surface microhardness measurement, focus variation 3D microscopy and contact stylus profilometry to assess enamel surface loss after erosive-abrasive challenges. PLoS ONE $\underline{12}$, e0175027

Hahnel S, Rosentritt M, Handel G, Bürgers R (2009a): In vitro evaluation of artificial ageing on surface properties and early Candida albicans adhesion to prosthetic resins. J Mater Sci Mater Med 20, 249-255

Hahnel S, Rosentritt M, Handel G, Bürgers R (2009b): Surface characterization of dental ceramics and initial streptococcal adhesion in vitro. Dent Mater 25, 969-975

Hahnel S, Henrich A, Rosentritt M, Handel G, Bürgers R (2010a): Influence of artificial ageing on surface properties and Streptococcus mutans adhesion to dental composite materials. J Mater Sci Mater Med 21, 823-833

Hahnel S, Henrich A, Bürgers R, Handel G, Rosentritt M (2010b): Investigation of mechanical properties of modern dental composites after artificial aging for one year. Oper Dent $\underline{35}, 412-419$

Hahnel S, Wieser A, Lang R, Rosentritt M (2015): Biofilm formation on the surface of modern implant abutment materials. Clin Oral Implants Res 26, 1297-1301

Hammad IA (2003): Intrarater repeatability of shade selections with two shade guides. J Prosthet Dent $\underline{89}, 50-53$

Han B, Dong Y, Gao X, Wang X, Tian F (2012): Effect of filler content on the microtensile bond strength of composite resin and dentin in Class I cavities. Quintessence Int $\underline{43}$, e16-e22

Hannig C, Hannig M (2009): The oral cavity-a key system to understand substratum-dependent bioadhesion on solid surfaces in man. Clin Oral Investig 13, 123-139

Harhammer R (2001): Zur Risikobewertung des zahnärztlichen Füllungswerkstoffes Amalgam. Bundesgesundheitsbl-Gesundheitsforsch-Gesundheitsschutz $\underline{44}$, 149-154 
Haus J: Optische Mikroskopie: Funktionsweise und Kontrastierverfahren. John Wiley \& Sons, Weinheim 2014

Hellwig E, Klimek J, Attin T: Einführung in die Zahnerhaltung: Prüfungswissen Kariologie, Endodontologie und Parodontologie. 6., überarb. Auflage; Dt. Zahnärzte-Verl., Köln 2013

Henningsen A, Smeets R, Hartjen P, Heinrich O, Heuberger R, Heiland M, Precht C, Cacaci C (2018): Photofunctionalization and non-thermal plasma activation of titanium surfaces. Clin Oral Investig $\underline{22}, 1045-1054$

Heravi F, Ramezani M, Poosti M, Hosseini M, Shajiei A, Ahrari F (2013): In Vitro Cytotoxicity Assessment of an Orthodontic Composite Containing Titanium-dioxide Nano-particles. J Dent Res Dent Clin Dent Prospects $\underline{\text {, }}$ 192-198

Herbst W, Hunger K: Industrielle Organische Pigmente: Herstellung, Eigenschaften, Anwendung. John Wiley \& Sons, Weinheim 2009

Heurich E, Beyer M, Jandt KD, Reichert J, Herold V, Schnabelrauch M, Sigusch BW (2010): Quantification of dental erosion--a comparison of stylus profilometry and confocal laser scanning microscopy (CLSM). Dent Mater 26, 326-336

Hosoya N, Honda K, Iino F, Arai T (2003): Changes in enamel surface roughness and adhesion of Streptococcus mutans to enamel after vital bleaching. J Dent $\underline{31}, 543-548$

Hosseinalipour M, Javadpour J, Rezaie H, Dadras T, Hayati AN (2010): Investigation of mechanical properties of experimental Bis-GMA/TEGDMA dental composite resins containing various mass fractions of silica nanoparticles. J Prosthodont 19, 112-117

Igiel C, Lehmann KM, Ghinea R, Weyhrauch M, Hangx Y, Scheller H, Paravina RD (2017): Reliability of visual and instrumental color matching. J Esthet Restor Dent 29, 303-308

Ilie N (2016): Bulk-Fill-Komposite: Eigenschaften und Perspektiven. der junge zahnarzt 7, 14-21

Ilie N, Hickel R (2009): Investigations on mechanical behaviour of dental composites. Clin Oral Investig $\underline{13}, 427$

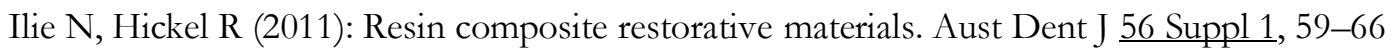

Ilie N, Jelen E, Clementino-Luedemann T, Hickel R (2007): Low-shrinkage composite for dental application. Dent Mater J 26, 149-155

Ilie N, Rosentritt M, Lohbauer U (2016): Update Materialforschung - direkte kunststoffbasierte Komposite. ZWR $\underline{125}$, 2-7

Ishikiriama SK, Ordoñéz-Aguilera JF, Maenosono RM, Volú FLA, Mondelli RFL (2015): Surface roughness and wear of resin cements after toothbrush abrasion. Braz Oral Res $\underline{29}, 1-5$

Ishiyama M, Miyazono Y, Sasamoto K, Ohkura Y, Ueno K (1997): A highly water-soluble disulfonated tetrazolium salt as a chromogenic indicator for $\mathrm{NADH}$ as well as cell viability. Talanta 44, 1299-1305

Jäger M (2018): Oberflächenmodifikationen von Implantaten. Teil 2: Klinische Anwendung. Orthopäde $\underline{47}, 445-458$ 
Jan Y-D, Lee B-S, Lin C-P, Tseng W-Y (2014): Biocompatibility and cytotoxicity of two novel lowshrinkage dental resin matrices. J Formos Med Assoc 113, 349-355

Janda R (2007): Toxikologie der polymerisierbaren Füllungsmaterialien. DFZ 10, 56-63

Janda R (2008a): Organische Polymere: Chemie und Physik, Teil 1. QZ 34(2), 190-204

Janda R (2008b): Organische Polymere: Chemie und Physik, Teil 2. QZ 34(4), 460-473

Janda R (2008c): Organische Polymere: Chemie und Physik, Teil 3. QZ 34(5), 584-594

Jayaraman M, Meyer U, Bühner M, Joos U, Wiesmann H-P (2004): Influence of titanium surfaces on attachment of osteoblast-like cells in vitro. Biomaterials $\underline{25}$, 625-631

Jiao Y, Ma S, Li J, Shan L, Yang Y, Li M, Chen J (2015): The influences of N-acetyl cysteine (NAC) on the cytotoxicity and mechanical properties of Poly-methylmethacrylate (PMMA)-based dental resin. PeerJ $\underline{3}$, e868

Jin J, Zhang L, Shi M, Zhang Y, Wang Q (2017): Ti-GO-Ag nanocomposite: The effect of content level on the antimicrobial activity and cytotoxicity. Int J Nanomedicine 12, 4209-4224

Johanning K: Vergleichende werkstoffkundliche Untersuchung marktgängiger und neu entwickelter Materialien zur Herstellung temporärer Kronen und Brücken. Med. Diss. Tübingen 2018

Joiner A (2004): Tooth colour: A review of the literature. J Dent $\underline{32}$, 3-12

Jung M, Eichelberger K, Klimek J (2007): Surface geometry of four nanofiller and one hybrid composite after one-step and multiple-step polishing. Oper Dent $\underline{32}$, 347-355

Jung YC, Bhushan B (2006): Contact angle, adhesion and friction properties of micro-and nanopatterned polymers for superhydrophobicity. Nanotechnology $\underline{17}, 4970$

Kaelble DH (1970): Dispersion-polar surface tension properties of organic solids. J Adhesion 2 , 6681

Kaga M, Noda M, Ferracane JL, Nakamura W, Oguchi H, Sano H (2001): The in vitro cytotoxicity of eluates from dentin bonding resins and their effect on tyrosine phosphorylation of L929 cells. Dental Materials 17, 333-339

Kamonwanon P, Yodmongkol S, Chantarachindawong R, Thaweeboon S, Thaweeboon B, Srikhirin $\mathrm{T}$ (2015): Wear resistance of a modified polymethyl methacrylate artificial tooth compared to five commercially available artificial tooth materials. J Prosthet Dent 114, 286-292

Kanerva L, Estiander T, Jolanki R, Tarvainijn K (1993): Occupational allergic contact dermatitis caused by exposure to acrylates during work with dental prostheses. Contact Dermatitis $\underline{28}, 268$ 275

Kappert HF, Eichner K: Zahnärztliche Werkstoffe und ihre Verarbeitung. 1. Grundlagen und Verarbeitung. Georg Thieme Verlag, Stuttgart 2005

Karabela MM, Sideridou ID (2008): Effect of the structure of silane coupling agent on sorption characteristics of solvents by dental resin-nanocomposites. Dent Mater 24, 1631-1639

Karabela MM, Sideridou ID (2011): Synthesis and study of properties of dental resin composites with different nanosilica particles size. Dent Mater 27, 825-835 
Kato J (1976): Influence of surface condition upon the cytotoxicity of copper-gold alloy (in vitro) (author's transl). Shika Rikogaku Zasshi 17, 63-78

Kedjarune U, Charoenworaluk N, Koontongkaew S (1999): Release of methyl methacrylate from heat-curved and autopolymerized resins: Cytotoxicity testing related to residual monomer. Aust Dent J $\underline{44}, 25-30$

Key JE, Rahemtulla FG, Eleazer PD (2006): Cytotoxicity of a new root canal filling material on human gingival fibroblasts. J Endod $\underline{32}, 756-758$

Kirmanidou Y, Sidira M, Drosou M-E, Bennani V, Bakopoulou A, Tsouknidas A, Michailidis N, Michalakis K (2016): New Ti-Alloys and Surface Modifications to Improve the Mechanical Properties and the Biological Response to Orthopedic and Dental Implants: A Review. Biomed Res Int 2016, 2908570

Knebel M (2010): Titan in Bedrängnis. Kunststoffe 100, 68-71

Koch C, Bürgers R, Hahnel S (2013): Candida albicans adherence and proliferation on the surface of denture base materials. Gerodontology $\underline{30}, 309-313$

Kocher T, Langenbeck N, Rosin M, Bernhardt O (2002): Methodology of three-dimensional determination of root surface roughness. J Periodont Res $\underline{37}, 125-131$

Korhonen JT, Huhtamäki T, Ikkala O, Ras RHA (2013): Reliable measurement of the receding contact angle. Langmuir 모, 3858-3863

Kostoryz EL, Tong PY, Chappelow CC, Eick JD, Glaros AG, Yourtee DM (1999): In vitro cytotoxicity of solid epoxy-based dental resins and their components. Dental Materials 15 , 363-373

Krastl G, Weiger R (2010): Frontzahnrestaurationen: Brauchen wir überhaupt Keramik? Quintessenz $\underline{61}, 511-520$

Krukemeyer MG, Alldinger I: Chirurgische Forschung. 1. Auflage. Thieme, Stuttgart 2005

Krüss (2010): Kontaktwinkel eines liegenden Tropfens. Krüss GmbH, [URL: http://www.kruss.de] Zugriff 24.05.2018

Kunert-Keil C, Gredes T, Richter D-U, Szyba M, Dominiak M, Gedrange T (2012): The survival and proliferation of fibroblasts on ceramic implants: An in vitro study. Biomed Tech (Berl) $\underline{57}, 11-$ 15

Kwon J-S, Illeperuma RP, Kim J, Kim K-M, Kim K-N (2014): Cytotoxicity evaluation of zinc oxideeugenol and non-eugenol cements using different fibroblast cell lines. Acta Odontol Scand $\underline{72}$, $64-70$

Lafuma A, Quéré D (2003): Superhydrophobic states. Nat Mater 2, 457

Lam CNC, Wu R, Li D, Hair ML, Neumann AW (2002): Study of the advancing and receding contact angles: Liquid sorption as a cause of contact angle hysteresis. Adv Colloid Interface Sci $\underline{96}, 169$ 191

Lamolle SF, Monjo M, Rubert M, Haugen HJ, Lyngstadaas SP, Ellingsen JE (2009): The effect of hydrofluoric acid treatment of titanium surface on nanostructural and chemical changes and the growth of MC3T3-E1 cells. Biomaterials $\underline{30}, 736-742$ 
Leal A, Paula A, Ramalho A, Esteves M, Ferreira MM, Carrilho E (2015): Roughness and microhardness of composites after different bleaching techniques. J Appl Biomater Funct Mater 13, e3818

Lebeaux D, Chauhan A, Rendueles O, Beloin C (2013): From in vitro to in vivo Models of Bacterial Biofilm-Related Infections. Pathogens 2 , 288-356

Lee M-J, Kim M-J, Kwon J-S, Lee S-B, Kim K-M (2017): Cytotoxicity of Light-Cured Dental Materials according to Different Sample Preparation Methods. Materials (Basel) 10, 288

Leggat PA, Kedjarune U (2003): Toxicity of methyl methacrylate in dentistry. Int Dent J $\underline{53}, 126-131$

Leyh R, Wilhelmi M, Herden T, Overbeck A, Kofidis T, Fischer S, Haverich A, Mertsching H: Artifiziell hergestellte Herzklappen mittels ,tissue engineering “ auf der Basis einer azellularisierten xenogenen Matrix: In-vivo Untersuchungen im Schafmodell. In: v. Siewert JR, Neugebauer E, Hartel W, Menger MDC (Hrsg.): Chirurgisches Forum 2002: Für experimentelle und klinische Forschung. (Deutsche Gesellschaft für Chirurgie, Chirurgisches Forum 2002 31): Springer. Berlin, Heidelberg 2002, 469-471

Lim BS, Ferracane JL, Condon JR, Adey JD (2002): Effect of filler fraction and filler surface treatment on wear of microfilled composites. Dent Mater 18, 1-11

Lim Y-K, Lee Y-K, Lim B-S, Rhee S-H, Yang H-C (2008): Influence of filler distribution on the color parameters of experimental resin composites. Dent Mater 24, 67-73

Lin S-Y, Chang H-C, Lin L-W, Huang P-Y (1996): Measurement of dynamic/advancing/receding contact angle by video-enhanced sessile drop tensiometry. Rev Sci Instrum 67, 2852-2858

Lomakina GY, Modestova YA, Ugarova NN (2015): Bioluminescence assay for cell viability. Biochemistry Mosc $\underline{80}, 701-713$

Lung CYK, Matinlinna JP (2012): Aspects of silane coupling agents and surface conditioning in dentistry: An overview. Dent Mater 28, 467-477

Lutter A-H, Scholka J, Richter H, Anderer U (2017): Applying XTT, WST-1, and WST-8 to human chondrocytes: A comparison of membrane-impermeable tetrazolium salts in $2 \mathrm{D}$ and $3 \mathrm{D}$ cultures. Clin Hemorheol Microcirc $\underline{67}, 327-342$

Madhyastha PS, Naik DG, Kotian R, Padma D, Srikant N, Bhat KMR (2015): Evaluation of Cytotoxicity of Silorane and Methacrylate based Dental Composites using Human Gingival Fibroblasts. J Clin Diagn Res $\underline{9}$, ZC05-8

Mai R, Kunert-Keil C, Grafe A, Gedrange T, Lauer G, Dominiak M, Gredes T (2012): Histological behaviour of zirconia implants: An experiment in rats. Ann Anat 194, 561-566

Malkoc S, Corekci B, Ulker HE, Yalçin M, Sengün A (2010): Cytotoxic effects of orthodontic composites. Angle Orthod $\underline{80}, 571-576$

Malkoc S, Öztürk F, Çörekçi B, Bozkurt BS, Hakki SS (2012): Real-time cell analysis of the cytotoxicity of orthodontic mini-implants on human gingival fibroblasts and mouse osteoblasts. Am J Orthod Dentofacial Orthop 141, 419-426 
Manhart J, Neuerer P, Scheibenbogen-Fuchsbrunner A, Hickel R (2000): Three-year clinical evaluation of direct and indirect composite restorations in posterior teeth. J Prosthet Dent $\underline{84}, 289$ 296

Meereis CTW, Leal FB, Ogliari FA (2016): Stability of initiation systems in acidic photopolymerizable dental material. Dent Mater $\underline{32}, 889-898$

Mei L, Busscher HJ, van der Mei HC, Ren Y (2011): Influence of surface roughness on streptococcal adhesion forces to composite resins. Dent Mater 27, 770-778

Melilli D, Currò G, Am Perna, Cassaro A (2009): Cytotoxicity of four types of resins used for removable denture bases: In vitro comparative analysis. Minerva Stomatol $\underline{58}, 425-434$

Mendonça G, Mendonça DBS, Aragão FJL, Cooper LF (2008): Advancing dental implant surface technology-from micron- to nanotopography. Biomaterials $\underline{29}$, 3822-3835

Metzler P, Wilmowsky C von, Stadlinger B, Zemann W, Schlegel KA, Rosiwal S, Rupprecht S (2013): Nano-crystalline diamond-coated titanium dental implants - a histomorphometric study in adult domestic pigs. J Craniomaxillofac Surg 41, 532-538

Milagres V, Teixeira ML, Miranda ME, Osorio Silva CH, Ribeiro Pinto JR (2012): Effect of gender, experience, and value on color perception. Oper Dent $\underline{37}, 228-233$

Miler M (2017): Characterisation of secondary metal-bearing phases in used dental amalgam and assessment of gastric solubility. Environ Geochem Health $\underline{39}$, 1607-1619

Milheiro A, Nozaki K, Kleverlaan CJ, Muris J, Miura H, Feilzer AJ (2016): In vitro cytotoxicity of metallic ions released from dental alloys. Odontology 104, 136-142

Mjör IA, Jokstad A (1993): Five-year study of Class II restorations in permanent teeth using amalgam, glass polyalkenoate (ionomer) cermet and resin-based composite materials. J Dent 21, 338-343

Möller B, Terheyden H, Açil Y, Purcz NM, Hertrampf K, Tabakov A, Behrens E, Wiltfang J (2012): A comparison of biocompatibility and osseointegration of ceramic and titanium implants: An in vivo and in vitro study. Int J Oral Maxillofac Surg 41, 638-645

Monjo M, Petzold C, Ramis JM, Lyngstadaas SP, Ellingsen JE (2012): In vitro osteogenic properties of two dental implant surfaces. Int J Biomater 2012, 181024

Moraschini V, Fai CK, Alto RM, Dos Santos GO (2015): Amalgam and resin composite longevity of posterior restorations: A systematic review and meta-analysis. J Dent $\underline{43}$, 1043-1050

Müller A: Einfärben von Kunststoffen. Carl Hanser Verlag, München 2002

Nasim I, Neelakantan P, Sujeer R, Subbarao CV (2010): Color stability of microfilled, microhybrid and nanocomposite resins--an in vitro study. J Dent 38 Suppl 2, e137-e142

Necula BS, van Leeuwen J, Fratila-Apachitei LE, Zaat S, Apachitei I, Duszczyk J (2012): In vitro cytotoxicity evaluation of porous $\mathrm{TiO}_{2}-\mathrm{Ag}$ antibacterial coatings for human fetal osteoblasts. Acta Biomater $\underline{8}, 4191-4197$

Netuschil L, Reich E, Unteregger G, Sculean A, Brecx M (1998): A pilot study of confocal laser scanning microscopy for the assessment of undisturbed dental plaque vitality and topography. Arch Oral Biol 43, 277-285 
Nyberg J, Hertzman S, Svensson B, Johansson CB (2013): Osseointegration of implants in irradiated bone with and without hyperbaric oxygen treatment: An experimental study in rat Tibiae. Int J Oral Maxillofac Implants $\underline{28}, 739-746$

Oguro R, Nakajima M, Seki N, Sadr A, Tagami J, Sumi Y (2016): The role of enamel thickness and refractive index on human tooth colour. J Dent $\underline{51}, 36-44$

Oliveira GUd, Mondelli RFL, Charantola Rodrigues M, Franco EB, Ishikiriama SK, Wang L (2012): Impact of filler size and distribution on roughness and wear of composite resin after simulated toothbrushing. J Appl Oral Sci 20, 510-516

Opdam NJM, Bronkhorst EM, Roeters JM, Loomans BAC (2007): A retrospective clinical study on longevity of posterior composite and amalgam restorations. Dent Mater $\underline{23}, 2-8$

Opdam NJM, Bronkhorst EM, Loomans BAC, Huysmans MCDNJM (2010): 12-year survival of composite vs. amalgam restorations. J Dent Res $\underline{89}, 1063-1067$

Orsini G, Assenza B, Scarano A, Piattelli M, Piattelli A (2000): Surface analysis of machined versus sandblasted and acid-etched titanium implants. Int J Oral Maxillofac Implants $\underline{15}$, 779-784

Owen BD, Guevara PH, Greenwood W (2017): Placement and replacement rates of amalgam and composite restorations on posterior teeth in a military population. US Army Med Dep J $\underline{17}, 88$ 94

Owens DK, Wendt RC (1969): Estimation of the surface free energy of polymers. J. Appl. Polym. Sci. $13,1741-1747$

Ozgünaltay G, Yazici AR, Görücü J (2003): Effect of finishing and polishing procedures on the surface roughness of new tooth-coloured restoratives. J Oral Rehabil 30, 218-224

Paddock SW, Eliceiri KW (2014): Laser scanning confocal microscopy: History, applications, and related optical sectioning techniques. Methods Mol Biol 1075, 9-47

Palotie U, Eronen AK, Vehkalahti K, Vehkalahti MM (2017): Longevity of 2- and 3-surface restorations in posterior teeth of 25- to 30-year-olds attending Public Dental Service-A 13-year observation. J Dent $\underline{62}, 13-17$

Papavasileiou D, Behr M, Gosau M, Gerlach T, Buergers R (2015): Peri-implant Biofilm Formation on Luting Agents Used for Cementing Implant-Supported Fixed Restorations: A Preliminary In Vivo Study. Int J Prosthodont 28, 371-373

Petty RD, Sutherland LA, Hunter EM, Cree IA (1995): Comparison of MTT and ATP-based assays for the measurement of viable cell number. J Biolumin Chemilumin 10, 29-34

Peutzfeldt A (1997): Resin composites in dentistry: The monomer systems. Eur J Oral Sci $\underline{105}$, $97-$ 116

Pfeifer CS, Silva LR, Kawano Y, Braga RR (2009): Bis-GMA co-polymerizations: Influence on conversion, flexural properties, fracture toughness and susceptibility to ethanol degradation of experimental composites. Dent Mater 25, 1136-1141

Piirilä P, Kanerva L, Keskinen H, Estlander T, Hytönen M, Tuppurainen M, Nordman H (1998): Occupational respiratory hypersensitivity caused by preparations containing acrylates in dental personnel. Clin Exp Allergy 28, 1404-1411 
Pilownic KJ, Carvalho CN, Romano AR, Morgental RD, Shen Y, Haapasalo M, Pappen FG (2017): Antibiofilm Activity of Five Different Endodontic Filling Materials Used in Primary Teeth Using Confocal Laser Scanning Microscopy. Pediatr Dent $\underline{39}$, 145-149

Polydorou O (2014): Update Kompositmaterialien. der junge zahnarzt $\underline{5}$, 12-20

Polzin C, Seitz H: 3D-Druck von Kunststoff-Medizinprodukten; In: RTejournal-Forum für Rapid Technologie 2012, 3409

Präbst K, Engelhardt H, Ringgeler S, Hübner H (2017): Basic Colorimetric Proliferation Assays: MTT, WST, and Resazurin. Methods Mol Biol $\underline{1601}, 1-17$

Pradeep N, Sreekumar AV (2012): An in vitro investigation into the cytotoxicity of methyl methacrylate monomer. J Contemp Dent Pract 13, 838-841

Prudil M: Einfluss der Füllkörper von Kompositmaterialien auf die initiale bakterielle Adhäsion. Med. Diss. Regensburg 2010

Quirynen M (1994): The clinical meaning of the surface roughness and the surface free energy of intra-oral hard substrata on the microbiology of the supra- and subgingival plaque: Results of in vitro and in vivo experiments. J Dent 22 Suppl 1, S13-6

Rabel W (1971): Einige Aspekte der Benetzungstheorie und ihre Anwendung auf die Untersuchung und Veränderung der Oberflächeneigenschaften von Polymeren. Farbe und Lack 7ㅜ, 997-1006

Rai R, Gupta R (2013): In vitro evaluation of the effect of two finishing and polishing systems on four esthetic restorative materials. J Conserv Dent 16, 564-567

Randolph LD, Steinhaus J, Möginger B, Gallez B, Stansbury J, Palin WM, Leloup G, Leprince JG (2016): Photopolymerization of highly filled dimethacrylate-based composites using Type I or Type II photoinitiators and varying co-monomer ratios. Dent Mater $\underline{32}, 136-148$

Rasines Alcaraz MG, Veitz-Keenan A, Sahrmann P, Schmidlin PR, Davis D, Iheozor-Ejiofor Z (2014): Direct composite resin fillings versus amalgam fillings for permanent or adult posterior teeth. Cochrane Database Syst Rev, CD005620

Rathore M, Singh A, Pant VA (2012): The dental amalgam toxicity fear: A myth or actuality. Toxicol Int $\underline{19}, 81-88$

Reddy, C. A., Beveridge, T. J., Breznak, J. A., \& Marzluf, G. (Hrsg.): Methods for general and molecular microbiology. 3. Auflage, ASM Press, Washington, D.C. 2007

Renisch B, Lauer W (2014): Erfahrungen und Empfehlungen des BfArM zur Genehmigung klinischer Prüfungen von Medizinprodukten und Bewertung schwerwiegender unerwünschter Ereignisse (SAE). Bundesgesundheitsbl-Gesundheitsforsch-Gesundheitsschutz 57, 1368-1375

Richardson GM, Wilson R, Allard D, Purtill C, Douma S, Gravière J (2011): Mercury exposure and risks from dental amalgam in the US population, post-2000. Sci Total Environ $\underline{409}$, 4257-4268

Riethe P (1980): Geschichtliche Entwicklung der Amalgame. Dtsch Zahnarztl Z $\underline{35}$, 443-449

Riss TL, Moravec RA, Niles AL (2011): Cytotoxicity testing: Measuring viable cells, dead cells, and detecting mechanism of cell death. Methods Mol Biol 4ㅜ, 103-114 
Riss TL, Moravec RA, Niles AL, Duellmann S, Benink HA, Worzella TJ, Minor L; In: Sittampalam GS, Coussens NP, Brimacombe K, Grossman A, Arkin M, Auld D, Austin C, Baell J, Bejcek B, Chung TDY et al. (2016): Assay guidance manual. [URL: https://www.ncbi.nlm.nih.gov/books/NBK144065/] Zugriff 20.11.2017

Ristic L, Vucevic D, Radovic L, Djordjevic S, Nikacevic M, Colic M (2014): Corrosive and cytotoxic properties of compact specimens and microparticles of Ni-Cr dental alloy. J Prosthodont $\underline{23}$, 221-226

Rodríguez-Corrales JÁ, Josan JS (2017): Resazurin Live Cell Assay: Setup and Fine-Tuning for Reliable Cytotoxicity Results. Methods Mol Biol 1647, 207-219

Romanò CL, Scarponi S, Gallazzi E, Romanò D, Drago L (2015): Antibacterial coating of implants in orthopaedics and trauma: A classification proposal in an evolving panorama. J Orthop Surg Res $\underline{10}, 157$

Rosa WLdOd, Piva E, Silva AFd (2015): Bond strength of universal adhesives: A systematic review and meta-analysis. J Dent $\underline{43}, 765-776$

Rosentritt M, Ilie N, Lohbauer U (Hrsg.) (2018): Werkstoffkunde in der Zahnmedizin: Moderne Materialien und Technologien. Georg Thieme Verlag, Stuttgart, New York 2018

Rothe H, Strickstrock M, Hildebrand G, Liefeith K (2015): Quantifizierung der 3D-Oberflächenrauigkeit von abrasiv behandelten Implantatoberflächen mittels der Stereo-Rasterelektronenmikroskopie. Z Zahnärztl Implantol $\underline{31}$, 43-51

Ruschel VC, Bona VS, Baratieri LN, Maia HP (2018): Effect of Surface Sealants and Polishing Time on Composite Surface Roughness and Microhardness. Oper Dent $\underline{43}$, 408-415

Rüttermann S, Dluzhevskaya I, Grosssteinbeck C, Raab WH-M, Janda R (2010): Impact of replacing Bis-GMA and TEGDMA by other commercially available monomers on the properties of resinbased composites. Dent Mater 26, 353-359

Rüttermann S, Beikler T, Janda R (2014): Contact angle and surface free energy of experimental resinbased dental restorative materials after chewing simulation. Dent Mater $\underline{30}, 702-707$

Ruyter IE (1988): Composites-characterization of composite filling materials: Reactor response. Adv Dent Res $\underline{2}, 122-133$

Ruyter IE (2009): Release of formaldehyde from denture base polymers. Acta Odontol Scand $\underline{38}, 17$ 27

Sabbagh J, Ryelandt L, Bachérius L, Biebuyck J-J, Vreven J, Lambrechts P, Leloup G (2004): Characterization of the inorganic fraction of resin composites. J Oral Rehabil $\underline{31}, 1090-1101$

Salazar DC, Dennison J, Yaman P (2013): Inorganic and prepolymerized filler analysis of four resin composites. Oper Dent $\underline{38}$, E201-E209

Salehi S, Gwinner F, Mitchell JC, Pfeifer C, Ferracane JL (2015): Cytotoxicity of resin composites containing bioactive glass fillers. Dent Mater $\underline{31}, 195-203$

Sammons RL, Lumbikanonda N, Gross M, Cantzler P (2005): Comparison of osteoblast spreading on microstructured dental implant surfaces and cell behaviour in an explant model of osseointegration. A scanning electron microscopic study. Clin Oral Implants Res $\underline{16}$, 657-666 
Sandner B, Baudach S, Davy KW, Braden M, Clarke RL (1997): Synthesis of BISGMA derivatives, properties of their polymers and composites. J Mater Sci Mater Med $\underline{8}, 39-44$

Santini A, Gallegos IT, Felix CM (2013): Photoinitiators in dentistry: A review. Prim Dent J 2, $30-33$

Schedle A, Franz A, Rausch-Fan X, Spittler A, Lucas T, Samorapoompichit P, Sperr W, Boltz-Nitulescu G (1998): Cytotoxic effects of dental composites, adhesive substances, compomers and cements. Dental Materials 14, 429-440

Schendel KU, Lenhardt M, Fusenig NE, Komposch G (1992): Testung der Toxizität von in der Kieferorthopädie verwendeten Kunststoffen. Fortschr Kieferorthop 프, 263-272

Schlegel KA, Prechtl C, Möst T, Seidl C, Lutz R, Wilmowsky C von (2013): Osseointegration of SLActive implants in diabetic pigs. Clin Oral Implants Res 24, 128-134

Schmalz G (2002): Biological interactions of dental cast alloys with oral tissues. Dent Mater $\underline{18}$, 396406

Schmid-Schwap M, Franz A, König F, Bristela M, Lucas T, Piehslinger E, Watts DC, Schedle A (2009): Cytotoxicity of four categories of dental cements. Dent Mater 25, 360-368

Schmidseder J: Ästhetische Zahnmedizin. Georg Thieme Verlag, Stuttgart 2008

Schmitz S: Der Experimentator: Zellkultur. Springer-Verlag, Heidelberg 2011

Schubert A, Ziegler C, Bernhard A, Bürgers R, Miosge N (2018): Cytotoxic effects to mouse and human gingival fibroblasts of a nanohybrid ormocer versus dimethacrylate-based composites. Clin Oral Investig, [Epub ahead of print]

Schuurs AH, Moorer WR (2000): Hormoonontregelaars. Pseudo-oestrogenen in tandheelkundige composieten en sealants? Ned Tijdschr Tandheelkd 107, 490-494

Schweikl H, Schmalz G (1996): Toxicity parameters for cytotoxicity testing of dental materials in two different mammalian cell lines. Eur J Oral Sci 104, 292-299

Shah FA, Johansson ML, Omar O, Simonsson H, Palmquist A, Thomsen P (2016): Laser-Modified Surface Enhances Osseointegration and Biomechanical Anchorage of Commercially Pure Titanium Implants for Bone-Anchored Hearing Systems. PLoS ONE 11, e0157504

Shimojo N, Kondo C, Yamashita K, Hoshino T, Hayakawa T (2007): Cytotoxicity analysis of a novel titanium alloy in vitro: Adhesion, spreading, and proliferation of human gingival fibroblasts. Biomed Mater Eng 17, 127-135

Shin H, Ko H, Kim M (2016): Cytotoxicity and biocompatibility of Zirconia (Y-TZP) posts with various dental cements. Restor Dent Endod 41, 167-175

Sideridou ID, Karabela MM (2009): Effect of the amount of 3-methacyloxypropyltrimethoxysilane coupling agent on physical properties of dental resin nanocomposites. Dent Mater $\underline{25}$, 13151324

Sjogren G, Sletten G, Dahl JE (2000): Cytotoxicity of dental alloys, metals, and ceramics assessed by

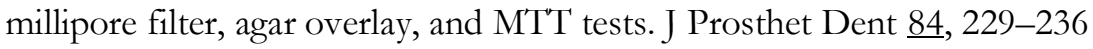

Smola T (2018): GESTIS-Stoffdatenbank: Methyleniodid: [URL: http://gestis.itrust.de/nxt/gateway.dll/gestis_de/492386.xml?f=templates $\$$ fn $=$ default.htm $\$ 3.0]$ Zugriff 13.08 .2018 
Söderholm K-J, Shang S-W (1993): Molecular orientation of silane at the surface of colloidal silica. J Dent Res $\underline{72}, 1050-1054$

Souza PPC, Aranha AMF, Hebling J, Giro EMA, Costa CAdS (2006): In vitro cytotoxicity and in vivo biocompatibility of contemporary resin-modified glass-ionomer cements. Dent Mater $\underline{22}$, 838-844

Stanislawski L, Daniau X, Lauti A, Goldberg M (1999): Factors responsible for pulp cell cytotoxicity induced by resin-modified glass ionomer cements. J Biomed Mater Res $\underline{48}, 277-288$

Starov VM, Zhdanov SA, Kosvintsev SR, Sobolev VD, Velarde MG (2003): Spreading of liquid drops over porous substrates. Adv Colloid Interface Sci $\underline{104}$, 123-158

Stäubert C (2018): Methoden der Zellbiologie: Zellen beim Wachsen und Sterben zuschauen - Tumorzellmodelle in 2D und 3D. BIOspectrum 24, 292-293

Steinmetz R, Brown NG, Allen DL, Bigsby RM, Ben-Jonathan N (1997): The environmental estrogen bisphenol A stimulates prolactin release in vitro and in vivo. Endocrinology 138, 1780-1786

Stellet Lourenço E, Côrtes J, Costa J, Linhares A, Alves G (2014): Evaluation of Commercial Latex as a Positive Control for In Vitro Testing of Bioceramics. Key Engineering Materials 631, 357362

Sun J, Forster AM, Johnson PM, Eidelman N, Quinn G, Schumacher G, Zhang X, Wu W-L (2011): Improving performance of dental resins by adding titanium dioxide nanoparticles. Dent Mater 27, 972-982

Syrjänen S, Hensten-Pettersen A, Kangasniemi K, Yli-Urpo A (1985): In vitro and in vivo biological responses to some dental alloys tested separately and in combinations. Biomaterials $\underline{6}, 169-176$

Takahashi Y, Tsuruta S, Arimoto M, Tanaka H, Yoshida M (2003): Placental transfer of mercury in pregnant rats which received dental amalgam restorations. Toxicology 185, 23-33

Tamura Y, Kakuta K, Ogura H (2013): Wear and mechanical properties of composite resins consisting of different filler particles. Odontology 101, 156-169

Teaford MF, Oyen OJ (1989): In vivo and in vitro turnover in dental microwear. Am J Phys Anthropol $\underline{80}, 447-460$

Teughels W, van Assche N, Sliepen I, Quirynen M (2006): Effect of material characteristics and/or surface topography on biofilm development. Clin Oral Implants Res 17 Suppl 2, 68-81

Thakur S, Cattoni DI, Nöllmann M (2015): The fluorescence properties and binding mechanism of SYTOX green, a bright, low photo-damage DNA intercalating agent. Eur Biophys J 44, 337348

Thonemann B, Schmalz G, Hiller K-A, Schweikl H (2002): Responses of L929 mouse fibroblasts, primary and immortalized bovine dental papilla-derived cell lines to dental resin components. Dent Mater 18, 318-323

Thorat S, Patra N, Ruffilli R, Diaspro A, Salerno M (2012): Preparation and characterization of a BisGMA-resin dental restorative composites with glass, silica and titania fillers. Dent Mater J $\underline{31}$, 635-644 
Tipton DA, Dabbous MK (1995): Effects of nicotine on proliferation and extracellular matrix production of human gingival fibroblasts in vitro. J Periodontol 66, 1056-1064

Tominaga H, Ishiyama M, Ohseto F, Sasamoto K, Hamamoto T, Suzuki K, Watanabe M (1999): A water-soluble tetrazolium salt useful for colorimetric cell viability assay. Anal. Commun. $\underline{36}, 47-$ 50

Topcu FT, Sahinkesen G, Yamanel K, Erdemir U, Oktay EA, Ersahan S (2009): Influence of different drinks on the colour stability of dental resin composites. Eur J Dent $\underline{3}, 50-56$

Torii Y, Itou K, Nishitani Y, Ishikawa K, Suzuki K (2002): Effect of phosphoric acid etching prior to self-etching primer application on adhesion of resin composite to enamel and dentin. Am J Dent 15, 305-308

Trautwein A, Kreibig U, Hüttermann J: Physik für Mediziner, Biologen, Pharmazeuten. 8., neu bearb. Auflage; de Gruyter, Berlin 2014

Trubiani O, Toniato E, Di Iorio D, Diomede F, Merciaro I, Arcangelo C d', Caputi S (2012): Morphological analysis and interleukin release in human gingival fibroblasts seeded on different denture base acrylic resins. Int J Immunopathol Pharmacol 25, 637-643

Tsarev VN, Ippolitov EV, Trefilov AG, Arutiunov SD, Pivovarov AA (2014): Features of adhesion of anaerobic periodontopathogenic bacteria and Candida albicans fungi to experimental samples of basis dental plastic depending on surface roughness and polishing method. Zh Mikrobiol Epidemiol Immunobiol, 21-27

Tsuchiya H, Hoshino Y, Tajima K, Takagi N (1994): Leaching and cytotoxicity of formaldehyde and methyl methacrylate from acrylic resin denture base materials. J Prosthet Dent $\underline{71}, 618-624$

Uchida H, Vaidyanathan J, Viswanadhan T, Vaidyanathan TK (1998): Color stability of dental composites as a function of shade. J Prosthet Dent $\underline{79}$, 372-377

Uyama Y, Inoue H, Ito K, Kishida A, Ikada Y (1991): Comparison of different methods for contact angle measurement. Curr Opin Colloid Interface Sci 141, 275-279

Valdés A, García-Cañas V, Cifuentes A (2013): CGE-laser induced fluorescence of double-stranded DNA fragments using GelGreen dye. Electrophoresis $\underline{34}, 1555-1562$

van Dijken JW, Wing KR, Ruyter IE (1989): An evaluation of the radiopacity of composite restorative materials used in Class I and Class II cavities. Acta Odontol Scand 47, 401-407

Viden S: Zytotoxizität von modellierbaren Bulk Fill Kompositmaterialien im Vergleich zu herkömmlichen modellierbaren Kompositmaterialien. Med. Diplomarbeit, Wien 2018

Voco (2010): Grandio: Wissenschaftliche Produktinformation: [URL: http://www.voco.de/de/product/grandio/Grandio_WP_DE_Internet.pdf] Zugriff 10.06.2018

Vrochari AD, Petropoulou A, Chronopoulos V, Polydorou O, Massey W, Hellwig E (2017): Evaluation of Surface Roughness of Ceramic and Resin Composite Material Used for Conservative Indirect Restorations, after Repolishing by Intraoral Means. J Prosthodont 26, 296-301

Walter MS, Frank MJ, Satue M, Monjo M, Ronold HJ, Lyngstadaas SP, Haugen HJ (2014): Bioactive implant surface with electrochemically bound doxycycline promotes bone formation markers in vitro and in vivo. Dent Mater $\underline{30}, 200-214$ 
Wang R, Habib E, Zhu XX (2017): Synthesis of wrinkled mesoporous silica and its reinforcing effect for dental resin composites. Dent Mater $\underline{33}, 1139-1148$

Wataha JC, Lockwood PE, Vuillème MN, Zürcher MH (1999): Cytotoxicity of Au-based dental solders alone and on a substrate alloy. J Biomed Mater Res $\underline{48}, 786-790$

Watari F (2005): In situ quantitative analysis of etching process of human teeth by atomic force microscopy. J Electron Microsc (Tokyo) 54, 299-308

Webb HK, Truong VK, Hasan J, Fluke C, Crawford RJ, Ivanova EP (2012): Roughness parameters for standard description of surface nanoarchitecture. Scanning $\underline{34}, 257-263$

Wegehaupt FJ, Taubock TT, Attin T, Belibasakis GN (2014): Influence of light-curing mode on the cytotoxicity of resin-based surface sealants. BMC Oral Health $\underline{14}, 48$

Winkler C, Schäfer L, Felthaus O, Allerdings J, Hahnel S, Behr M, Bürgers R (2014): The bacterial adhesion on and the cytotoxicity of various dental cements used for implant-supported fixed restorations. Acta Odontol Scand $\underline{72}, 241-250$

Wu J, Weir MD, Melo MAS, Xu HHK (2015): Development of novel self-healing and antibacterial dental composite containing calcium phosphate nanoparticles. J Dent 43 , 317-326

Xiao GQ, Corle TR, Kino GS (1988): Real-time confocal scanning optical microscope. Appl Phys Lett $\underline{53}, 716-718$

Yoshii E (1997): Cytotoxic effects of acrylates and methacrylates: Relationships of monomer structures and cytotoxicity. Journal of Biomedical Materials Research Part A $\underline{37}, 517-524$

Yuan Y, Lee TR: Contact angle and wetting properties; In: Surface science techniques: Springer 2013, 3-34

Yudovin-Farber I, Beyth N, Nyska A, Weiss EI, Golenser J, Domb AJ (2008): Surface characterization and biocompatibility of restorative resin containing nanoparticles. Biomacromolecules $\underline{9}$, 3044-3050

Zhang CY, Cheng H, Lin DH, Zheng M, Ozcan M, Zhao W, Yu H (2012): Effects of recasting on the biocompatibility of a Ni-Cr alloy. Chin J Dent Res $\underline{15}, 105-113$

Zhu M-y, Zhang X-y (2015): Effect of amount of silane coupling agent on flexural strength of dental composite resins reinforced with aluminium borate whisker. Shanghai Kou Qiang Yi Xue $\underline{24}$, 294-297 
DANKSAgUNG

Ich danke besonders meinem Doktorvater Herrn Professor Ralf Bürgers für die Überlassung des Themas und die konstruktive Betreuung.

Des Weiteren gebührt ein großer Dank Herrn Dr. Torsten Wassmann für seine Unterstützung bei allen aufgetretenen Fragen.

Frau S. Kiecke möchte ich für ihren unermüdlichen Einsatz beim Lehren der Untersuchungstechniken und ihre Hilfestellung bei der Durchführung der Versuche danken.

Abschließend möchte ich mich bei Herrn Dipl. Stom. R. Kurbad, Frau Dipl. Stom. H. Kurbad, Frau StD P. Wassmann sowie meiner Kollegin Frau Dr. A. Schubert für das stilistische Lektorat bedanken. 


\section{LEBENSLAUF}

Ich, Oliver Kurbad (geb. Hartmann), wurde am 23.11.1980 als zweites Kind von Dipl. Stom. Heike Kurbad (geb. Hartlep) und Uwe Hartmann in Leinefelde geboren. 1983 nahm ich den Nachnamen des zweiten Ehemannes meiner Mutter, Dipl. Stom. Rolf Kurbad, an.

Von 1987 bis 1990 besuchte ich die Grundschule in Leinefelde. Nach einem weiteren Jahr auf der Grundschule in Großbodungen wechselte ich 1991 auf das Staatliche Gymnasium Worbis, welches ich 1999 mit der allgemeinen Hochschulreife verließ. Von 1999 bis 2003 absolvierte ich erfolgreich eine Ausbildung zum Zahntechniker bei der Dental-Studio-Trias GmbH in Göttingen und erwarb von 2003 bis 2007 im dortigen Betrieb entsprechende Berufserfahrung. Von April 2007 bis November 2012 studierte ich Zahnmedizin an der Universitätsmedizin der Georg-August-Universität Göttingen und schloss dieses Studium 2012 mit dem Staatsexamen erfolgreich ab. Seit Dezember 2012 bin ich als Zahnarzt in der Poliklinik für Zahnärztliche Prothetik der Universitätsmedizin Göttingen angestellt. Meine Arbeitsschwerpunkte liegen in der prothetischen Versorgung von Tumor- und Gesichtsdefektpatienten sowie der vorklinischen Lehre und der zahnärztlichen Forschung. 